Policy Research Working Paper 7477

Shock Waves: Managing the Impacts of Climate Change on Poverty

Background Paper

\title{
Climate Change Impacts and Mitigation in the Developing World
}

\section{An Integrated Assessment of the Agriculture and Forestry Sectors}

\author{
Petr Havlik \\ Hugo Valin \\ Mykola Gusti \\ Erwin Schmid \\ David Leclère \\ Nicklas Forsell \\ Mario Herrero \\ Nikolay Khabarov \\ Aline Mosnier \\ Matthew Cantele \\ Michael Obersteiner
}

\section{WORLD BANK GROUP}

Development Economics

Climate Change Cross-Cutting Solutions Area

November 2015 
Policy Research Working Paper 7477

\begin{abstract}
This paper conducts an integrated assessment of climate change impacts and climate mitigation on agricultural commodity markets and food availability in low- and middle-income countries. The analysis uses the partial equilibrium model GLOBIOM to generate scenarios to 2080. The findings show that climate change effects on the agricultural sector will increase progressively over the century. By 2030, the impact of climate change on food consumption is moderate but already twice as large in a world with high inequalities than in a more equal world. In the long run, impacts could be much stronger, with global average calorie losses of 6 percent by 2050 and 14 percent by 2080 . A mitigation policy to stabilize climate below $2^{\circ} \mathrm{C}$ uniformly applied to all regions as a carbon tax would
\end{abstract}

also result in a 6 percent reduction in food availability by 2050 and 12 percent reduction by 2080 compared to the reference scenario. To avoid more severe impacts of climate change mitigation on development than climate change itself, revenue from carbon pricing policies will need to be redistributed appropriately. Overall, the projected effects of climate change and mitigation on agricultural markets raise important issues for food security in the long run, but remain more limited in the medium term horizon of 2030. Thus, there are opportunities for low- and middle-income countries to pursue immediate development needs and thus prepare for later periods when adaptation needs and mitigation efforts will become the greatest.

This paper was commissioned by the World Bank Group's Climate Change Cross-Cutting Solutions Area and is a background paper for the World Bank Group's flagship report: "Shock Waves: Managing the Impacts of Climate Change on Poverty." It is part of a larger effort by the World Bank to provide open access to its research and make a contribution to development policy discussions around the world. Policy Research Working Papers are also posted on the Web at http://econ.worldbank. org. The authors may be contacted at havlikpt@iiasa.ac.at and valin@iiasa.ac.at.

The Policy Research Working Paper Series disseminates the findings of work in progress to encourage the exchange of ideas about development issues. An objective of the series is to get the findings out quickly, even if the presentations are less than fully polished. The papers carry the names of the authors and should be cited accordingly. The findings, interpretations, and conclusions expressed in this paper are entirely those of the authors. They do not necessarily represent the views of the International Bank for Reconstruction and Development/World Bank and its affliated organizations, or those of the Executive Directors of the World Bank or the governments they represent. 


\title{
Climate Change Impacts and Mitigation in the Developing World: An Integrated Assessment of the Agriculture and Forestry Sectors*
}

\author{
Petr Havlíka , Hugo Valinª, Mykola Gustia, Erwin Schmid ${ }^{b}$, David Leclère ${ }^{a}$, Nicklas Forsell ${ }^{a}$, Mario \\ Herreroc$^{c}$, Nikolay Khabarov ${ }^{a}$, Aline Mosnier ${ }^{a}$, Matthew Cantele ${ }^{a}$, Michael Obersteiner ${ }^{a}$
}

Keywords: food security, climate change, land use change, bioenergy, poverty

JEL: Q10, Q23, Q54, Q56

\footnotetext{
* Corresponding authors: Petr Havlík (havlikpt@iiasa.ac.at) and Hugo Valin (valin@iiasa.ac.at). Analysis contributing to this study was partly conducted in partnership with the CGIAR Research Program on Climate Change, Agriculture and Food Security (CCAFS).

The results and views expressed in this document are the sole personal responsibility of the authors and do not reflect those of their institutions of affiliation. Any errors or omissions remain the responsibility of the authors.

a International Institute for Applied Systems Analysis (IIASA), A-2361, Laxenburg, Austria.

b Institute for Sustainable Economic Development, University of Natural Resources and Life Sciences, A-1200 Vienna, Austria

${ }^{c}$ Commonwealth Scientific and Industrial Research Organisation, Brisbane, QLD, 4067, Australia
} 


\section{Summary of main findings}

We generate scenarios through 2080 with the partial equilibrium model GLOBIOM and look at the impacts of climate change and climate mitigation policies at different time horizons, with a focus on the medium term 2030 as these impacts could hamper immediate development goals. The main results are:

\section{On the climate change impact and adaptation side}

- In the most optimistic scenario, average crop yield across climate models is found to decrease by $2 \%$ globally by 2030 , even when the positive effects of elevated $\mathrm{CO}_{2}$ concentration are accounted for. Without $\mathrm{CO}_{2}$ effects, these impacts could be as severe as $-10 \%$ in 2030 already.

- Climate change will hit regions unevenly but least advanced countries will be particularly affected. The most severely exposed regions by changes in crop yield are South Asia, Eastern Asia and Pacific, and Latin America, where agriculture will need to adapt drastically. Impacts in Sub-Saharan Africa and North Africa Middle-East should be partly attenuated by $\mathrm{CO}_{2}$ effects, but will also become severe if this effect does not materialize.

- The societal impacts of these changes will depend on the adaptation capacity of the different regions. Various adaptation channels can be used to mitigate the impact of climate change on food supply: i) change in crop management at field level (input level, irrigation), ii) change in the choice of crops cultivated, iii) reallocation of production within regions, iv) increase in cultivated areas, v) international trade adjustments.

- The possibilities to use these mechanisms will be influenced by the level of development of the agricultural sector as well as the investment capacity and the institutional environment, locally and globally. We look at two different contexts of these dimensions across the two Shared Socio-Economic Pathways SSP4 (low adaptation capacity and dysfunctional markets and institutions for least advanced countries) and SSP5 (high adaptation capacity, integrated markets and an enabling institutional environment in least advanced countries).

- At the global level, and for the two background socioeconomic scenarios, no significant price variation is observed in the long run if climate change is contained at 2 degrees. On some specific markets, effects could however be visible as soon as $2030:+15 / 27 \%$ for sorghum (with/without $\mathrm{CO}_{2}$ effects), $+7 / 25 \%$ for millet, $+4 / 15 \%$ for soya, $+2 / 11 \%$ for corn, $+0 / 7 \%$ for cassava.

- The impact on food supply remains very limited by 2030. On average across climate scenarios and SSPs, global consumption decreases by $0.6 \%$ with $\mathrm{CO}_{2}$ effects and $1.9 \%$ without $\mathrm{CO}_{2}$ effects compared to a situation without climate change. These impacts become more severe and more largely influenced by the baseline assumption over time. Impacts reach -2.0/-4.3\% (with/without $\mathrm{CO}_{2}$ effects) by 2080 under a macroeconomic scenario favorable to adaptation (SSP5) and up to $-4.4 /-8.7 \%$ under poor adaptation capacity (SSP4).

- South Asia and Sub-Saharan Africa are the regions the most impacted in 2030 but with $\mathrm{CO}_{2}$ effects, impacts remain limited under SSP5 at $-30 \mathrm{kcal} / \mathrm{cap} /$ day and $-16 \mathrm{kcal} / \mathrm{cap} /$ day, respectively, and moderate at $-50 \mathrm{kcal} / \mathrm{cap} /$ day and $-14 \mathrm{kcal} / \mathrm{cap} /$ day under SSP4. The impacts are more pronounced by 2080 . South Asia consumption decreases by --182 kcal/cap/day and $-125 \mathrm{kcal} / \mathrm{cap} /$ day in SSP4 and SSP5, respectively. Sub-Saharan Africa loses $-180 \mathrm{kcal} / \mathrm{cap} / \mathrm{day}$ under SSP4 and $-129 \mathrm{kcal} / \mathrm{cap} /$ day under SSP5. Without $\mathrm{CO}_{2}$ effects, these impacts are more than doubled by 2080 and are the most acute for sub-Saharan Africa: under SSP4, the region could lose up to $-382 \mathrm{kcal} / \mathrm{cap} /$ day in 2080, whereas the impacts would be contained at around $-220 \mathrm{kcal} / \mathrm{cap} / \mathrm{day}$ under SSP5. 


\section{On the climate change mitigation side}

- In order to limit the global warming to $2^{\circ} \mathrm{C}$ by 2100 compared to preindustrial times, agriculture, forestry and other land use (AFOLU) emissions would be required to decrease by $64 \%$ in 2030, compared to their 2000 level. In such a scenario, land use change would have to become a net carbon sink, and any increase in direct emissions from agriculture would be limited to $+7 \%$. Large abatement would be provided by Latin America (LAM) and Sub-Saharan Africa (SSA), which would contribute by $55 \%$ and $21 \%$ to the global AFOLU abatement, respectively.

- Total amount of bioenergy is already projected to increase by $12 \%$ by 2030 without climate change policies, and a major shift from traditional biomass use to industrial bioenergy production is expected. Under a full mitigation policy, an additional $80 \%$ of biomass for energy would be required by 2030 . LAM would contribute $28 \%$ to this increase and SSA $24 \%$.

- Mitigation policies implemented through a uniform global carbon price would have negative effects on agricultural production. Crop production globally would be by $4 \%$ lower by 2030 compared to the reference scenario. Livestock production would be slightly more affected, with production down by $5 \%$ globally for meat ( $9 \%$ for milk) compared to the reference scenario, and higher impacts in Latin America (-9\% for meat/milk) and South Asia (-15\% for meat/milk), and in Sub-Saharan Africa (-17\%/-21\% for meat/milk). Forestry would be little affected by 2030 with a $1 \%$ increase globally.

- Agricultural commodity prices would increase as a result of a carbon price. Crop prices would increase just moderately by $4 \%$ and livestock prices by $7 \%$ on average. The livestock price increase would be particularly high in regions with GHG emission intensive production systems, and even higher under SSP4 with slow productivity improvements - $+13 \%$ in South Asia (+8\% for SSP5), $+17 \%$ in Latin America, and $+22 \%$ in Sub-Saharan Africa. These changes in prices will have negative effects on food availability, although they could benefit some specific farming sectors.

- Food availability would decrease globally by $3 \%$ under the climate stabilization scenario compared to reference levels by 2030. Developing regions would be more affected than developed ones as poorer population groups are more sensitive to price fluctuations, and the strongest decrease would occur for livestock product consumption in sub-Saharan Africa ($12 \%)$.

- On the producer side, climate mitigation policies will impact the total level of revenue in agriculture and forestry through changes in the cost of production (pricing of emissions), in the levels and type of production (less conventional products and more demand for bioenergy feedstocks), and through new income opportunities such as payments for carbon sequestration through afforestation. Net social benefits would however depend on how these revenues are shared between land owners and workers. On average, global impacts are limited by 2030 . However, SSA is again seriously affected. This is because the region loses on revenues from conventional agricultural production, is unable to create within the medium term sufficient new income from carbon sequestration, and the new source of income in terms of commercial biomass production for energy is not sufficient to cover the losses.

- In order to avoid that mitigation policies have more severe impacts on development than climate change itself, the carbon price revenue needs to be redistributed appropriately. The adverse effects of mitigation policies could be further reduced by targeting just particular land use sectors: Expanding biomass production appears a better compromise than halting deforestation, whereas direct restrictions on crop and livestock emissions pose the largest problems to food security. 


\section{Introduction}

There is now compelling evidence that the climate is changing globally at a pace unprecedented in human history and that this change is directly related to anthropogenic greenhouse gas (GHG) emissions (IPCC, 2013). Impacts of these changes will be felt in many domains, but few appear as exposed and critical to human basic needs as agriculture. Agricultural development has indeed formed the basis for the emergence of civilizations and sustainable provision of food and revenues for poor farmers is still today a concern in many low- and middle-income countries. As the world is still comprised of close to one billion undernourished people, climate disturbances in regions already facing significant weather variability represent a critical challenge. At the same time, agriculture, forestry and other land use (AFOLU) are responsible for a quarter of all anthropogenic GHG emissions (Smith et al., 2014). By 2030, land related mitigation strategies including reduction of direct emissions from agriculture and deforestation, increased carbon sequestration through afforestation, and most importantly, substitution of fossil energy sources by biomass feedstocks, could account for $20-60 \%$ of the mitigation effort necessary to slow climate change (Rose et al., 2012). A considerable share of biomass for energy use is projected to originate in developing countries, and the potential for emissions reductions and sink enhancement from other sources is largest there. As both climate change impacts and climate change mitigation are projected to have the strongest effect on land use sectors in the same regions - the low- and middle-income countries - it is useful to examine the two sides of this coin in a single coherent framework.

A large body of literature has investigated the social impacts from climate change, and an extensive overview is provided through the synthesis work of the Intergovernmental Panel on Climate Change (IPCC), in particular Working Group II (IPCC, 2014a). Understanding the extent and location of these impacts is a complicated task, in particular for the agricultural sector, due to the complexity of the chain of effects and their uncertainties. Increases in GHG atmospheric concentrations and additional anthropogenic perturbations of the climate system affect the spatial and temporal distribution of weather regimes which contribute to shaping the diversity of agricultural activities throughout the world. But beyond the shared diagnostic of a future increase in the mean surface temperature, the different general circulation models (GCMs) do not agree on the magnitude, location and direction of change for variables that are crucial to agricultural activities, such as precipitation.

Crop yield and harvest quality as well as operational aspects of agricultural production are directly affected by changing patterns of precipitation, temperature, wind, air moisture and incoming shortwave solar energy, but also indirectly through water availability for irrigation. Livestock is also affected through pasture yield and quality, heat stress and water availability (Thornton et al., 2009). Other forms of stress, particularly dependent on climate (pests, disease, sea level rise) can also affect agricultural activities. Crop and vegetation models permit estimation of the impacts of such drivers on crop and pasture yields. In conjunction with scenarios which account for various climate projection uncertainties, these models translate climatic impact into a biophysical impact. In addition to climate projection related uncertainties, crop models face their own intrinsic sources of uncertainties (e.g., the response of crop growth to elevated atmospheric $\mathrm{CO}_{2}$ concentration remains a large source of divergence in model results). Assumptions on the nitrogen stress is also raised as a critical parameter underpinning model result discrepancies (Rosenzweig et al., 2014). 
The effects of climate change on farm systems and population depend on not only the biophysical impacts but also the manner in which agents react and how these dynamics propagate through economic markets. Producers can adapt by changing their production methods or switching to other land-based products; cultivated areas can also be varied, and markets and trade used to accommodate supply and demand imbalances as illustrated for the crop sector in Nelson et al. (2014) and for the livestock sector in Havlík et al. (2015). The ultimate socioeconomic impacts can vary according to geographical location and occupation. Three-quarters of the world's poor live in rural areas of Africa, Asia and Latin America and they are particularly vulnerable as their low income relies more heavily on these activities. But the poor are also the most exposed on the consumption side, as they purchase products with low degree of transformation and hence are more sensitive to market price fluctuations, and the food purchases represent large part of their expenditure. Estimation of impact therefore requires economic assessment tools and market equilibrium models are the most common approaches to estimate this final level of impact in the chain of effects. Large comparison exercises have been performed to compare the impacts on food production and consumption of climate change, such as the Agricultural Model Intercomparison and Improvement Project (AgMIP, see von Lampe et al., 2014). All models project a reduction of food availability for households but the final impact on consumption is usually lower than initial biophysical impacts (Leclère et al., 2014; Mosnier et al., 2014; Valin et al., 2014).

Agriculture is also a key sector for mitigation of $\mathrm{GHG}$ emissions. Agricultural non- $\mathrm{CO}_{2}$ emissions represent about half of the total AFOLU emissions. Livestock is directly responsible for more than $70 \%$ of these emissions, with enteric fermentation and manure left on pasture being by far the most important sources. The remainder of the emissions come mainly from synthetic fertilizers applied to soils and rice cultivation. Extant literature generally differentiates between three types of mitigation wedges: technological options and structural adjustments on the producer side, and reduced consumption on the consumer sider. A rather comprehensive overview of technological options which may include use of anaerobic digesters, $\mathrm{N}$-inhibitors and others, can be found in Beach et al. (2008), Smith et al. (2008), or more recently Hristov et al. (2013). Within the livestock sector, Herrero et al. (2013) illustrated the huge variances in terms of GHG efficiency (unit of product per unit of GHG emission) which exist for each product/species across current production systems and regions. Their results suggest that even optimization of production within the current systems provides substantial opportunities for emissions reduction. Havlík et al. (2014) also found that optimal allocation of livestock production across systems is to a large extent a cost-effective mitigation measure, along with other structural adjustments like relocation of production within and across regions. However, the most straightforward measure to reduce direct emissions from agriculture still seems to be reducing consumption of livestock and other GHG intensive products (Stehfest et al., 2009; Popp et al., 2010), particularly in regions where overconsumption causes serious health problems. However, the economic and social consequences of this option, as well as associated policy levers, have not yet been fully elucidated.

Emissions from forestry and other land use, including emissions from deforestation, contribute about the same proportion to total anthropogenic emissions as direct emissions from agriculture. Although these emissions represent a third of all anthropogenic emissions generated over the period 1750-2011, they are currently the only source of GHG which has slowly decreased in absolute numbers since the last decade or so (Smith et al., 2014). Agricultural land expansion is the major cause of land use change (Geist and Lambin, 2002; Gibbs et al., 2010). At the same time, crop yield growth over the past 50 years 
prevented the conversion of more than a billion of hectares which otherwise would have be converted to arable land, and hence helped to avoid some $590 \mathrm{GtCO}_{2}$ e of emissions (Burney et al., 2010). Land productivity growth in the agricultural sector could play an important role in avoiding GHG emissions also in the future (Havlík et al., 2013). However, the net effect will depend on technology and on the strength of a potential rebound effect (Valin et al., 2013). Overall, climate change mitigation through reducing emissions and increasing the sink in the forestry and other land use sectors appears to be a very cost-effective measure (Kindermann et al., 2008a), which causes relatively little competition with food production (Havlík et al., 2014), and which is projected to play a crucial role in attaining ambitious mitigation targets (Rose et al., 2012; Kriegler et al., 2014). ${ }^{1}$

Energy produced from biomass can under certain circumstances be considered close to carbon neutral because during combustion only carbon previously stored in the biomass is emitted. If such a system were linked to carbon capture and sequestration (CCS), which consists of permanently storing the carbon emitted during combustion, the system would actually provide negative emissions/sink (Obersteiner et al., 2001). Recent studies based on integrated assessment models agree on the need for large scale bioenergy deployment to reach ambitious stabilization targets. Although the feasibility of large scale CCS deployment is still uncertain (Fuss et al. 2014), its role in the stabilization scenarios is crucial.; Kriegler et al. (2014) found that limiting atmospheric GHG concentration to $450 \mathrm{ppm} \mathrm{CO}$ equivalent by 2100 would be 2.5 times more expensive without CCS technology availability. Lignocellulosic biomass from dedicated plantations would be the major source of biomass, next to residues, and more than 500 million ha of land would be needed to produce the required amounts (Popp et al., 2010). In one respect this represents a challenge to increase agricultural land productivity further, not only to allow for carbon sequestration but also to provide land to satisfy these new demands along with sufficient food production. On the other hand, the demand for energy feedstock will present a new income opportunity in agricultural and forest sectors.

As illustrated in the structure of the IPCC Assessment Reports, analyses of climate change impacts and mitigation have been conducted independently and so far have yet to allow for direct comparison of the relative effects of impacts and mitigation. The present paper tries to fill this gap within a consistent scenario set drawing on the new matrix framework structured along Shared Socio-economic Pathways (SSPs) and Representative Concentration Pathways (RCPs) (van Vuuren et al., 2014). SSPs provide socioecomic drivers such as population, economic growth, and technological change, for alternative future scenarios attempting to span the space of plausible futures. Here we focus on SSP4 and SSP5, representing unequal fragmented world and fast growing integrated world, respectively. RCPs define

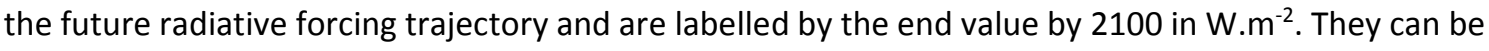
used both for impact scenarios assessment where they define the level of climate change, and for mitigation scenarios assessment where they define the mitigation target. We do not attempt to present an exhaustive ensemble of scenarios here but rather focus on the most extreme variants, delineating the span of possible future outcomes. For this, we selected RCP2.6 and RCP8.5, which corresponds to temperature increase below $2^{\circ} \mathrm{C}$ for the former, compared to pre-industrial times, and beyond $4^{\circ} \mathrm{C}$ for the latter. This reflects two contrasted situations of limited and extreme climate change impacts on the one side, and high mitigation efforts and no mitigation efforts on the other side.

\footnotetext{
${ }^{1}$ This however presupposes that expansion of wood plantation could take place in the large areas of land not already used as cropland or grassland, overcoming some potential hidden barriers such as labor constraints, infrastructure development needs, and non-degradation of the available land.
} 
Another advantage of this approach is that it allows consideration of the mitigation efforts and the climate impacts separately in the analysis; RCP2.6 has a negligible climate change impact but a high level of mitigation, and RCP8.5 has a strong climate change impact but no mitigation.

The assessment is carried out with the Global Biosphere Management Model, GLOBIOM (Havlík et al., 2011; Havlík et al., 2014), a partial equilibrium bottom-up model that has recently participated in the Impact, Adaptation and Vulnerability (IAV) community activities, like AgMIP (von Lampe et al., 2014) and ISI-MIP (Nelson et al., 2014), and has been applied to autonomous impact assessments (Leclère et al., 2014; Mosnier et al., 2014; Havlík et al., 2015), but at the same time has a long track record in climate change mitigation assessments (Mosnier et al., 2012; Reisinger et al., 2012; Böttcher et al., 2013; Havlík et al., 2013; Valin et al., 2013; Cohn et al., 2014; Havlík et al., 2014), including bioenergy (Havlík et al., 2011; Frank et al., 2013; Lauri et al., 2014). The model is used here to compare impacts on production, agricultural markets and food consumption with a focus on low and middle income countries. Although the climate change impacts and mitigation efforts are expected to substantially in magnitude towards the end of this century, here we take a development perspective and try to identify whether there are major challenges to be expected in the medium term.

The rest of the paper is structured as follows: in a Section 2, we briefly present the modeling chain used for the assessments of climate change impact and mitigation effects; in Section 3, we detail the set of scenarios chosen for this analysis; in Section 4, we expose the most important results, and in Section 5 we put these results into perspective while underlying uncertainties. A brief summary of the most important results, caveats to be considered and future pathways conclude this paper. 


\section{Modeling framework}

The analysis provided throughout this paper relies on an integrated assessment framework designed for analyzing the chain of climate change impact, and climate change mitigation. The global partial equilibrium agriculture and forest sector model GLOBIOM (Havlík et al., 2011; Havlík et al., 2014) constitutes the central component of this framework. GLOBIOM is combined with the EPIC crop model (Williams, 1995) to calculate the impact of climate change on the agricultural sector, according to a framework described in Leclère et al. (2014) and Havlík et al. (2015). For a comprehensive accounting of greenhouse gas emissions from afforestation, deforestation and forest management and the effect of mitigation, GLOBIOM is coupled with the Global Forest Model (G4M, Kindermann et al., 2008a). ${ }^{2}$

GLOBIOM is a partial equilibrium model covering the agricultural, forestry and bioenergy sectors. It represents the world partitioned into 30 economic regions, in which a representative consumer tries to optimize his consumption, depending on his income, preferences and product prices. On the production side, producers maximize their margins and the model solves the market equilibrium corresponding to the overall welfare maximization based on the spatial equilibrium modeling approach (Takayama and Judge, 1971; McCarl and Spreen, 1980). More extensive information on the model structure and parameterization can be found in (Havlík et al., 2011; Havlík et al., 2014).

The supply side of the model relies on a detailed spatial resolution based on the concept of Simulation Units, which are aggregates of 5 pixels belonging to the same altitude, slope, and soil class, within the same 30 arcmin pixel, and in the same country. For crops, livestock, and forest activities, different production systems are parameterized using sectoral biophysical models, such as EPIC for crops, RUMINANT for livestock (Herrero et al., 2013), and G4M for forestry. For this study, the supply side spatial resolution is aggregated to 120 arcmin (about $200 \times 200 \mathrm{~km}$ at the Equator). The model is calibrated to the year 2000 FAOSTAT activities levels and prices, and is then recursively solved in 10 year time-steps until 2100.

Production in the model reacts to economic incentives with activities and land use allocation as important aspects of the model responses. Six land cover types are distinguished: cropland, grassland, short rotation tree plantations, managed forest, unmanaged forest and other natural vegetation. Depending on the relative profitability of the individual activities and on the recursivity constraints, the model can switch from one land cover type to another. Comprehensive greenhouse gas accounting for agriculture forestry and other land use is implemented in the model. Detailed description of these accounts and additional background information are provided in Valin et al. (2013) and Havlík et al. (2014).

EPIC is an important component of the framework for the estimation of climate change impacts. This crop model is used in GLOBIOM to simulate yield associated to each location, management practice and climatic conditions. The model estimates the biophysical and environmental parameters of 18 crops for three different types of management systems (low input rain-fed, high input rain-fed and irrigated systems). To predict impacts of climate change, daily climate input data of solar radiation, min and max temperature, precipitation, relative humidity and wind speed are taken as inputs from

\footnotetext{
${ }^{2} \mathrm{G} 4 \mathrm{M}$ is a spatially explicit global forest dynamics model used to project patterns of deforestation and afforestation based on relative profitability of forestry compared to other land based activities. It can be used as a GLOBIOM module in order to refine estimates of carbon stock losses and carbon sequestration under different land use and carbon pricing policies.
} 
the climate models. Future increase in atmospheric $\mathrm{CO}_{2}$ is also taken into account and increases both light-use and water-use efficiency. Such a representation of $\mathrm{CO}_{2}$ effects generates estimates that lie in the upper range of the wide span of results found in the literature. However, since the strength of the final $\mathrm{CO}_{2}$ fertilization effect is still debated (Tubiello et al., 2007), we consider two different levels of $\mathrm{CO}_{2}$ fertilization responses - full and none - which frame the space of the uncertainty in this respect. EPIC already includes in its modeling some adjustments in crop response to climate (field scale autonomous adjustments). This includes in particular changes in fertilizer and irrigation water use, as well as shifts in annual planting and harvesting dates. Other larger scale adjustments mechanisms are handled directly in GLOBIOM.

Competition between agricultural and forestry uses of land is at the core of the climate mitigation challenge, due to the large needs for biomass resource to substitute fossil energy. Biomass supply for energy production can be sourced in GLOBIOM from dedicated forest plantations or from managed forests. Dedicated plantations potential are determined on the basis of suitability maps and net primary productivity (NPP) estimates as documented in Havlík et al. (2011). The available woody biomass resources from managed forests are inputs to GLOBIOM from the G4M model for each forest area unit determined by mean annual increments, which are based on NPP maps from (Cramer et al., 1999) and from different downscaling techniques as described in (Kindermann et al., 2008b). The main forest management options considered by G4M are variation of thinning levels and choice of rotation length. The rotation length can be individually selected or optimally estimated to maximize increment, stocking biomass or harvestable biomass.

The model set-up described above has been applied successfully to various scientific and policy applications (see section 1) but has not yet been used to look at climate impact and climate mitigation simultaneously. For this purpose, a consistent scenario framework is necessary, as outlined in the following section.

\section{Baseline and scenario description}

We apply in this paper the new IPCC scenario framework which adopts a matrix approach to look at climate change impacts and mitigation strategies. This framework is articulated around two orthogonal dimensions of scenario drivers: socioeconomic drivers with the Shared Socioeconomic Pathways (SSPs) and level of radiative forcing with the Representative Concentration Pathways (RCPs) for the climate change component (van Vuuren et al., 2011).

\subsection{Socioeconomic scenarios and drivers}

Five different SSPs have been developed in the framework of climate change research ( $\mathrm{O}^{\prime} \mathrm{Neill}$ et al., 2014). These correspond to five different visions of the future structured around two axes: level of challenge to adaptation and level of challenge to mitigation. In this paper we focus on two particularly contrasted scenarios for the developing world: SSP4 with pronounced inequality between developed and developing countries, and SSP5, where developing countries are catching up with the developed ones.

SSP4, commonly labelled "Inequality", is characterized by a world where emissions can be kept low through development of new technologies but least advanced countries experience very limited growth and a significant rise of inequalities increases the vulnerability to climate change of the poorest 
regions. SSP4 is also characterized by decreased collaborations between regions of the world with a decline of international trade flows. ${ }^{3}$

SSP5, commonly labelled "Conventional development", is characterized by much more investment in human capital and a decrease of inequalities and vulnerability to climate change. Under this scenario however, high economic growth is based on conventional technologies with high carbon and resource intensities, which increases the challenge for mitigation; international cooperation is high and characterized by strong trade relations. However, a lack of environmental consideration leads to patterns of consumption putting higher pressure on natural resources, particularly in terms of diets. ${ }^{4}$

The SSP narratives aim to describe alternative futures in a comprehensive way, covering all sectors of the economy. Here, we have considered only a subset of the scenario elements, based on their relevance and compatibility with the model structure. . Table 1 summarizes the covered elements. The SSPs provide quantitative information for a handful of drivers, namely economic growth (GDP) and demographic change in terms of total population distributed by sex, age and education. The magnitude and direction of many other drivers is provided only qualitatively or semi-quantitatively ( $\mathrm{O}^{\prime} \mathrm{Neill}$ et al., 2014). Semi-quantitative drivers relevant for agriculture and forestry were quantified for this study mostly following the approach presented in Herrero et al. (2014).

Crop yield projections are estimated based on historical development over the period 1980-2010 using an econometric relation linking the yields to GDP per capita development. The projections hence vary across SSPs and are performed for four classes of countries grouped by level of income (Herrero et al., 2014). GDP per capita change has been selected as the explanatory variable because it can be considered as proxy both for resources available for investment in the necessary R\&D and for the demand developments, and because it is provided quantitatively as part of the SSPs.

Table 1. Differentiated drivers and their quantification the two SSPS used in this paper

\begin{tabular}{llll}
\hline Driver & \multicolumn{1}{c}{ Method / Source } & \multicolumn{2}{c}{ Scenario pattern } \\
\cline { 3 - 4 } Population & $\begin{array}{l}\text { IIASA population } \\
\text { projection (Lutz et al., } \\
\text { 2014) }\end{array}$ & $\begin{array}{l}\text { Sigh population growth } \\
\text { globally, due to high growth } \\
\text { rates in Africa and Asia }\end{array}$ & $\begin{array}{l}\text { Low population growth } \\
\text { globally, due to low growth } \\
\text { rate in Africa and Asia }\end{array}$ \\
\hline GDP per capita & $\begin{array}{l}\text { OECD GDP projection } \\
\text { (IIASA, 2015) }\end{array}$ & $\begin{array}{l}\text { Strong GDP per capita } \\
\text { growth in advanced } \\
\text { regions; moderate growth } \\
\text { in middle income countries; } \\
\text { low growth for least } \\
\text { advanced countries }\end{array}$ & $\begin{array}{l}\text { Strong GDP per capita } \\
\text { growth in all regions of the } \\
\text { world }\end{array}$ \\
\hline Crop yield projection & $\begin{array}{l}\text { Growth rates } \\
\text { correlation with } \\
\text { patterns of GDP per }\end{array}$ & $\begin{array}{l}\text { Strong yield growth for } \\
\text { advanced regions, } \\
\text { moderate yield growth in } \\
\text { middle income countries, }\end{array}$ & $\begin{array}{l}\text { Strong yield growth for all } \\
\text { regions, with catching up of } \\
\text { middle income regions on } \\
\text { advanced regions. }\end{array}$ \\
\hline
\end{tabular}

\footnotetext{
${ }^{3}$ The SSP4 scenario is used as a backbone for the analysis of a "Poverty" case in the World Bank report on Climate Change and Poverty.

${ }^{4}$ The SSP5 scenario is used as a backbone for the analysis of a "Prosperity" case in the World Bank report on Climate Change and Poverty due to the catching up patterns observed for income per capita in developing countries. In our analysis, SSPs and level of global warming are not considered correlated, making such an interpretation possible. It should be noted however that in practice, much higher cost would have to be supported by the energy sector to limit drastic increase in GHG emission levels. This question goes however beyond the scope of this paper
} 


\begin{tabular}{|c|c|c|c|}
\hline & $\begin{array}{l}\text { capita (Herrero et al., } \\
\text { 2014) }\end{array}$ & $\begin{array}{l}\text { low yield growth in least } \\
\text { advanced countries }\end{array}$ & \\
\hline $\begin{array}{l}\text { Food demand } \\
\text { projections }\end{array}$ & $\begin{array}{l}\text { FAO diet projections } \\
\text { for SSP4 (Alexandratos } \\
\text { and Bruinsma, 2012) } \\
\text { and authors' own } \\
\text { assumptions for SSP5 } \\
\text { based on scenario } \\
\text { narratives }\end{array}$ & $\begin{array}{l}\text { Diets follow similar } \\
\text { patterns as projected by } \\
\text { FAO, in particular } \\
\text { consumption of meat } \\
\text { remains stable in } \\
\text { developed regions, and diet } \\
\text { remain mostly vegetarians } \\
\text { in India }\end{array}$ & $\begin{array}{l}\text { Food consumption around } \\
\text { the world converges to } \\
\text { Western diet types, with } \\
\text { higher intake of meat and } \\
\text { milk than in SSP4. }\end{array}$ \\
\hline Trade policies & $\begin{array}{l}\text { Authors' own } \\
\text { assumption based on } \\
\text { scenario narratives }\end{array}$ & $\begin{array}{l}\text { Trade barriers increase } \\
\text { considerably compared to } \\
\text { today's situation between } \\
\text { all large regions of the } \\
\text { world }\end{array}$ & $\begin{array}{l}\text { Trade costs remain } \\
\text { unchanged compared to } \\
\text { today's situation }\end{array}$ \\
\hline Food waste & $\begin{array}{l}\text { Authors' own } \\
\text { assumption based on } \\
\text { scenario narratives }\end{array}$ & $\begin{array}{l}\text { Constant waste level in } \\
\text { supply chain and food } \\
\text { consumption }\end{array}$ & $\begin{array}{l}\text { Constant waste level in } \\
\text { supply chain and increased } \\
\text { waste in food consumption }\end{array}$ \\
\hline
\end{tabular}

Income elasticities for food demand per capita are calibrated for SSP4 on food consumption projections from FAO (Alexandratos and Bruinsma, 2012) using GDP assumption from the same source. Therefore, food demand calculated for SSP4 takes into account the specificities of the population and GDP per capita development of this scenario. For SSP5, income elasticity patterns are changed to represent a nutrition transition in developing countries with a catching up in the long run of developing regions towards level of consumption of animal products in developed regions, which leads for instance to higher poultry meat demand for India. Additionally, the level of waste on the food consumption side is adjusted to the narrative of each scenario, and we assume fixed domestic waste level in SSP4 at the historical levels and increased domestic waste for SSP5.

Trade assumptions are also varied depending on the SSP. For SSP5, the narrative specifies that global cooperation favors trade and we keep the standard trade specification of GLOBIOM, reproducing current levels of tariffs and trade cost progressively decreasing over time. For SSP4, however, cooperation between countries is low and economic integration fails with many regions becoming isolated. This leads to higher trade costs in our scenario which significantly restricts expansion of trade in the baseline as well as the capacity to adapt to climate or policy shocks.

\subsection{Climate change impact scenarios}

The most recent generation of climate change scenarios available at the time of this study corresponds to the fifth phase of the Coupled Model Intercomparison Project (CMIP5) (Taylor et al., 2011). In CMIP5, more than 50 climate models were used to simulate four radiative forcing scenarios (Representative Concentration Pathways, or RCPs). The four RCPs cover a range of radiative forcing, going from 2.6 to $8.5 \mathrm{~W} / \mathrm{m}^{2}$ in the year 2100 (van Vuuren et al., 2011). Depending on the climate model, these levels of radiative forcing would spread the global temperature increase above the pre-industrial levels, from below $1{ }^{\circ} \mathrm{C}$ for RCP2.6 to about $7^{\circ} \mathrm{C}$ for RCP8.5, the median across the models for the latter RCP8.5 being just below $5{ }^{\circ} \mathrm{C}$ (Rogelj et al., 2012).

The ISI-MIP provided impact modelers with spatially interpolated and bias-corrected climate datasets for all four RCPs and for five GCMs (GFDL-ESM2M, HadGEM2-ES, IPSL-CM5A-LR, MIROC-ESM-CHEM, 
NorESM1-M) selected to span the CMIP5 range of global mean temperature changes and relative precipitation changes (Warszawski et al., 2013). Of the five GCMs, ISI-MIP retained HadGEM2-ES as the reference model, and we do the same in this study. Under RCP8.5, HadGEM2-ES projects a global temperature increase for 2050 of about $2.5^{\circ} \mathrm{C}$ and an average increase in precipitation of about 3 percent. This ranks HadGEM2-ES as the hottest and driest of the five GCMs, with potentially the most negative effects on agricultural production.

For this paper, we focus on the two most extreme RCPs: RCP2.6 and RCP 8.5. This choice appears the most practical as it allows to infer the effect of the intermediate emission pathways impacts by approximate interpolation. Effects of different RCPs are then compared to a situation without additional forcing, here represented by the historical climate observed between 1980 and 2010.

In the first scenario, RCP 2.6 , a radiative forcing of $2.6 \mathrm{~W} / \mathrm{m}^{2}$ is assumed by the end of the century, after peaking at $3 \mathrm{~W} / \mathrm{m}^{2}$ before 2050. In terms of GHG concentration, this scenario is equivalent to about $450 \mathrm{ppm}$ of $\mathrm{CO}_{2}$ equivalent in the atmosphere by 2100 . It corresponds to a limited level of climate change, at about $+1 \pm 0.3^{\circ} \mathrm{C}$ by $2046-2065$ and $+1 \pm 0.4^{\circ} \mathrm{C}$ by $2081-2100$ on the earth surface, compared to $1980-2010$ levels. On emerged land, the temperature increase is on average $+1.2 \pm 0.6^{\circ} \mathrm{C}$ by 2081 2100 (Collins et al., 2013).

The second scenario, RCP 8.5, corresponds to a high increase in radiative forcing, reaching $8.5 \mathrm{~W} / \mathrm{m}^{2}$ by the end of the century. Under this scenario, GHG concentration in the atmosphere increases up to $1370 \mathrm{ppm}$ of $\mathrm{CO}_{2}$ equivalent by 2100 . This leads to significant magnitude in climate change at about +2 $\pm 0.4{ }^{\circ} \mathrm{C}$ by $2046-2065$ already and $+3.7 \pm 0.7{ }^{\circ} \mathrm{C}$ by $2081-2100$, compared to $1980-2010$ level. On emerged land, anticipated temperature increase is even higher, at $+4.8 \pm 0.9^{\circ} \mathrm{C}$ by $2081-2100$ (Collins et al., 2013). This scenario can be seen as an extreme climate change situation; however the recent emission developments exceed even the RCP8.5 emission levels for the corresponding years (Peters et al., 2013).

The level of uncertainty in temperature and precipitation change comes from the uncertainty related to the impact of GHGs atmospheric concentration on climate, as predicted by general circulation models (GCMs). For the same level of radiative forcing, GCMs tend to broadly agree on magnitude of temperature changes, but notably disagree on the regional patterns, and on evolution of precipitation patterns. Considering different sets of possible impacts is therefore crucial to reflect the model projection diversity. Therefore, for each RCP, we look at the impacts of GHG concentration on climate according to five different GCMs: HadGEM2-ES, IPSL-CM5A-LR, GFDL-ESM2M, MIROC-ESM-CHEM and NorESM1-M. These provide spatially explicit results for temperature and precipitation changes that are then used in the EPIC crop model on a global grid (see section 2). As a standard assumption, we keep the default modeling of the $\mathrm{CO}_{2}$ effects as represented in the EPIC model, which includes crop response in terms of photosynthesis (fertilization effect) as well as the impact on water-use efficiency resulting from decreased evapotranspiration. Because the resulting yield impact of these $\mathrm{CO}_{2}$ effects is an important source of uncertainty, we also consider one additional scenario as a sensitivity analysis on RCP8.5 where $\mathrm{CO}_{2}$ effects are disabled. This scenario, labelled RCP8.5* in the paper, is run with the HadGEM2-ES climate change projections. Under RCP8.5, HadGEM2-ES projects a global temperature increase for 2050 of about $2.5^{\circ} \mathrm{C}$ and an average increase in precipitation of about 3 percent. This ranks HadGEM2-ES as the hottest and driest of the five ISI-MIP models, with potentially the most 
negative effects on agricultural production (Warszawski et al., 2013). The list of climate scenarios is summarized in Table 2.

Table 2 Climate change scenarios setting

\begin{tabular}{|c|c|c|c|}
\hline Scenario name & GHG concentration & GCM & $\mathrm{CO}_{2}$ concentration \\
\hline Reference & $1980-2010$ average & None & $\begin{array}{l}\text { Constant at } 2005 \text { level } \\
(380 \mathrm{ppm})\end{array}$ \\
\hline \multirow{5}{*}{$\begin{array}{l}\text { RCP2.6 } \\
\text { (5 scenarios) }\end{array}$} & \multirow{5}{*}{450 ppm $\mathrm{CO}_{2}$-eq } & HadGEM2-ES & \multirow{5}{*}{ Increase at $450 \mathrm{ppm}$ ) } \\
\hline & & IPSL-CM5A-LR & \\
\hline & & GFDL-ESM2M & \\
\hline & & MIROC-ESM-CHEM & \\
\hline & & NorESM1-M & \\
\hline \multirow{5}{*}{$\begin{array}{l}\text { RCP } 8.5 \\
\text { (5 scenarios) }\end{array}$} & \multirow{5}{*}{1370 ppm CO 2 -eq } & HadGEM2-ES & \multirow{5}{*}{ Increase at $1370 \mathrm{ppm}$ ) } \\
\hline & & IPSL-CM5A-LR & \\
\hline & & GFDL-ESM2M & \\
\hline & & MIROC-ESM-CHEM & \\
\hline & & NorESM1-M & \\
\hline RCP 8.5* & 1370 ppm CO CO $_{2}$-eq & HadGEM2-ES & $\begin{array}{l}\text { Constant at } 2005 \text { level } \\
\text { (380 ppm) }\end{array}$ \\
\hline
\end{tabular}

\subsection{Mitigation policies}

The Integrated Assessment Modeling (IAM) community has put substantial efforts over the past years into quantifying the alternative SSP reference scenarios, as well as the stabilization scenarios corresponding to the RCPs' radiative forcing levels. Unfortunately, this work has not yet been finalized and therefore we have decided to anchor the mitigation part of this report rather in the set of scenarios representing the backbone of the IPCC WGIII $5^{\text {th }}$ Assessment Report on mitigation (IPCC, 2014b). These scenarios are the outcome of the Stanford Energy Modeling Forum Study 27 (EMF27, (Kriegler et al., 2014). The scenarios are constructed along two dimensions: i) climate policy assumption, and ii) technology assumption. Out of the five alternative policy assumptions, we have decided to consider the only one which was compatible with the climate change impact scenario RCP2.6, and that was an idealized policy scenario where all regions and all sectors participate starting in the year 2010 and implement a uniform carbon price ensuring a cost-effective achievement of atmospheric concentration of $450 \mathrm{ppm} \mathrm{CO}{ }_{2}$ e by 2100 .

Similar to the uncertainty with respect to the climate change effects on agricultural markets, the level of the mitigation efforts required from the AFOLU sector and bioenergy substitution for attaining a specific level of climate stabilization is also subject to substantial uncertainties. The cost competitive mitigation efforts demanded from the land use sectors will depend on the technical and economic potential of AFOLU and bioenergy assumed in each integrated assessment model, on the assumptions about developments in other economic sectors, on societal preferences and also on new knowledge and technology which may become available over the long time horizon over which climate change mitigation is planned.

EMF27 explored in total nine technology assumptions and their effects on carbon price and bioenergy demand. The estimated AFOLU contribution to the mitigation efforts compatible with cost effective achievement of the 450 ppm target goes from $-2 \%$ to $69 \%$ in the period 2010-2030. A comparable range of uncertainty exists also for energy from biomass, which depending on the model is required to 
contribute $0-20 \%$ of primary energy production by 2030 . In order not to overwhelm this study and still highlight the non-deterministic character of the mitigation efforts required in the future from the land use sectors, we focus here on three of these technology scenarios: FullTech, LowEl and LimBio.

FullTech is the reference scenario in which the IAMs allow all the available technology to enter the solution portfolio according to its relative competitiveness assumed in the standard model implementation. LowEl is the scenario where technologies are available as in FullTech but further investments in energy efficiency lead to final energy demand lower by $20-30 \%$ in 2050 and by $35-45 \%$ in 2100 compared to the reference case. This scenario hence requires lower mitigation efforts compared to the reference case. Finally, we include the LimBio scenario, which puts a limit on industrial biomass use for energy at $100 \mathrm{EJ} / \mathrm{yr}$. There are many uncertainties with respect to the potential of biomass production for energy in the future both related to the biophysical potential (hundreds of millions of hectares are projected to be required for biomass production in the ambitious mitigation scenarios), and to the sustainability of sourcing large amounts of biomass for energy both with respect to environmental and social criteria. In LimBio, the competition with conventional agriculture and forestry for feedstock is less important than in FullTech, however the carbon prices are higher indicating the GHG abatements in other sectors need to contribute more to climate stabilization.

Two variables are key to determine the level of expected mitigation effort from the land use sectors in GLOBIOM: carbon price and bioenergy demand. Carbon price determines what level of AFOLU emissions reduction is cost-efficient compared with mitigation in the other sectors. Bioenergy demand comes in play as a new substantial source of demand for feedstocks from both agricultural land and forests. Carbon prices and bioenergy demand were derived by the Integrated Assessment Models as part of EMF27, and here we rely on the output from the MESSAGE model which is a major component of the IIASA integrated assessment toolbox (McCollum et al., 2014). As Figure 1 shows, the carbon price is zero in the reference scenario, but it is $\$ 37, \$ 17$, and $\$ 84$ per $\mathrm{tCO}_{2}$ for the technology scenarios FullTech, LowEl and LimBio, respectively, by 2030. The biomass demand for energy is $45 \mathrm{EJ}$ per year in 2000 , in the reference scenario it goes down to $35 \mathrm{EJ}$ per year in 2030 . However in the $450 \mathrm{ppm}$ scenario, the biomass demand for energy depends on the technology assumption: 70, 33, and $59 \mathrm{EJ}$ per year, for FullTech, LowEI and LimBio, respectively (Figure 2).

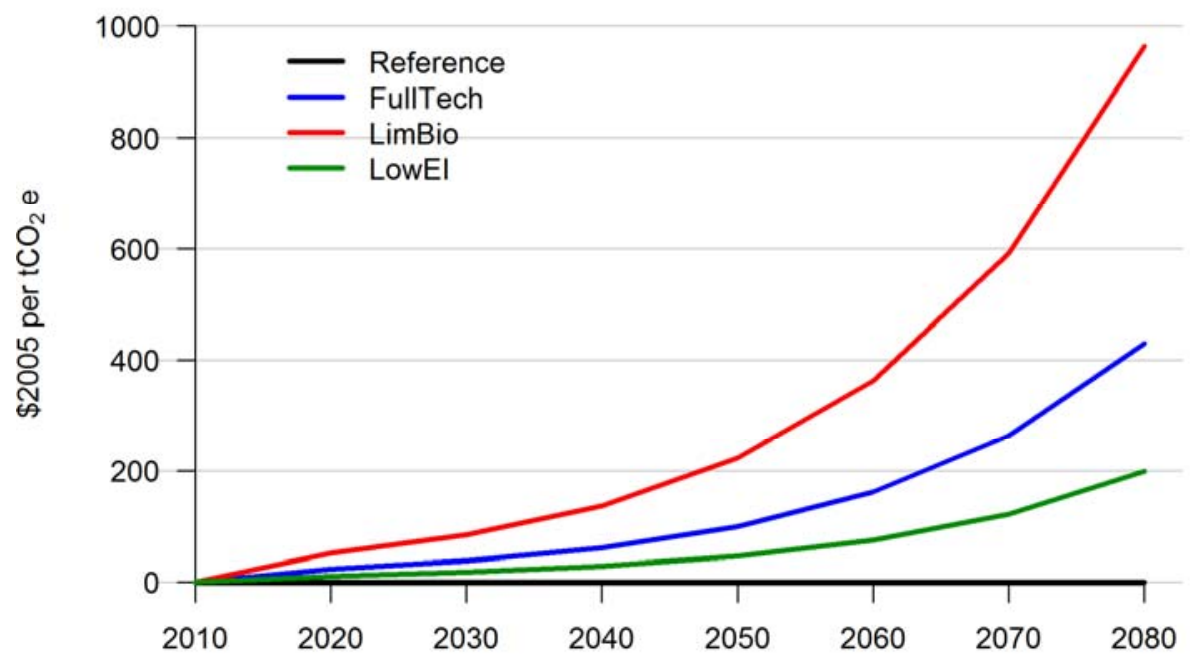


Figure 1 Carbon prices underlying mitigation scenarios as calculated by the MESSAGE model in the framework of EMF27 [US\$2005/t CO2] (Source: (McCollum et al., 2014))

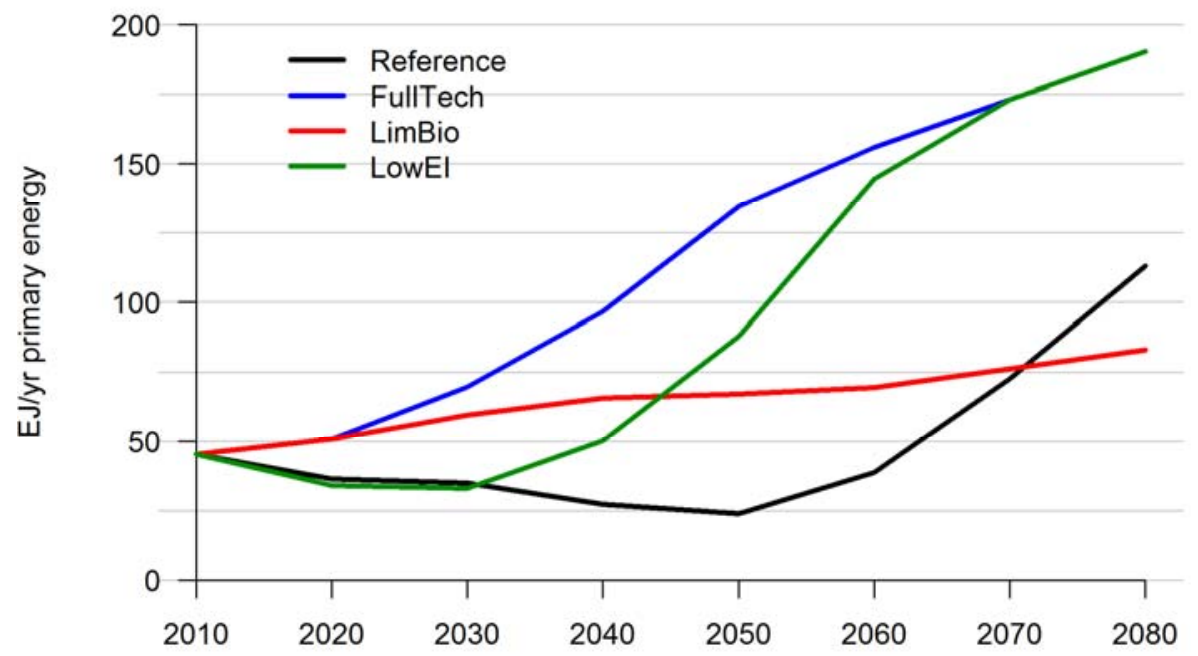

Figure 2 Primary energy from biomass underlying mitigation scenarios as calculated by the MESSAGE model in the framework of EMF27 [EJ primary energy] (Source: McCollum et al. 2014)

\subsection{Crossing dimensions}

The different dimensions above can in principle be crossed: the two possible socio-economic developments can be combined with different levels of climate change - as predicted by different GCM models. Climate change and socio-economic pathways can in addition be associated with different mitigation efforts, consistent with the final climate change outcome.

In this paper we selected a tractable number of scenarios to analyze and compare adaptation and mitigation impacts. We chose to disentangle the climate impact and climate mitigation scenarios analysis for the two different socioeconomic pathways but they both relate to the same consistent analytical framework across these dimensions. The overall scenario setting of the paper can therefore be summarized as in Table 3. Climate change and climate mitigation scenarios are systematically compared to their respective baseline without climate change nor mitigation in SSP4 or SSP5. For mitigation scenarios, to better disentangle the effects, the impact of climate change is not applied in the model. Therefore, the difference between the mitigation scenario and the baseline is the result of mitigation policies only. Conversely, the different levels of climate change are not related to any mitigation efforts in the impact scenarios. This stylized approach is well-adapted to the question and scenario setting of our paper, where under climate stabilization policies aiming at $450 \mathrm{ppm}$ (RCP2.6), the climate change feedback is negligible, and vice versa, where the strong climate change scenario is the result of non-existing mitigation efforts. However, one limitation of our set up is that the same set of carbon prices and biomass demand values is used for two very different socio-economic scenarios. It is not unlikely that the strong economic growth under SSP5 would require more mitigation effort and hence higher carbon prices and biomass demand than those corresponding to SSP4. 
Table 3. Overall scenario design in the paper

\begin{tabular}{|c|c|c|c|c|c|}
\hline & & & \multicolumn{3}{|c|}{ Climate change } \\
\hline $\begin{array}{l}\text { Socioeconomic } \\
\text { pathway } \\
(2000-2100)\end{array}$ & $\begin{array}{l}\text { Impacts } \\
\text { Mitigation } \\
\text { Policy }\end{array}$ & - & Present climate & $\begin{array}{l}\text { Low climate change } \\
\text { RCP2.6 }\end{array}$ & $\begin{array}{l}\text { High climate change } \\
\text { RCP8.5 }\end{array}$ \\
\hline \multirow[t]{2}{*}{ SSP4 } & Impacts & & 1 reference SSP4 & $\begin{array}{l}5 \text { climate impact } \\
\text { scenarios for } 450 \mathrm{ppm} \\
\text { with } \mathrm{CO}_{2} \text { effects }\end{array}$ & $\begin{array}{l}5 \text { climate impact } \\
\text { scenarios for } 1370 \\
\text { ppm with } \mathrm{CO}_{2} \text { effects } \\
+1 \text { scenario without } \\
\mathrm{CO}_{2} \text { effects }\end{array}$ \\
\hline & $\begin{array}{l}\text { Mitigation } \\
\text { policy }\end{array}$ & & & $\begin{array}{l}3 \text { stabilization } \\
\text { scenarios at } 450 \mathrm{ppm} \\
\text { stabilization with } \\
\text { alternative } \\
\text { technological } \\
\text { assumptions }\end{array}$ & \\
\hline \multirow[t]{2}{*}{ SSP5 } & Impacts & & 1 reference SSP5 & $\begin{array}{l}5 \text { climate impact } \\
\text { scenarios for } 450 \text { ppm } \\
\text { with } \mathrm{CO}_{2} \text { effects }\end{array}$ & $\begin{array}{l}5 \text { climate impact } \\
\text { scenarios for } 1370 \\
\text { ppm with } \mathrm{CO}_{2} \text { effects } \\
+1 \text { scenario without } \\
\mathrm{CO}_{2} \text { effects }\end{array}$ \\
\hline & $\begin{array}{l}\text { Mitigation } \\
\text { policy }\end{array}$ & & & $\begin{array}{l}3 \text { stabilization } \\
\text { scenarios at } 450 \text { ppm } \\
\text { stabilization with } \\
\text { alternative } \\
\text { technological } \\
\text { assumptions }\end{array}$ & \\
\hline
\end{tabular}

\section{Results}

The GLOBIOM model is used to assess the impact of climate change and climate change mitigation scenarios between 2000 and 2080. In the sections below, we focus our results on primarily short term impacts (2030) and long term impacts (2080) for six large regions dominated by low and middle income countries (LMI): Latin America, Eastern Europe \& Central Asia, North Africa \& Middle-East, Sub-Saharan Africa, South Asia and Eastern Asia \& Pacific. More details on the regional grouping are provided in the appendix.

\subsection{Climate change impacts}

The scope of our analysis goes from climate change impacts on yield, through adjustments in producer strategies up to market rebalancing, which translates into price adjustments and ultimately food availability at the consumer level. This logic is also followed in the presentation of our results below. Climate shocks are modeled by shocking the 17 crop yields, as well as grass productivity in each grid cell of the model. This leads to change in level of production, market prices and consumption in the different economic regions.

\subsubsection{Impact of climate change on yield}

The magnitude of impacts on average crop yields globally is presented in Figure 3 for the different scenarios. The climate change impacts are represented as relative change between the projected yield in $\mathbf{2 0 3 0}$ or $\mathbf{2 0 8 0}$ with climate change effects, compared to projected yield without these effects. 
At the horizon 2030, the impact of climate change, when $\mathrm{CO}_{2}$ effects are considered, is expected on average to be of $-1.8 \%$ under RCP 2.6 and $-2.9 \%$ under RCP 8.5. The two sets of RCPs differ more by GCM at this time horizon, because the scenarios diverge only after 2010 and GHG concentrations are still close to each other in 2030. Furthermore, the delay between effective reduction of GHG emissions and climate change response limits the possibilities to influence climate change at such a short time horizon, which impedes heavily to historical emissions. The HadGEM2-ES and MIROC-ESM-CHEM models have the largest average impacts, with $-5.0 \%$ and $-5.1 \%$ respectively. When $\mathrm{CO}_{2}$ effects are not considered (only analyzed with HadGEM2-ES here), the impacts are found to be more significant at $10.2 \%$.

The impact of different levels of radiative forcing is much more pronounced when looking at the longterm developments. By 2080, the average impact under strong climate change (RCP 8.5) reaches globally $-13.9 \%$ by 2080 when $\mathrm{CO}_{2}$ effects are considered (max. MIROC-ESM-CHEM at $-20.2 \%$ ). Under limited climate change (RCP 2.6), effects remain rather stable, close to their 2030 range of impact, with average at $-1.8 \%$ in 2080 . Some positive impacts are even observed for two climate models. Considering a strong climate change with no $\mathrm{CO}_{2}$ effects leads to strongly negative crop yield impacts, reaching $-32.7 \%$ globally by 2080 (red bar).

World 2030

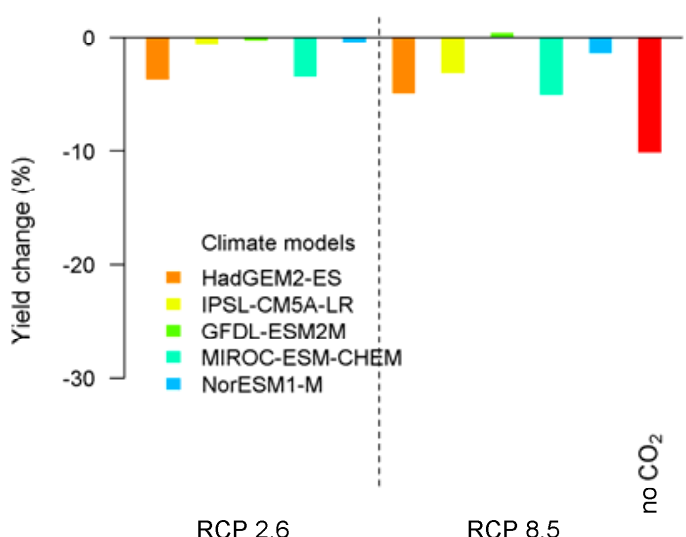

World 2080

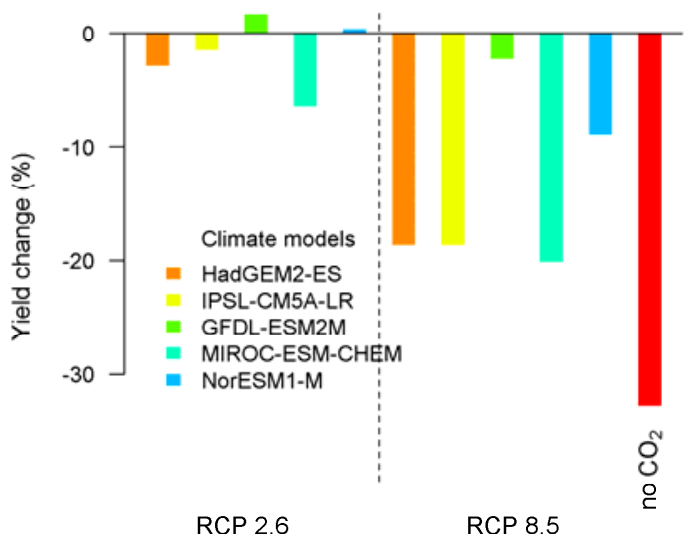

Figure 3. Climate change impact on average crop yield at global level in 2030 and 2080 for different climate scenarios and climate models. Crops correspond to the 18 species represented in the GLOBIOM model and impacts are aggregated on a dry matter yield basis.

Looking at the regional patterns, some contrasting situations appear for the different regions in the world (Figure 4). Latin America, South Asia, Sub-Saharan Africa and Eastern Asia \& Pacific are consistently found to suffer in terms of crop yields by 2080, for RCP 8.5 with $\mathrm{CO}_{2}$ effects, whatever GCM results are considered. Impacts can be as severe as $-23.3 \%$ for South Asia, and reach on average $-17.4 \%$ for Eastern Asia \& Pacific, -15.2\% for Sub-Saharan Africa and -13.9\% for Latin America. Other regions experience positive yield impacts due to $\mathrm{CO}_{2}$ effects. Middle-East \& North Africa yields increase 
on average by $7.8 \%$ in RCP 8.5 and Eastern Europe and Central Asia gain $9.2 \%$ by $2080 .{ }^{5}$ This picture seems to be relatively robust over time, since similar spatial patterns can be found by 2030 , although impacts are of much lower magnitude.

If $\mathrm{CO}_{2}$ effects do not materialize, overall impacts are more severe and all regions experience negative yield changes. Effects are found particularly dramatic for most affected regions under RCP 8.5 with $\mathrm{CO}_{2}$ effects, by 2080. Eastern Asia \& Pacific lose -37.1\% in crop yield whereas impacts in South Asia reach $34.6 \%$. Yields in Sub-Saharan Africa are also substantially affected with an average impact of $-29 \%$.
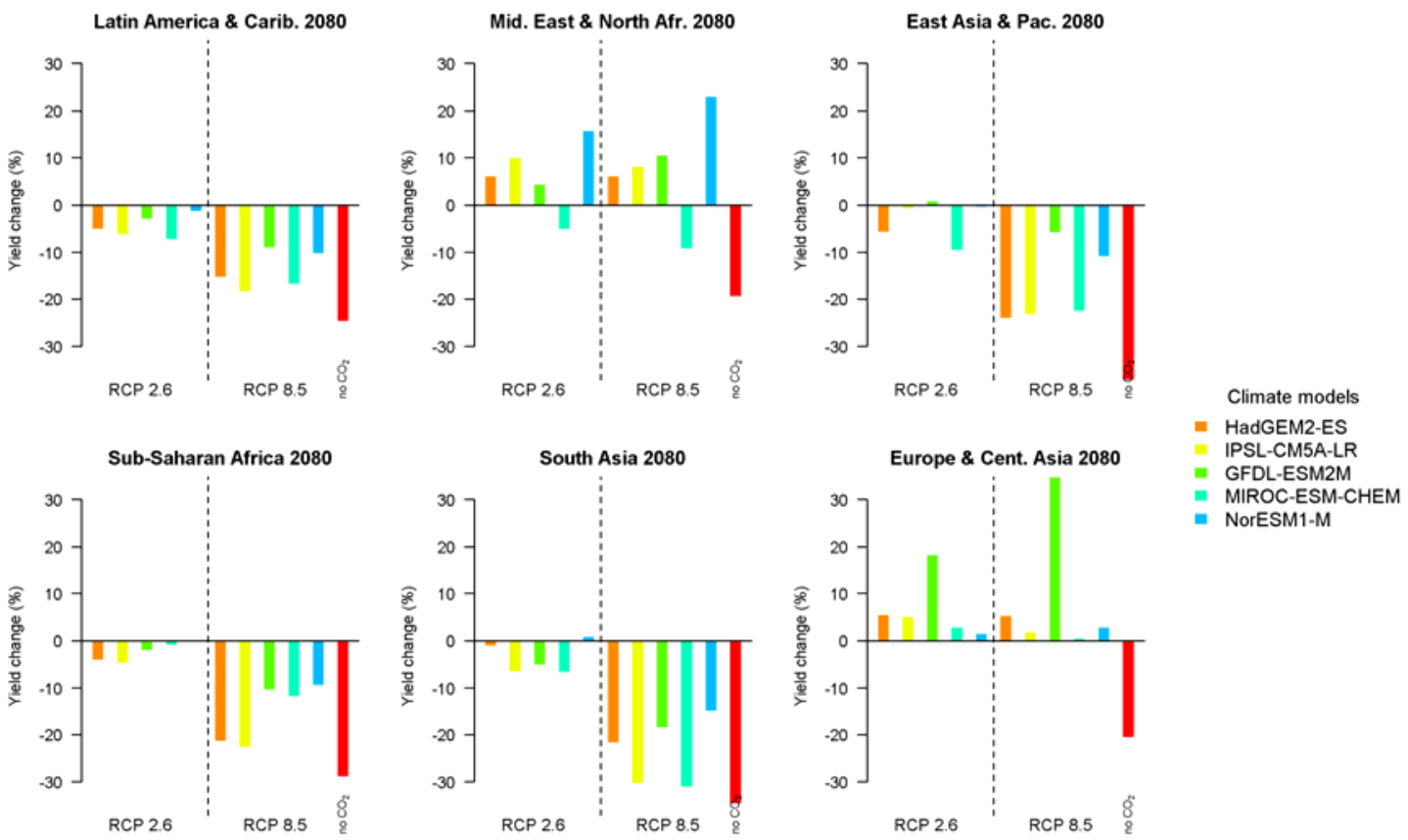

Figure 4. Climate change impact on average crop yield for six regions in 2080 for different climate scenarios and climate models. Crops correspond to the 18 species represented in the GLOBIOM model and impacts are aggregated on a dry matter yield basis. For results in 2030 see figure D-1 in appendix D.

Within each region, crops are also differently affected. Figure 5 illustrates the contrasted impacts under the RCP 8.5 scenario, when $\mathrm{CO}_{2}$ effects are taken into account. Depending on the regional patterns of climate change and on where and under what management a crop is grown, impacts can vary widely. For instance, wheat, which is very severely impacted in Eastern Asia \& Pacific $(-29.9 \%)$ is impacted positively in all other regions. Rice is impacted negatively in Sub-Saharan Africa (-8.6\%) but positively in North Africa and Middle-East (+12.0\%). Some crops are particularly hit across all regions, such as potatoes (up to $-65 \%$ in Sub-Saharan Africa), groundnuts (up to $-49.1 \%$ in Sub-Saharan Africa) or cotton (up to $-50.6 \%$ in Eastern Asia \& Pacific).

\footnotetext{
${ }^{5} \mathrm{MENA}$ region sees the highest difference worldwide in yield response with and without $\mathrm{CO}_{2}$ effects (resp. $+6 \%$ and $-20 \%$, see figure 4 ), and illustrates the particularities of elevated $\mathrm{CO}_{2}$ concentration impacts: in addition to increasing photosynthesis rate for a given level of incoming solar radiation (fertilization effect), increasing $\mathrm{CO}_{2}$ directly increases crop water-use efficiency. Such an effect is included in most state-of-the-art crop models, and can significantly alleviate water constrains to production. In the case of MENA, it counterbalances robust but relatively small decreases in precipitation. Further details on how water affects crop yield and irrigation developments in GLOBIOM are documented in Leclère et al. (2014).
} 

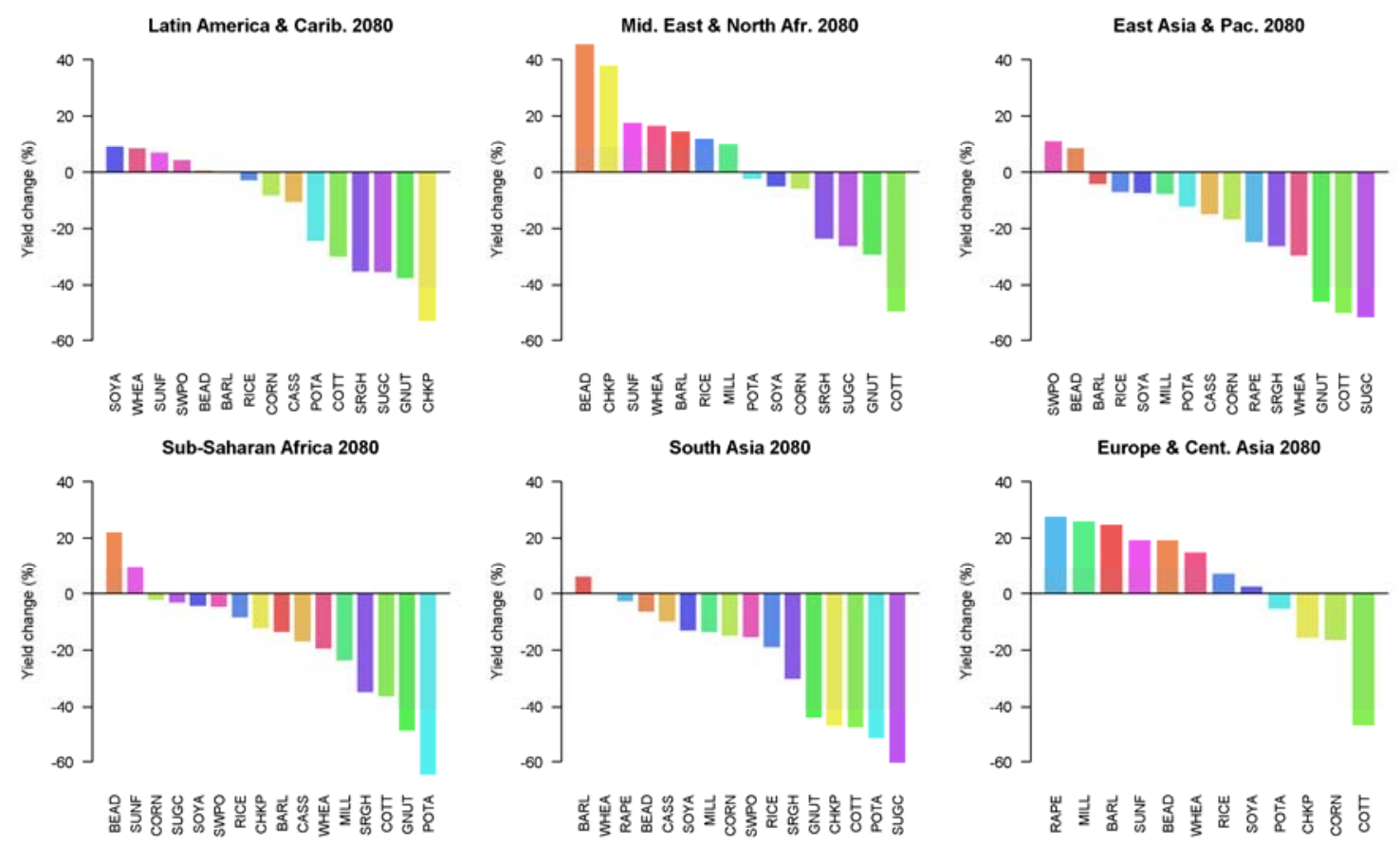

Figure 5. Climate change impact on by crop for six regions in 2080 for the RCP 8.5 scenario with $\mathrm{CO}_{2}$ effects. Impacts are averaged across the five GCMs in the analysis. Only crops with cultivated areas greater than 100,000 ha in 2000 are represented. Crop acronyms: $W H E A=$ wheat, $R I C E=$ rice, $C O R N=$ corn, SOYA = soybean, RAPE = rapeseed, BARL = barley, CASS = cassava, SUNF = sunflower, $M I L L=$ millet, $S R G H=$ sorghum, SUGC = sugar cane, $B E A D=$ dry beans, COTT =

cottonseed, $C H K P=$ chick peas, $S W P O=$ sweet potatoes, POTA = potatoes, GNUT = groundnuts. For results in 2030 see figure $D-2$ in appendix $D$.

\subsubsection{Adaptation responses along the supply chain}

Climate change impacts on crop yields affect agricultural output in the different regions and pose a challenge for overall food availability. ${ }^{6}$ Figure 6 illustrates the chain reaction triggered in the agricultural markets by the biophysical yield shocks in 2030 and 2080. For each economic variable, the relative change to the baseline value is shown, which allows attribution of the different sources of adaptation. Adaptation responses increase with the size of the shock and allow alleviation of a significant part of the shock.

First of all, farmers adapt their management (fertilizer input system, irrigation) in response to crop productivity change and the final yield decrease is therefore lower than the initial biophysical shock. Some regional reallocation within each region can also take place and is reflected in the response of this variable. Adaptation also occurs through harvested area adjustments, made necessary to maintain sufficient production under lower yields and to make use of the new opportunities. In 2030 and 2080, harvested areas increase, and partly compensate the effect of yield decrease. As a consequence, the overall impact of climate change on production is smaller than the initial biophysical shock.

Second, countries buffer their deficit of production by trade adjustments. This can be illustrated by the indicator of trade share, defined here as the ratio of net trade over regional market size (here, the

\footnotetext{
${ }^{6}$ Note that in the rest of paper, we will refer indifferently to food availability or to food consumption to designate the quantity of food supplied to households for their domestic use. This includes effective ingestion of food by human beings but also domestic food waste.
} 
average of production and consumption in the baseline). ${ }^{7}$ At the global level and aggregated across all crops, these effects remain limited and marginal in 2030. But as climate change becomes more severe, trade appears as an important contributor to adaptation. The adjustments through trade in 2080 represent $0.4 \%$ and $1.2 \%$ of the global production under RCP 8.5 with and without $\mathrm{CO}_{2}$ effects, respectively, between the ten different macro-regions considered here. This is equivalent to average extra trade flows of 120 and 260 million tonnes dry matter, respectively, between these regions. ${ }^{8}$

Third, the consumption side adapts to the change in prices. Food consumption decreases, with some socioeconomic implications - see subsection 4.1.4 for more results - but feed consumption decreases even more, because it is more price elastic. This adjustment on the feed side also limits the food impact of the losses on the production side, as a larger part of the production can be allocated to food use.

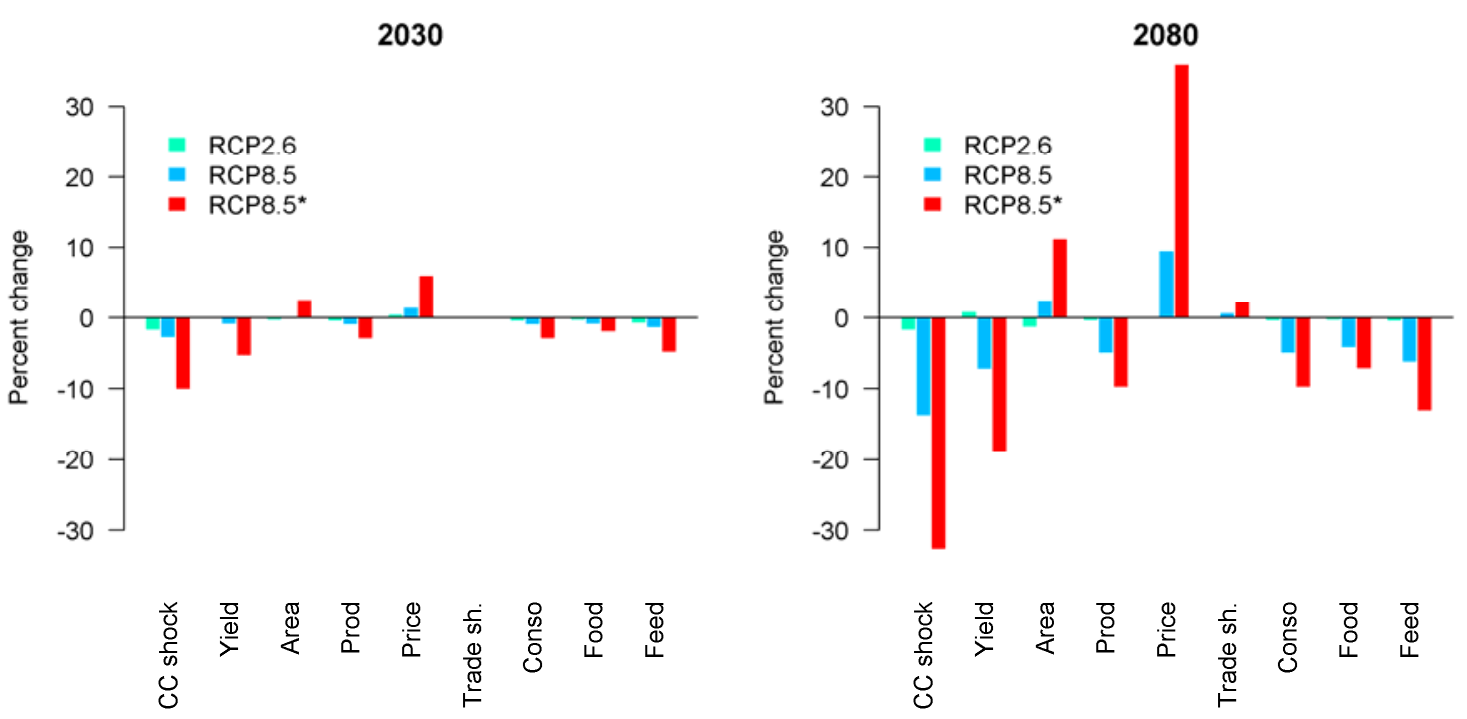

Figure 6. Propagation of climate change impact along the chain of economic indicators in 2030 and 2080 across different climate scenarios. CC shock corresponds to the average biophysical impact of climate change on dry matter yield; Yield corresponds to final resulting dry matter yield, including adaptation response; Area is the total change in harvested area; Prod is the change in total crop production in dry matter basis; Price is the average crop price index; Trade sh. corresponds to difference in the share of interregional trade (export-import) in total crop production; conso is the change in total crop consumption, and food and feed the relative change in the consumption of food and feed. The average responses for the five GCM models and the two SSP4 and SSP5 scenario are considered. For RCP8.5* sensitivity analysis, only the HadGEM2-ES GCM is featured. Units are average relative change to the baseline.

At the level of the different regions, similar dynamics of response are observed, as illustrated in Figure 7 with the case of RCP 8.5 with $\mathrm{CO}_{2}$ effects. Yield management and harvested areas are used to buffer the adverse effect of climate change on the supply side, and trade and consumption responses help to accommodate the impacts on production.

The magnitude of effects and responses however differs depending on the region. In Latin America, South Asia and Eastern Asia \& Pacific, area adjustments are strong and allow for a partial compensation

\footnotetext{
${ }^{7}$ Market share in the graphs are compared with the baseline as difference (and not in relative change). As a consequence, one percent increase in market share indicator means that net trade increased and provided the equivalent of $1 \%$ of the production or consumption. As net trade flows cancel at global level, the indicator for world is calculated by accounting only the net trade flows between regions that are positive.

${ }^{8}$ Intra-region trade flows are not presented here.
} 
of the yield effect. Area changes have a more limited role in the two African regions, particularly in Sub-Saharan Africa where smallholders have more difficulties to adapt. In Latin America or Eastern Asia \& Pacific, little change in food consumption is observed, whereas these impacts are important in Sub-Saharan Africa and in South Asia.

Trade pattern differences are also very visible in Figure 7. Regions with increases in production (Latin America, Middle East and North Africa, Eastern Europe and Central Asia) export more, whereas regions with decreases in production (South Asia, Sub-Saharan Africa and, to a lower extent, Eastern Asia \& Pacific) use imports to buffer a part of the effects on production. Interestingly, the different specifications for the two SSPs are well reflected in the trade results. Under SSP4 (red), trade is considered relatively constrained and trade adjustments remain low. Under SSP5 (blue), observed responses are much larger and partly help to mitigate price impacts, for instance in South Asia or Eastern Asia \& Pacific, or provide export opportunities to relatively less affected regions (Latin America, Eastern Europe and Central Asia).
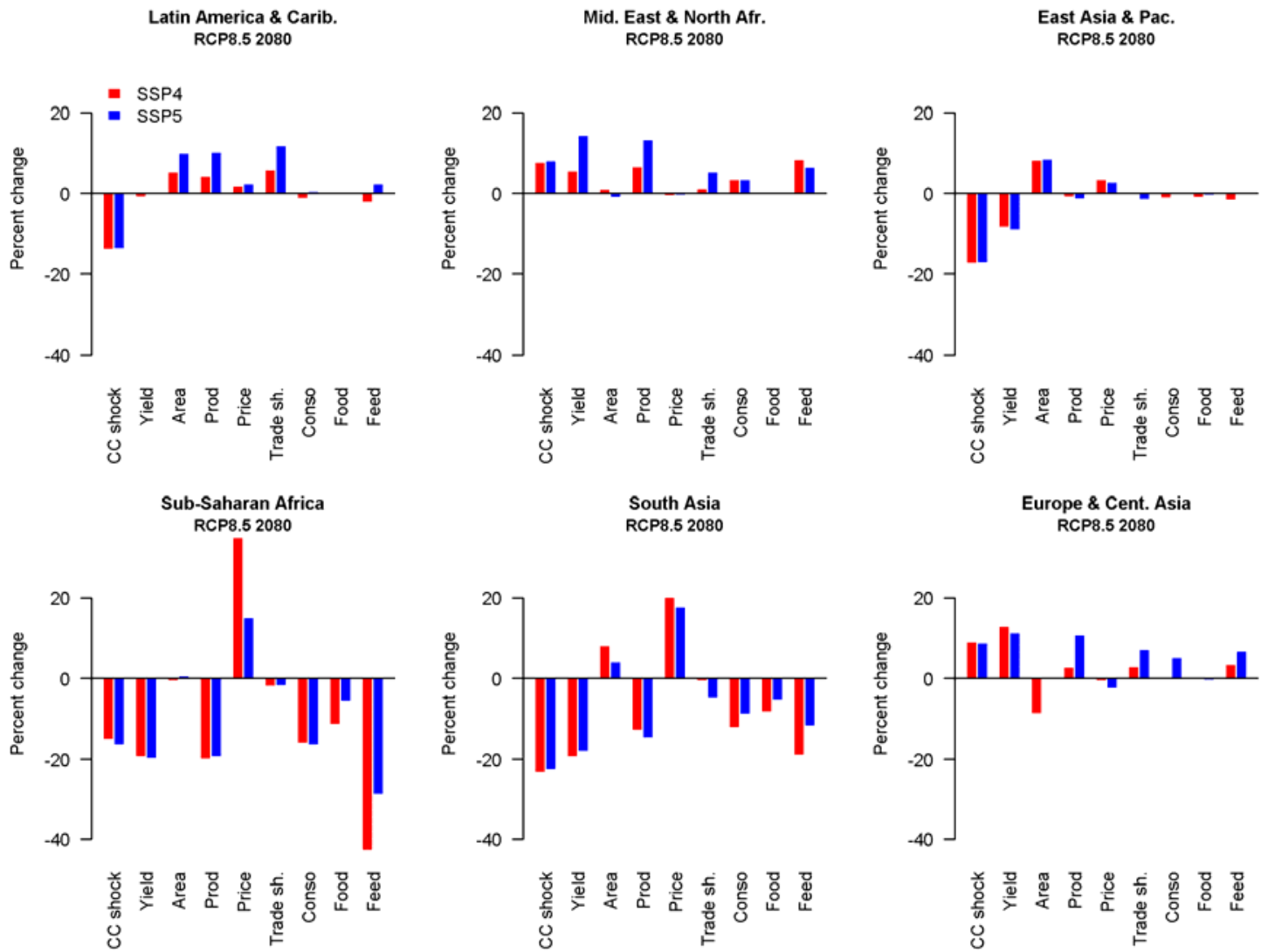

Figure 7. Propagation of climate change impact along the chain of economic indicators for SSP4 and SSP5 in 2080 for RCP 8.5 with $\mathrm{CO}_{2}$ effects. CC shock corresponds to the average biophysical impact of climate change on dry matter yield; Yield corresponds to final resulting dry matter yield, including adaptation response; Area is the total change in harvested area; Prod is the change in total crop production in dry matter basis; Price is the average crop price index; Trade sh. corresponds to difference in the share of interregional trade (export-import) in total crop production; conso is the change in total crop consumption, and food and feed the relative change in the consumption of food and feed. The average responses for the five GCM models are considered. Units are relative change to the baseline. For results in 2030 see figure D-3 in appendix D. 


\subsubsection{Crop and livestock sector impacts}

The different agricultural sectors will be affected with different levels of severity depending on the region but also on the activity type. Figure 8 shows with this respect the contrast in situations for different types of farm production.
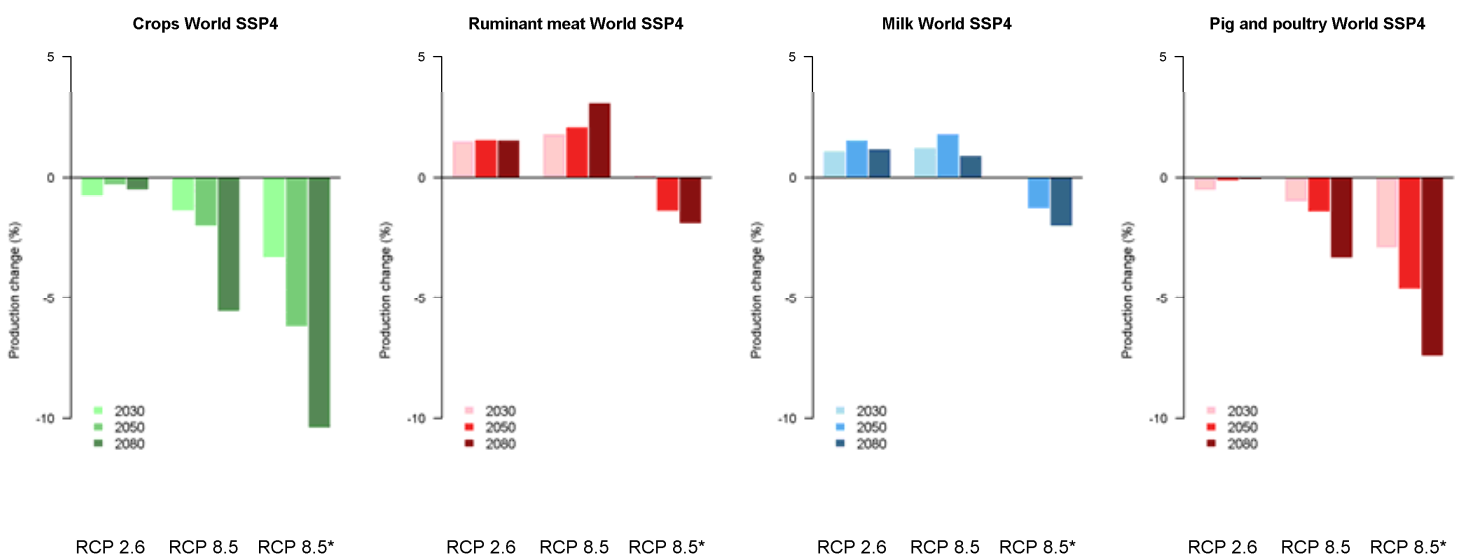

Figure 8. Change in production of different products for different climate change scenarios under SSP4Crops are aggregated by dry matter tonnes, meat by animal carcass weight, and milk by volume. The average responses for the five GCM models are considered except for the RCP8.5* sensitivity analysis, based on the HadGEM2-ES GCM.

For the crop sectors, as emphasized in the previous section, farmers can mitigate a part of the yield shock by adapting their management to the effect of climate change, which leads to lower shocks on final yields. They also mitigate the loss of productivity by expanding harvested areas, where possible. Overall impacts of climate change on crop supply are therefore found less severe as suggested by yield impact. In 2080, the impact of climate change under RCP 8.5 on crop production is $-5.6 \%$ and $-10.4 \%$ with and without $\mathrm{CO}_{2}$ effects, respectively.

Changes in the production of the different livestock sectors depend on their link with the crop sectors, and also on the impact of climate change on grassland (Havlík et al., 2015). The pig and poultry sectors depend heavily on grain concentrates and the impact of climate change on crops hit this sector directly through the feed channel. As a consequence, pig and poultry production under RCP 8.5 decreases globally by $-3.4 \%$ and $-7.4 \%$ with and without $\mathrm{CO}_{2}$ effects, respectively. Ruminant animals benefit from the increased grass productivity under scenarios with $\mathrm{CO}_{2}$ effects. Therefore, beef, lamb and goat meat output increase by $3.1 \%$ in 2080 under RCP 8.5 , whereas milk output rises by $0.9 \%$. However, without $\mathrm{CO}_{2}$ effects, grass and crop productivities are both negatively affected, and the two sectors decrease their production by $-1.9 \%$ and $-2.0 \%$ by 2080 .

\subsubsection{Socioeconomic impacts}

Agricultural prices are a sensitive parameter when examining poverty impacts. Even when food is produced in sufficient quantity overall, problems of distribution and access can lead to prohibitive prices in some regions, preventing the poorest from meeting their minimum needs and leading to food insecurity in absence of social programs or safety nets.

Agricultural prices are projected in our model to only moderately grow until 2030 for the two SSPs without climate change. Crop and livestock product prices increase by $7 \%$ and $9 \%$, respectively, under 
the SSP4 reference scenario by that time horizon. Under SSP5, the change would be even lower, with a stable price for crops and $+5 \%$ for livestock commodities. Differences come mostly from the faster technological growth and international market integration in SSP5. The market integration effect is very significant also for the regional prices. While under SSP5, crop prices vary between - $1 \%$ in Eastern Europe \& Central Asia and 4\% in Sub-Saharan Africa, the same prices still stagnate for the former under SSP4, but grow by $24 \%$ for the latter due to increased market isolation.

Under climate change, producer prices increase for sectors negatively impacted, and the effects are much more severe under high climate change - and even more so when $\mathrm{CO}_{2}$ fertilization is not considered. The magnitude of price response is also determined by the capacity of regions to adjust to the different adaptation channels, as illustrated by the previous section. Therefore, and in spite of the possibility of aligning prices to international price for the most traded products, price changes do not affect all regions in the same way (see Figure 9). Patterns also vary significantly between socioeconomic scenarios, because levels of development are not the same in each region. For instance, Sub-Saharan Africa is the most severely impacted region under SSP4 with up to an $11.9 \%$ increase in crop prices in 2030 for RCP 8.5 without $\mathrm{CO}_{2}$ effects. Impacts in this region are relatively less severe for the same scenario under SSP5, with a $5.6 \%$ price increase. This can be explained by the more restricted trade conditions under SSP4. A similar difference between the two socioeconomic scenarios is observed in the case of South Asia.
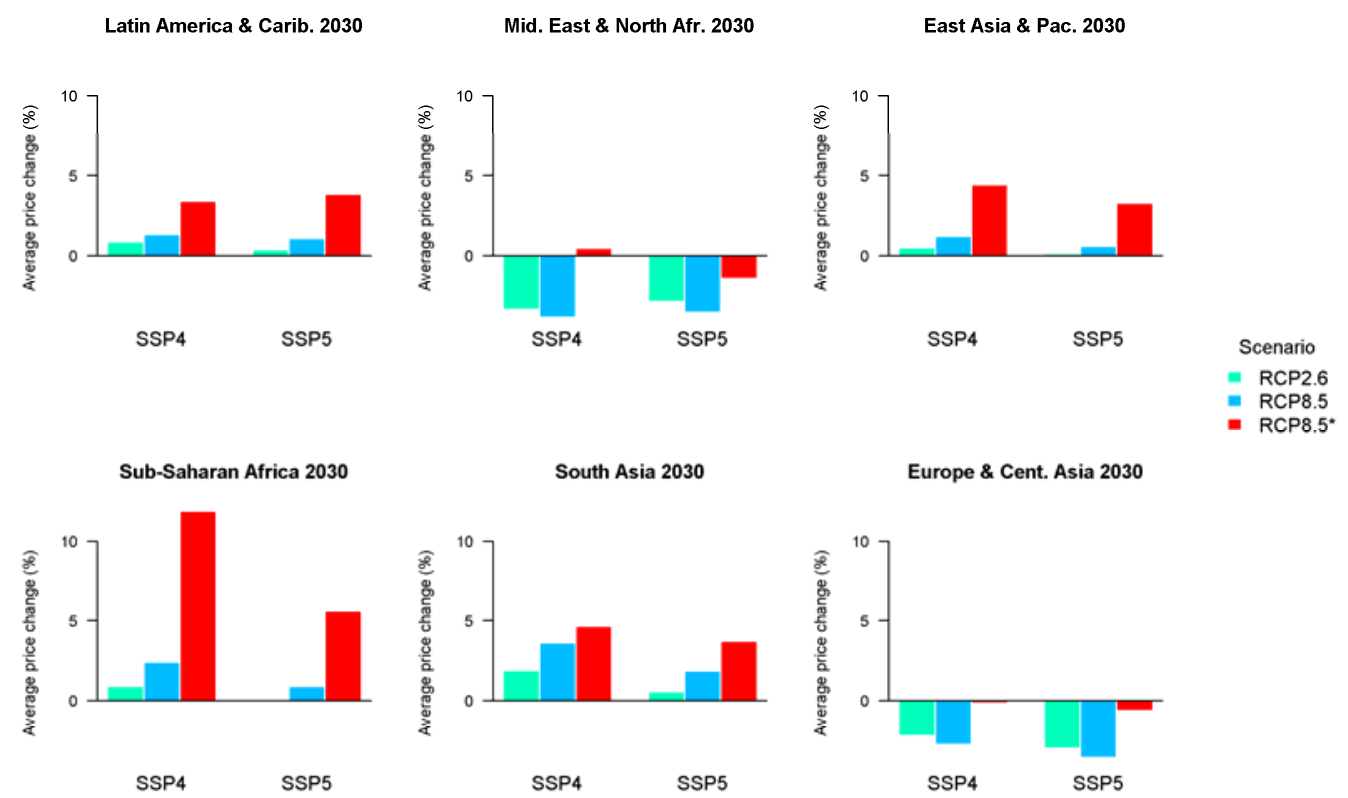

Figure 9. Climate change impact on agricultural prices in 2030 at regional level for different climate scenarios under SSP4 (left bar group in each panel) and SSP5 (right bar group). Price indexes are aggregated across crops using 2000 base year production. The average responses for the five GCM models are considered except for the RCP8.5* sensitivity analysis, based on the HadGEM2-ES GCM.

Without climate change, food demand is projected to grow by $4 \%$ and $11 \%$ between 2000 and 2030, under SSP4 and SSP5, which corresponds to increases from 2700 kilocalories per capita per day (kcal/cap/day) to 2800 and $3000 \mathrm{kcal} / \mathrm{cap} /$ day, respectively. While under SSP4, the increase would be the strongest in East Europe \& Central Asia, $+241 \mathrm{kcal} / \mathrm{cap} /$ day, under SSP5, it would be the strongest 
in Sub-Saharan Africa, $+645 \mathrm{kcal} / \mathrm{cap} /$ day, showing nicely the economic and technological catching up of the region. If these trends are strongly shaped by the effect of economic growth, prices also determine directly the final level of food consumption, and GLOBIOM represents a log linear response for each product between prices and consumption level. The overall global impacts of climate change on food consumption can be observed in Figure 10. Impacts are very limited for low climate change (RCP 2.6) but for high climate change, impacts on food consumption become progressively more severe over time, culminating for SSP4 at $-4.4 \%$ with $\mathrm{CO}_{2}$ effects and at $-8.7 \%$ without $\mathrm{CO}_{2}$ effects (left panel). This latter case results in a complete stagnation of calorie consumption globally compared to the present day situation ( $+30 \mathrm{kcal} / \mathrm{cap} /$ day between 2080 and 2000) and effects are much more dramatic in developing regions, with for example a decrease by $79 \%$ of additional food availability per capita in Sub-Saharan Africa.

Under SSP5, the impacts of climate change on food consumption are found to be much lower, which is fully consistent with the previous observation of lower price changes. Larger trade adjustments in SSP5 reinforce adaptation responses and minimize price responses in this scenario. Impacts therefore remain at a level of $-2.8 \%$ and $-4.3 \%$ under RCP 8.5 with and without $\mathrm{CO}_{2}$ effects, respectively. Additionally, demand becomes more inelastic over time as the different regions develop and this effect is much stronger under SSP5, where a faster economic growth is assumed. As a consequence, differences in magnitude of impacts tend to be more visible in 2080 than in 2030 or 2050. Impacts of climate change materialise here in a context where food is much more abundant than in SSP4, and therefore, even in the worst climate change scenario, the final food consumption per capita by 2080 is $3,429 \mathrm{kcal}$ globally, which is comparable to the present day levels of consumption in Europe.

World SSP4

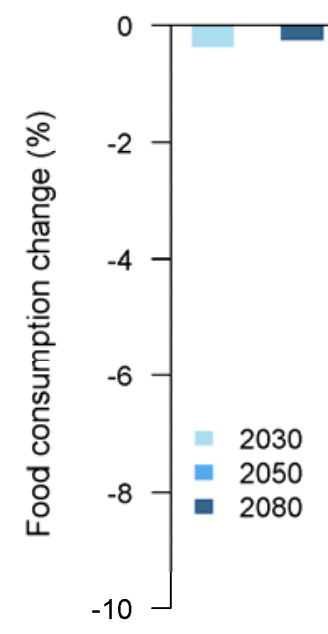

RCP 2.6

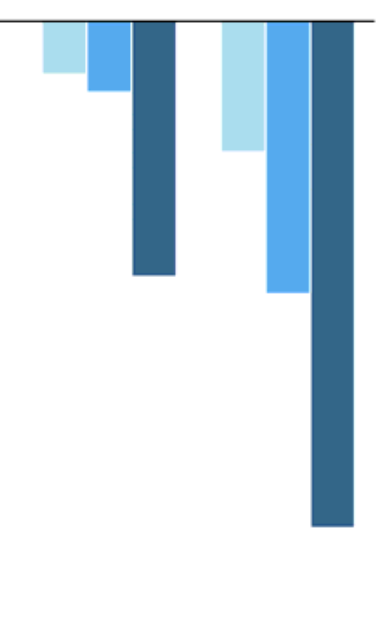

RCP $8.5 \quad \operatorname{RCP} 8.5^{*}$

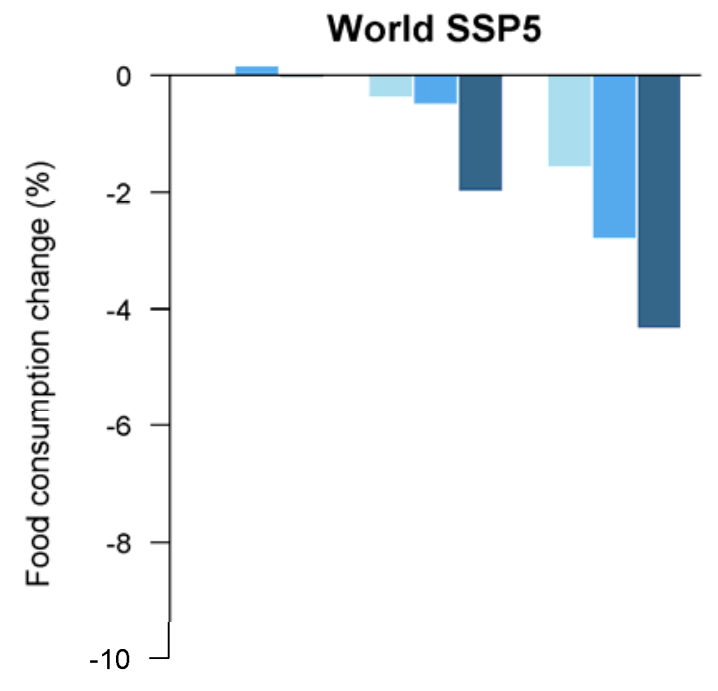

RCP $2.6 \quad \operatorname{RCP} 8.5 \quad \operatorname{RCP} 8.5^{*}$

Figure 10. Climate change impact on global food consumption at different time horizon for different climate scenarios under SSP4 (left) and SSP5 (right). Food products are aggregated by their calorie content. The average responses for the five GCM models are considered except for the RCP8.5* sensitivity analysis, based on the HadGEM2-ES GCM. 
The regional impacts of the different scenarios illustrate the contrasting fortunes of different regions (Figure 11 for the short term impacts in 2030). Regions that are found to be the most affected are SubSaharan Africa, South Asia and Eastern Asia \& Pacific. The differentiated effects on food consumption reflect the heterogeneity in regional results on food prices, but also the different specificities of diets. For instance, Latin America, which relies on a diversified diet where animal based products play a significant role, is less affected than South Asia where diets are mostly based on some vulnerable crops, such as rice, wheat, sorghum, potato.

Another important source of differences is the values of price elasticities of demand which vary for each region (larger for least advanced countries). Developed countries also experience higher prices (not in figure) but they react much less on the food demand side. For instance, for an $11.9 \%$ increase in crop prices in Sub-Saharan Africa in 2030 (RCP 8.5 without $\mathrm{CO}_{2}$ effects), food consumption decreases by $5.2 \%$. At the same time in North America, prices increase by $18.2 \%$ but food consumption decreases only by $1.4 \%$.
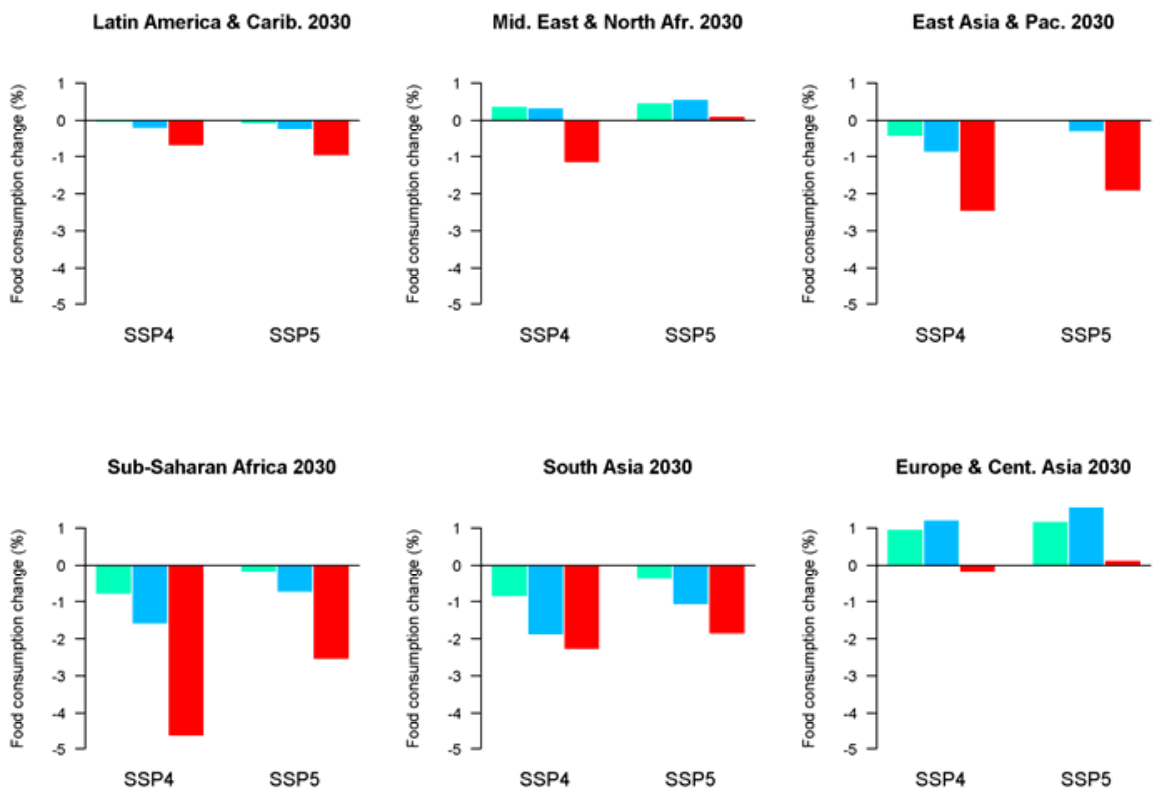

Figure 11. Climate change impact on food consumption per capita in 2030 for different climate scenarios under SSP4 (left bar group in each panel) and SSP5 (right bar group) at regional level. Food products are aggregated by their calorie content. The average responses for the five GCM models are considered except for the RCP8.5* sensitivity analysis, based on the HadGEM2-ES GCM.

\subsection{Climate change mitigation}

While it seems that without additional measures humanity is well on track to reach GHG emission levels corresponding to RCP8.5, stabilizing the emissions at levels compatible with RCP2.6 will require substantial mitigation efforts. In this sub-section, we present three alternative levels of effort in terms of mitigation of AFOLU emissions and biomass supply corresponding to different technological assumptions, but compatible with climate change stabilization at the RCP2.6 level. There are several mechanisms through which the idealized mitigation policy considered here will impact the agricultural and forest sectors; carbon prices will increase the production cost of GHG emitting activities, and the 
demand for GHG reducing activities, like afforestation and biomass for energy production, will increase the competition for resources, in particular for land. As for climate change impacts, these changes in agricultural and forestry markets can affect commodity prices and food availability.

\subsubsection{Emissions from agriculture, forestry and other land use (AFOLU)}

By 2000, AFOLU emissions, as accounted for in GLOBIOM, amounted to some $11 \mathrm{GtCO}_{2}$ e globally, of which about $60 \%$ came from land use change. Figure 12 shows how these emissions are distributed across different regions. Latin America, Sub-Saharan Africa and Eastern Asia \& Pacific represented together $77 \%$ of total AFOLU emissions in 2000 . These numbers are well in line with the recently reported levels by Smith et al. (2014) who estimated total average AFOLU emissions for the period 2000-2010 at 10-12 $\mathrm{GtCO}_{2}$ e per year, with emissions from agriculture amounting to 5.0-5.8 $\mathrm{GtCO}_{2} \mathrm{e}$ per year and emissions from land use and land use change amounting to some 4.3-5.5 $\mathrm{GtCO}_{2} \mathrm{e}$ per year. Even without climate change policy, net emissions from forestry and other land use would under SSP4 go down by $24 \%$ between 2000 and 2030 . At the same time, direct, non- $\mathrm{CO}_{2}$, emissions from agriculture would increase by $28 \%$, leading to overall AFOLU emissions reduction by $5 \%$. Under SSP5, similar reduction in emissions from land use change is projected. However, because of the sustained food demand, in particular for livestock products, non- $\mathrm{CO}_{2}$ emissions from agriculture would be $4 \%$ higher by 2030 than under SSP4. The difference between SSPs is getting more pronounced over time. For instance under SSP4 by 2080 , AFOLU emissions are projected to decrease by $49 \%$ compared to 2000 , while under SSP5, the AFOLU emissions would be $25 \%$ higher compared to the same year under SSP4.
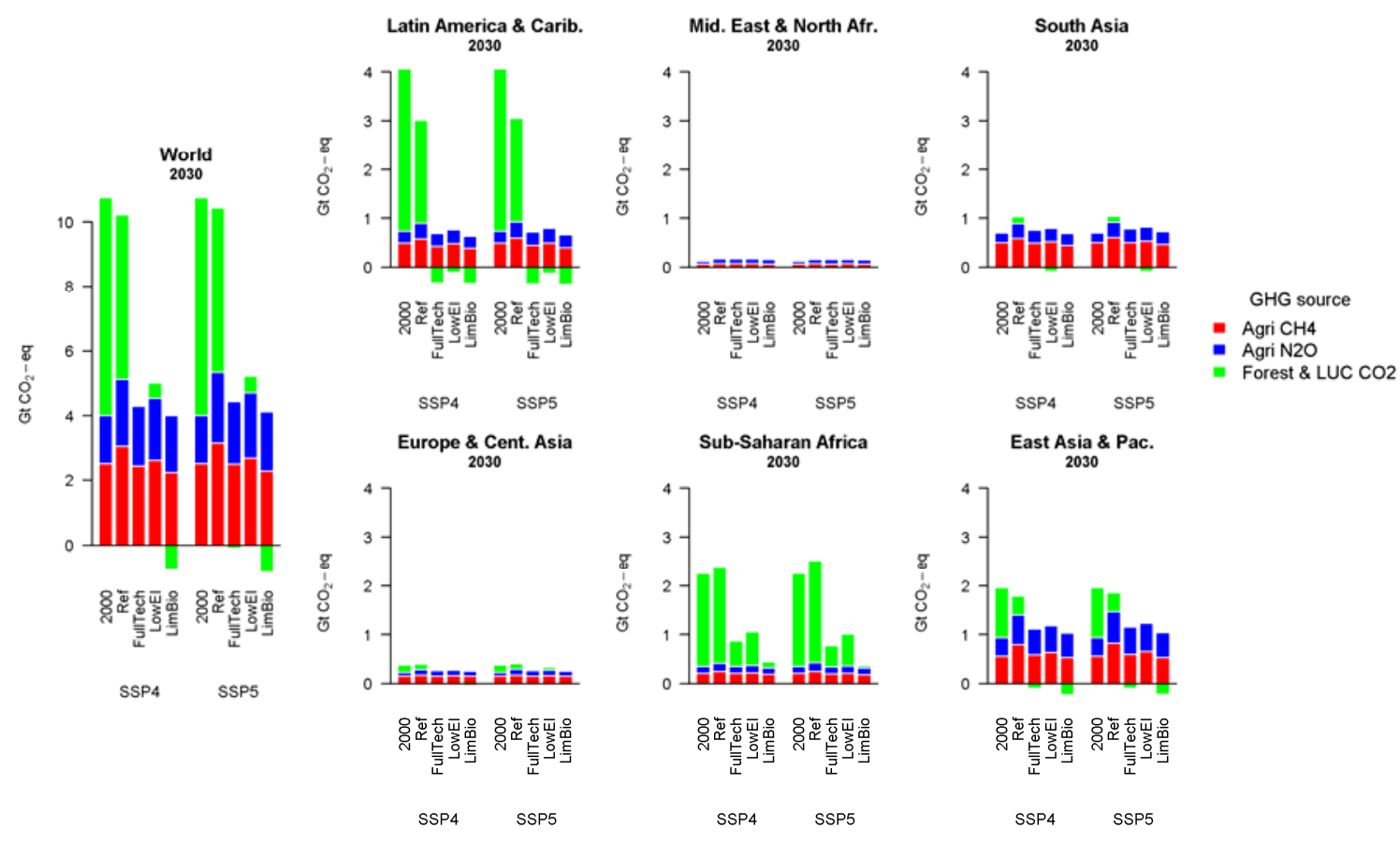

Figure 12 GHG emissions in 2030 from agriculture, forestry and other land use in the reference and the different mitigation scenarios, at global and regional level [ $\mathrm{GtCO}_{2}$ e]. The first bar of each panel corresponds to the base year 2000 calibration results.

In the climate stabilization scenario with Full Technology (FullTech) assumption, AFOLU emissions as calculated by GLOBIOM would decrease by $58 \%$ compared to the reference level by 2030 under the 
SSP4 scenario. This result is consistent with the EMF27 results themselves, where the models estimate that under this stabilization scenario, AFOLU emissions would need to be reduced by $-4 \%$ to $99 \%$ (Smith et al., 2014). According to our results, Latin America, Sub-Saharan Africa and Eastern Asia \& Pacific would contribute $45 \%, 26 \%$ and $13 \%$ of the global AFOLU abatement, respectively, providing together the large majority of the global mitigation effort in this sector. Under this stabilization scenario, direct emissions from agriculture remain roughly at their 2000 level, and net emissions from land use change approach zero, mostly because of reduced emissions from deforestation accompanied by afforestation. As one would expect, under the Low Energy Intensity scenario (LowEI), less mitigation effort is required from the AFOLU sector; total AFOLU emissions would then be about $20 \%$ higher than under FullTech. With limited role of bioenergy in the mitigation portfolio (LimBio scenario), agricultural emissions would be required to go even lower than under FullTech, and land use change would need to become a net sink of emissions already in 2030. This shows the need for substitution of negative emissions from bioenergy with carbon capture and storage by negative emissions from afforestation in order to achieve the climate stabilization.

\subsubsection{Biomass supply for energy}

Total amount of bioenergy is in the reference scenario without mitigation policy projected to slowly decrease until 2050 because of the decreasing importance of traditional fuelwood use, and to start to increase afterwards because modern bioenergy becomes competitive even without mitigation policies. Figure 13 provides an overview of how biomass supply for bioenergy would develop under stabilization scenarios. In the FullTech stabilization scenario, demand for bioenergy by 2030 would be multiplied by two compared to the reference scenario. Sub-Saharan Africa, Latin America and Eastern Asia \& Pacific would again be important players supplying each about $20 \%$ of the total biomass demand. This result is in line with the findings by Rose et al. (2012) that up to $80 \%$ of the biomass for energy production would come from non-OECD countries. With respect to the source of the biomass, our projections suggest that while in Latin America the quasi-totality of the biomass would come from dedicated plantations, in Sub-Saharan Africa and Eastern Asia \& Pacific, 30\%, respectively 20\%, of the total biomass would come from traditional forests. This differentiation is due to high plantation yields and large areas of suitable land in the case of Latin America, and vast areas of tropical forests where currently only a small fraction of the biomass, high quality woods, is extracted from the managed zones. The required biomass supply would be $43 \%$ lower in the LowEl scenario, and, it would be $15 \%$ lower also under the LimBio scenario. The demand for biomass is projected to continue to grow substantially beyond 2030. Under the FullTech scenario, biomass demand would more than triple between 2030 and 2080. This new demand represents future income opportunities in the forestry and agricultural sectors. 


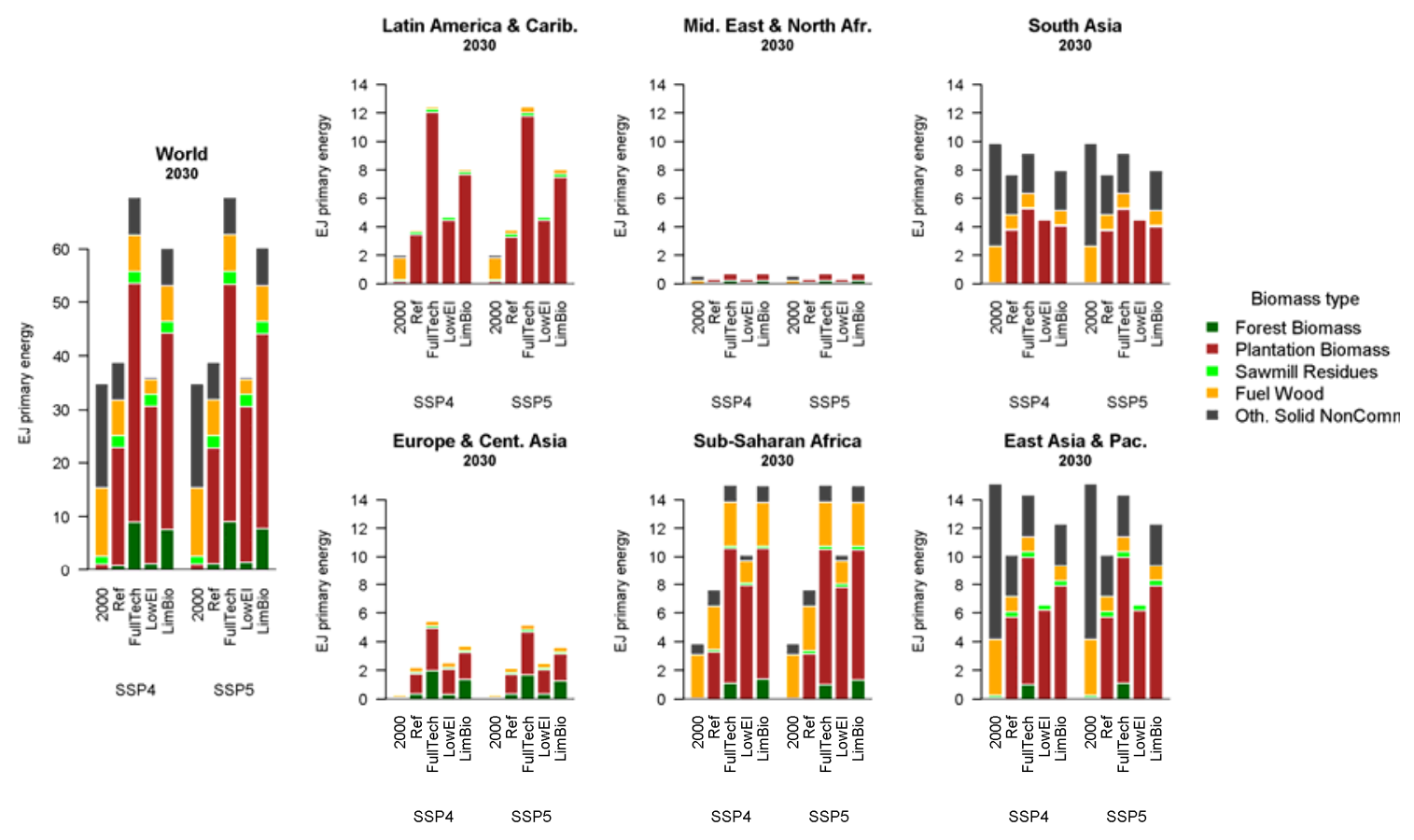

Figure 13 Biomass supply for energy production in 2030 for SSP4 and SSP5 in the reference and in the alternative stabilization scenarios [EJ primary energy per year].

\subsubsection{Crop and livestock production}

Crop production for the 17 products in the model represented $2.4 \mathrm{Gt}$ dry matter in 2000. It is projected to grow without mitigation policies by an additional $1.4 \mathrm{Gt}$ and $1.7 \mathrm{Gt}$ for SSP4 and SSP5 respectively, between 2000 and 2030. The growth is projected to be particularly high due to income growth, population growth and changes in preferences in developing regions under SSP5 where diet preferences converge towards more Western trends. Hence, in South Asia crop production is projected to grow by $307 \mathrm{Mt}$ ( $340 \mathrm{Mt}$ ), in Middle East \& North Africa by $69 \mathrm{Mt}(60 \mathrm{Mt}$ ) and in Sub-Saharan Africa by $171 \mathrm{Mt}(197 \mathrm{Mt}$ ) for SSP4 (SSP5). Climate stabilization efforts would substantially impact the crop production growth, as illustrated in Figure 14. In Sub-Saharan Africa, the production growth would be 9\% (13\%) lower under FullTech than under the reference scenario, and even by $12 \%(14 \%)$ lower under the LimBio scenario, leading potentially to decreases in farmers income and less food available for the consumers. It is interesting to note that even under the LimBio scenario for SSP5, the total production is higher than in the reference scenario for SSP4. 

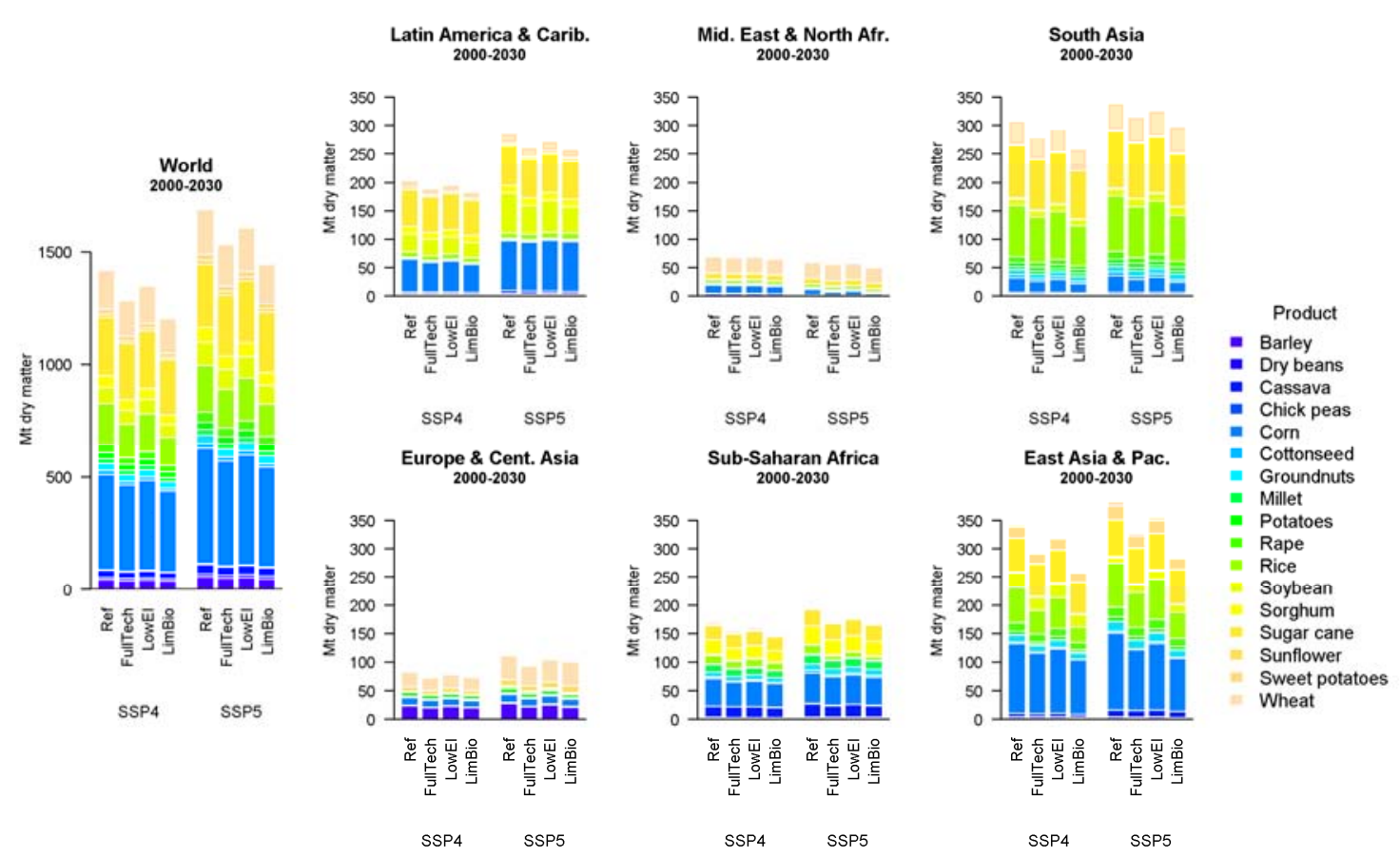

Figure 14 Difference in crop production levels between 2000 and 2030 in the reference and alternative stabilization scenarios, at global and regional level, under different SSPs [million dry matter tonne]. Full product definitions in Appendix.

As for crop production, livestock production is also subject to a strong global increase in the reference scenario, from $53 \mathrm{Mt}$ of protein supply in 2000 to $82 \mathrm{Mt}$ in 2030 under SSP4, and $90 \mathrm{Mt}$ under SSP5. Developing regions again show the largest increases leading to a more than doubling of the production in Sub-Saharan Africa, South Asia and Mid East \& North Africa. As shown in Figure 15, the livestock sector would be directly impacted by the mitigation policy, but all sub-sectors would not be affected equally; depending on the technology scenario, ruminant meat production would decrease, by 6 to $16 \%$ relative to the reference scenario. Poultry meat production would decrease by maximum $2 \%$. This comes from the relative GHG emissions (in)efficiency of the different sub-sectors (de Vries and de Boer, 2010), which implies that ruminant meat production is much more affected by a carbon price than poultry production. While the relative effect of the climate stabilization scenarios is similar under SSP4 and SSP5, because of the larger growth in the reference scenario in SSP5, the global livestock production in the latter scenario would remain above the reference level of SSP4 in all the technology scenarios. 

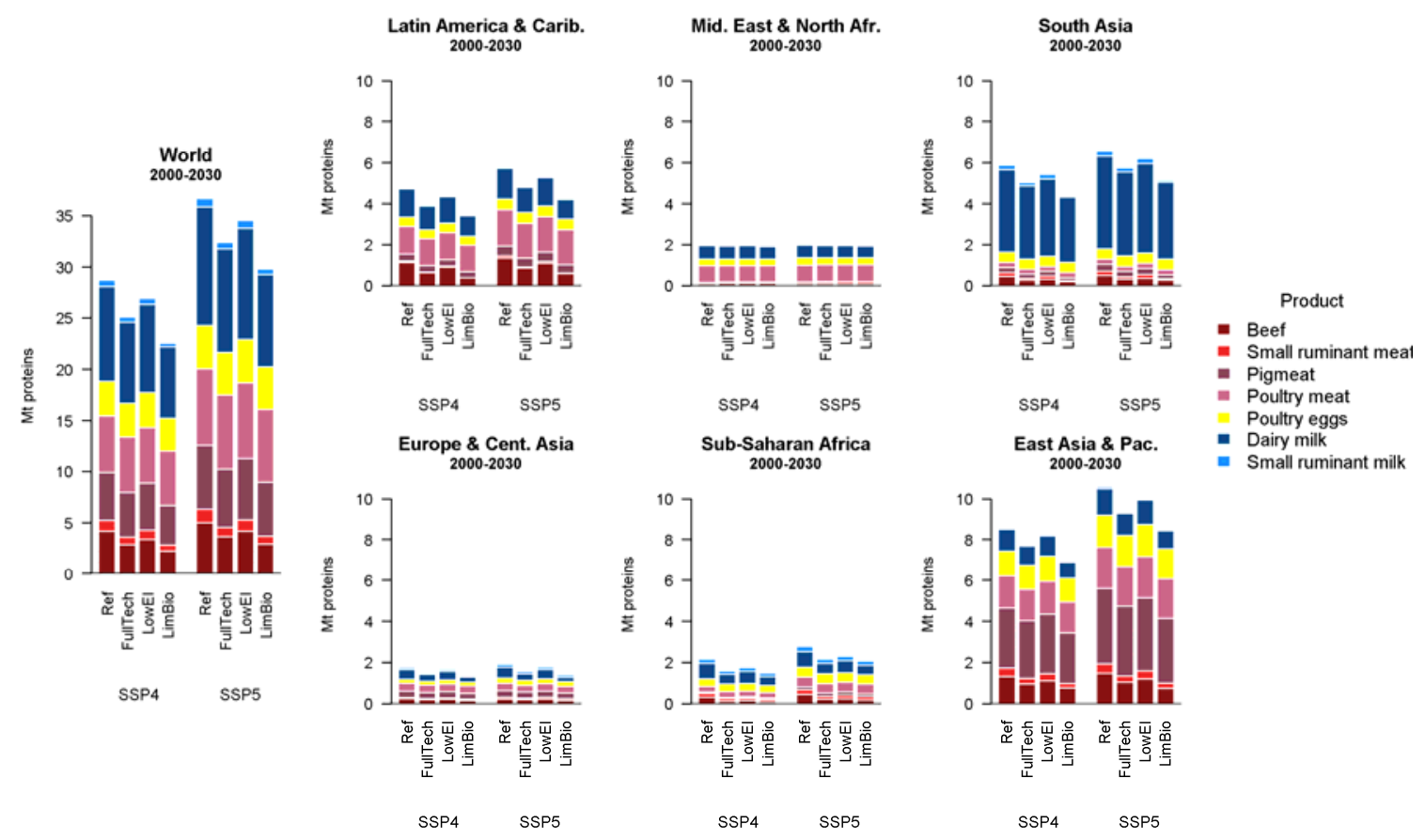

Figure 15 Difference in livestock product output between 2000 and 2030 in the reference SSP4 and SSP5 and the alternative stabilization scenarios, at global and regional level [million tonnes proteins].

GHG emission efficiency also largely varies within each livestock sub-sector depending on the production system (Herrero et al., 2013). The differences are particularly large in the ruminant sector, and a carbon tax would lead to significant reallocation of production from extensive grazing systems to (semi-) intensive mixed systems (Havlík et al., 2014). Reallocations across livestock systems for the different mitigation scenarios are visible in Figure 16. The share of beef supply coming from grazing systems (" $\mathrm{LG}$ " in the figure) would be in the mitigation scenarios under SSP4 around 5 percentage points lower by 2030 than in the reference scenario, $12 \%$ compared to $17 \%$. In Sub-Saharan Africa the share of intensive mixed systems ("MRT" in the figure) in beef production would be 4 percentage points higher in the stabilization scenarios than in the reference, $29 \%$ as compared to $25 \%$. Similar observations hold in the case of SSP5. An enabling environment needs to be created to support such intensification of extensive systems, or where biophysical conditions do not allow for this, alternative sources of income need to be proposed to the pastoralists. 


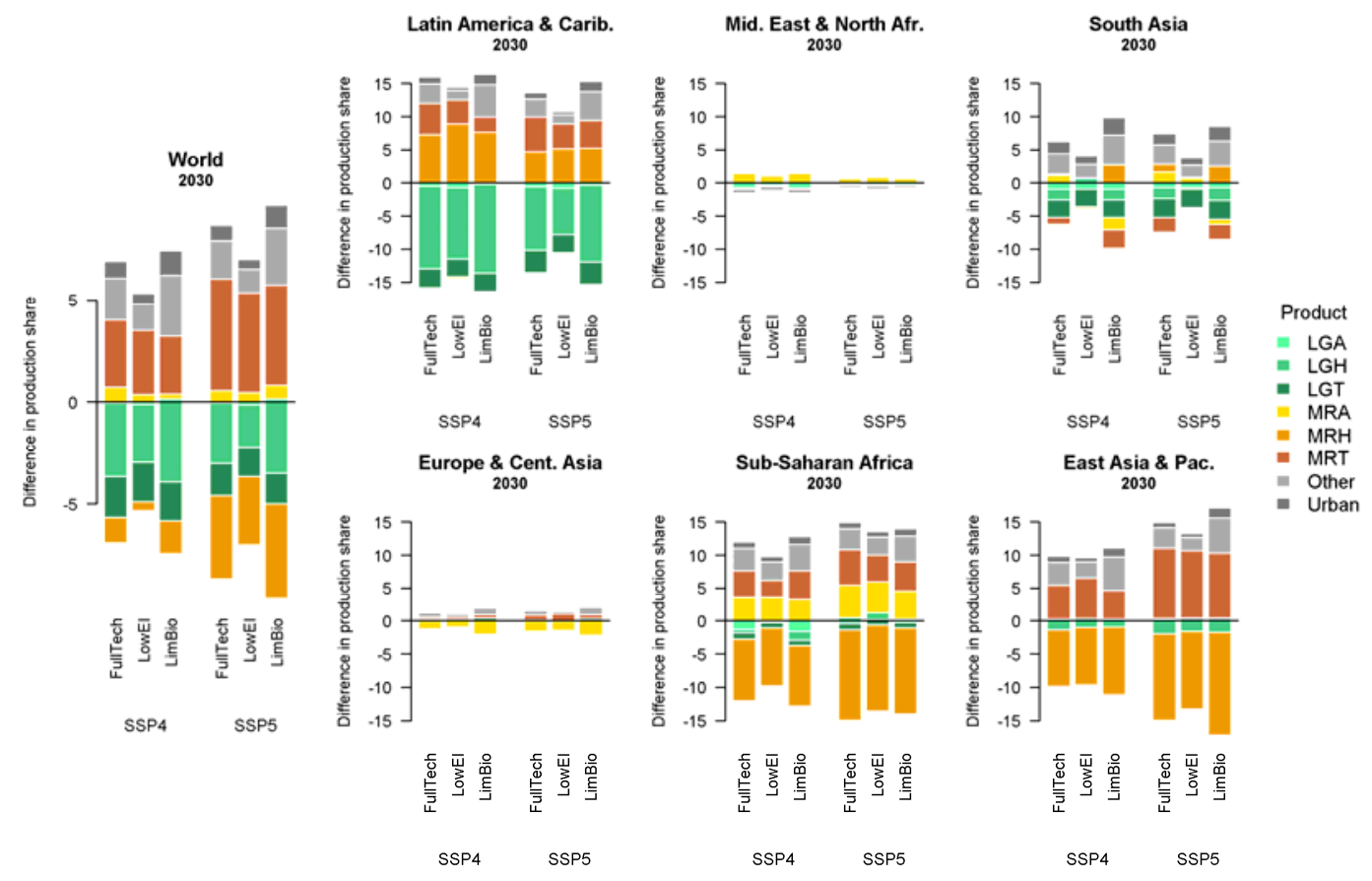

Figure 16 Difference in shares of beef production allocation to different production systems in 2030 for the different stabilization scenarios, compared to the reference SSP4 or SSP5 [percentage points]. (LGA - grazing systems arid, LGH grazing systems humid, LGT - grazing systems temperate and in tropical highlands, MRA - mixed crop-livestock systems arid, MRH -mixed crop-livestock systems humid, MRT-mixed crop-livestock systems temperate and in tropical highlands).

\subsubsection{Forest sector production}

Industrial round wood supply is projected to increase by $49 \%(61 \%)$ in the reference scenario SSP4 (SSP5) by 2030. Globally, the different variants of stabilization scenarios have very limited impact on round wood supply, Figure 17. Regionally, we can see some significant differences. In LAM, FullTech scenario leads to a slightly increased round wood supply, $+5 \%$ in SSP5, which can be traced back to the increased value of forest based by-products and thereby lowering the cost of producing the final timber products. On the other hand, mitigation under the FullTech scenario leads to reduced round wood supply in Eastern Europe \& Central Asia, because of substantial sourcing of biomass for bioenergy from the traditional forests and limited potentials to increase the total forest harvest level. In this region, we also clearly see the differentiated impact of increased biomass demand on pulpwood and saw logs supply. Pulpwood can be either main product from the forest, or, more often, it is a lower grade by-product of saw logs harvesting. Both saw logs and pulpwood type of biomass can be used for energy production. Hence, while the energy feedstock can be a by-product of saw logs harvesting, and so improve the economics of the latter leading to an increased supply, it is direct competitor to pulpwood production. 

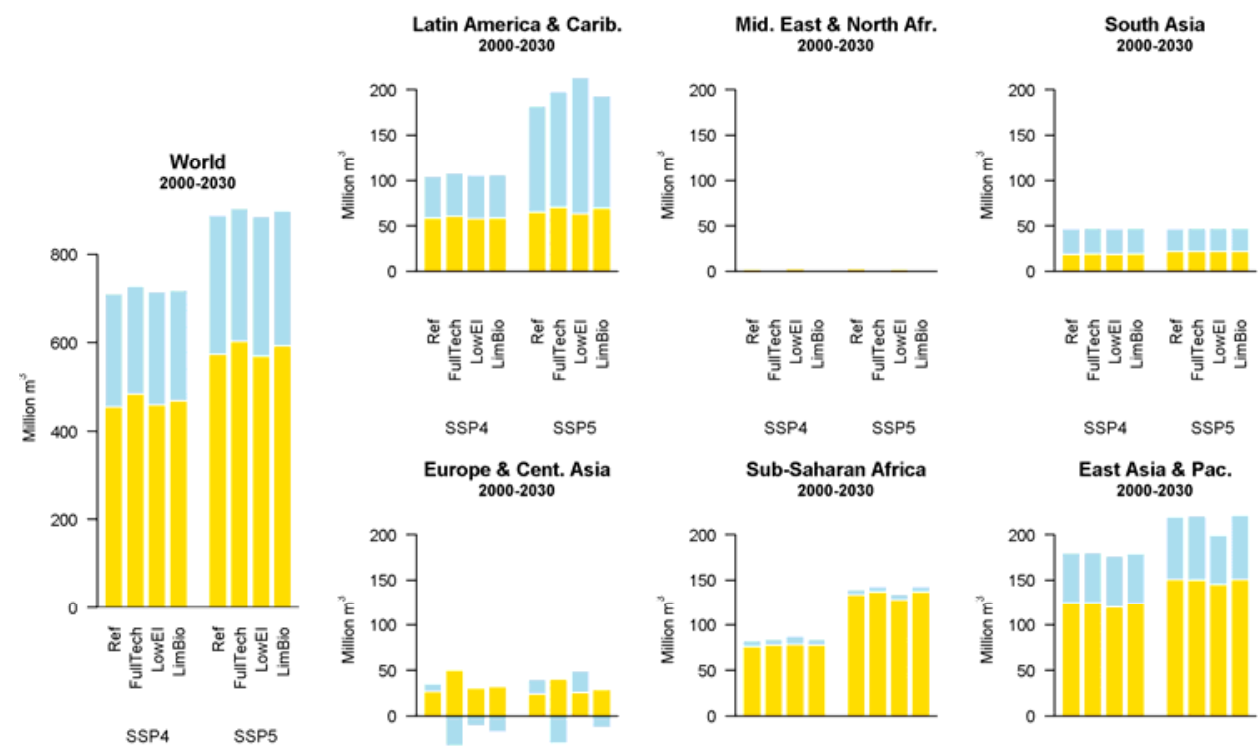

Europe \& Cent. Asia 2000-2030

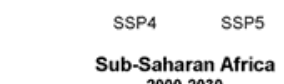

2000-2030
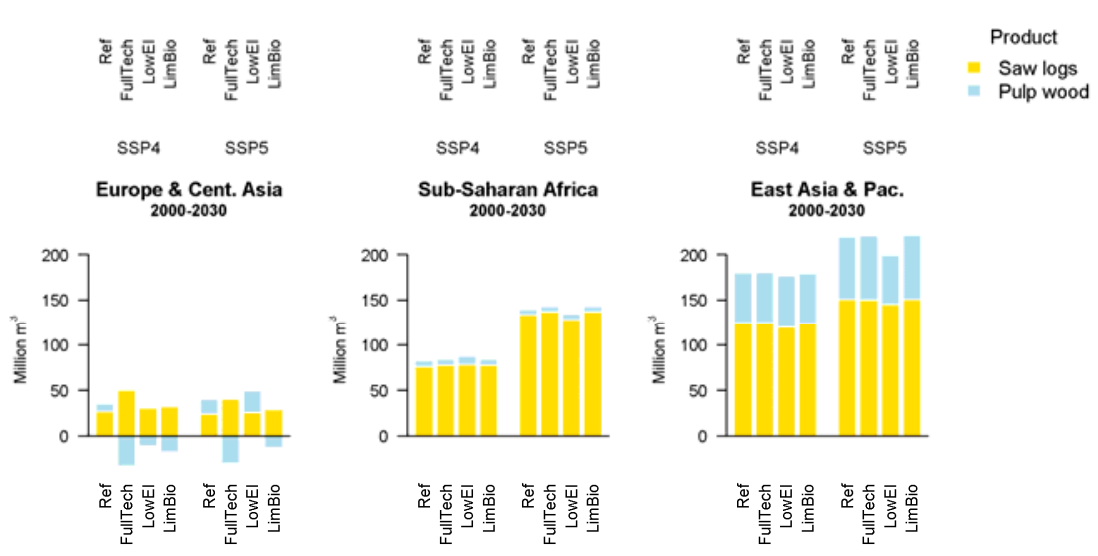

SSP4 SSP5

East Asia \& Pac. 2000-2030

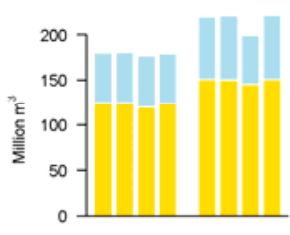

SSP4 SSP5

SSP4 SSP5

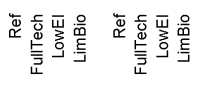

SSP4 SSP5

Figure 17 Difference in industrial roundwood production between 2000 and 2030 for the reference SSP4 and SSP5 and the alternative stabilization scenarios, across wood type products [million cubic meters].

\subsubsection{Land cover change}

Land cover development is a good aggregate indicator of the change in agriculture, forestry and other land use, and illustrates the transformational challenges implied by the ambitious stabilization scenarios. Under the reference scenario SSP4, cropland is projected to expand by 58 million hectares, grassland by 117 million hectares, and dedicated energy plantations by 82 million hectares between 2000 and 2030 (Figure 18). 78\% of cropland expansion would occur in Sub-Saharan Africa, grassland expansion would be shared mostly by Eastern Asia \& Pacific, Sub-Saharan Africa, and Latin America, and plantations expansion would be similar across the regions. About one third of the newly cultivated land would come from former forests, and two thirds from other natural vegetation. The major difference under SSP5 would be the 30\% higher expansion of grasslands due to the economic development and shifts in diet preferences. 

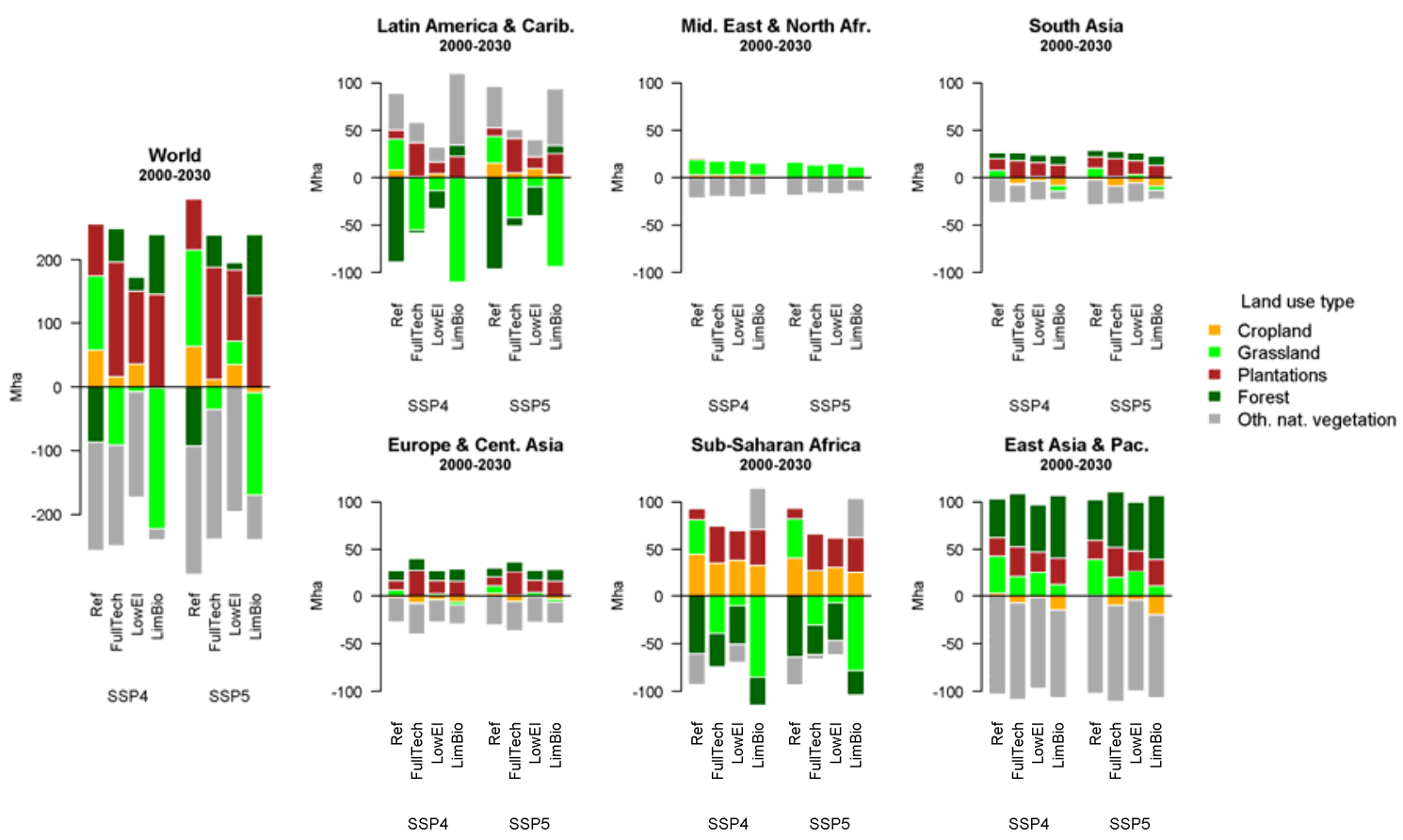

Figure 18. Difference in land cover between 2000 and 2030 in reference and alternative stabilization scenarios [million hectares].

Under the mitigation scenario FullTech in SSP4, cropland area would increase only by 17 million hectares between 2000 and 2030, grassland area would decrease by 91 million hectares and energy plantations area would increase by 180 million hectares, which means that an additional 100 million hectares would be mobilized for energy plantations compared to the reference scenario. Forest area would not decrease as in the reference scenario, but rather increase, by 52 million hectares, driven by incentives to reduce deforestation and to increase afforestation, as well as by the greater biomass demand increasing the value of the standing forests compared to a cleared one. Most of the grassland sparing, 78\%, would occur in Sub-Saharan Africa and Latin America. $61 \%$ of the total forest loss would be avoided in Latin America. With limited bioenergy capacity under the LimBio scenario, an additional 183 million hectares of natural land would be spared mostly because of reduced area of grasslands but also because of 35 million hectares less required for energy plantations. The results are similar for both SSPs.

\subsubsection{Socioeconomic impacts}

Technology assumptions play an important role in the evolution of agricultural prices under the stabilization scenarios. For instance under SSP4, crop prices in the FullTech scenario would be $4 \%$ higher by 2030 than in the reference case, but the increase would be $1 \%$ and $7 \%$ under the LowEl and LimBio scenarios, respectively. Livestock product prices would be also $4 \%$ to $15 \%$ higher compared to the reference scenario, and the most affected commodity would be beef with higher prices by $8 \%$ to $28 \%$ globally. Overall, agricultural commodity prices would grow by $3 \%$ to $12 \%$. The effects on prices would be much more pronounced by 2080 . Where in the worst scenario, LimBio, global crop prices would be higher by about $80 \%$ compared to the reference level, and livestock prices would be up to $140 \%$ higher. These results have very similar patterns to those obtained by Reilly et al. (2012). 
The rather moderate aggregate effects by 2030 can be more pronounced on the regional level, reflecting the relative GHG efficiency of the different regions (Figure 19). For instance, while beef prices would increase by just about $10 \%$ in Western Europe or North America, they would increase by more than $40 \%$ in Latin America and in Sub-Saharan Africa under the FullTech scenario, with strong implications for local consumers. Regional results also reveal different patterns across SSPs, in particular for Latin America and Asian regions. SSP5 impacts are in these cases relatively higher than in SSP4 for all stabilization scenarios. This is due in particular to the higher share of livestock products in human diets, whose prices are strongly hit by the mitigation measures.
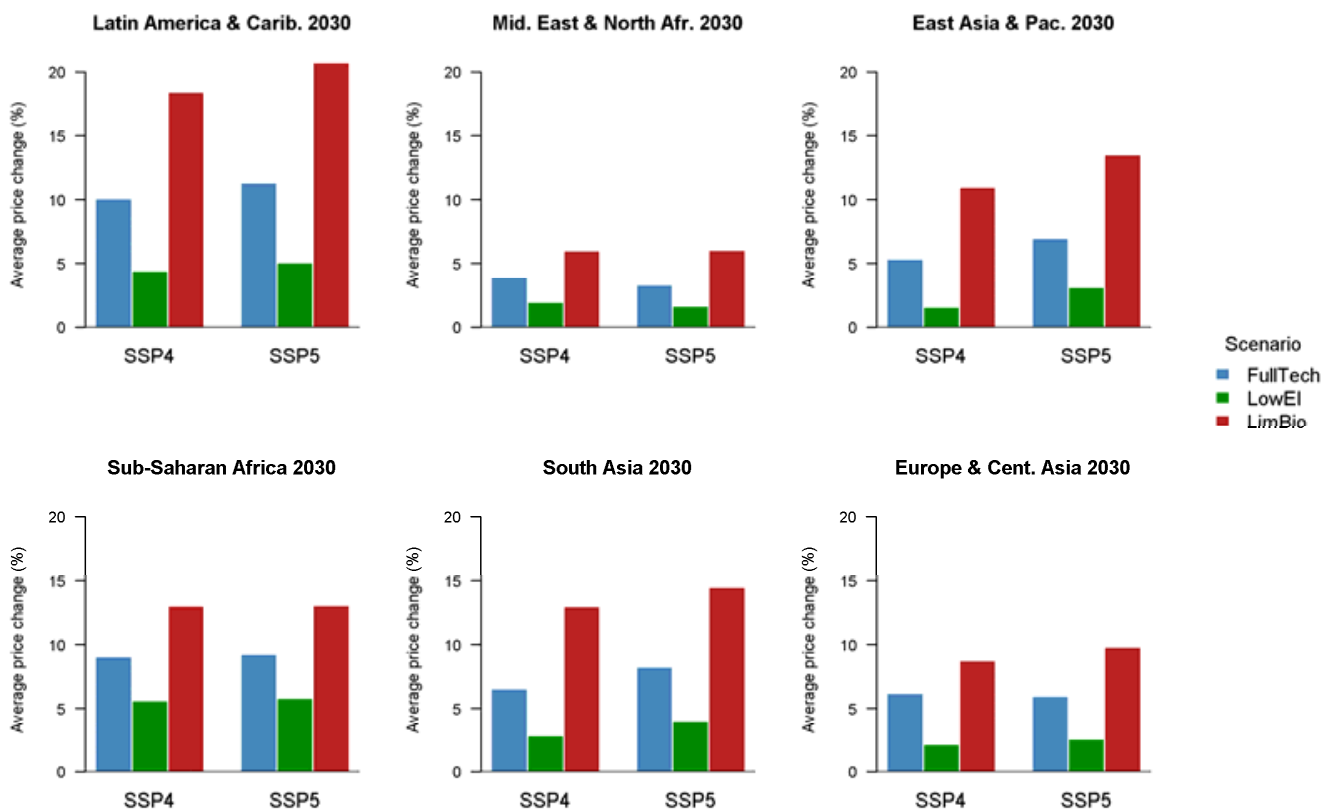

Figure 19 Change in food prices in the different stabilization scenarios compared to the reference SSP4 and SSP5, at global and regional level [\%].Price indexes are aggregated across crops and livestock product using 2000 base year production.

Price increases in the mitigation scenarios are related both to the increased competition for land for carbon sequestration (afforestation, avoided deforestation) and for biomass production, as well as to the carbon tax directly increasing the production costs. Overall impacts on farmer revenues will depend on whether they can benefit from the increased land rent (Zekarias et al., 2013) and on their GHG emissions efficiency which will become a part of their comparative advantage. On the consumer side, however, such mitigation policies would have negative effects on food availability through the increased food prices.

When looking at final food availability, the impact of agricultural prices appears strong for all mitigation scenarios (see Figure 20). The mitigation scenario FullTech, would reduce the global food availability growth by $68 \%$ under SSP 4 and by $27 \%$ under SSP5. In the scenario with limited bioenergy availability, LimBio, food availability in 2030 would be under the SSP4 scenario even slightly lower than in 2000. 
World SSP4

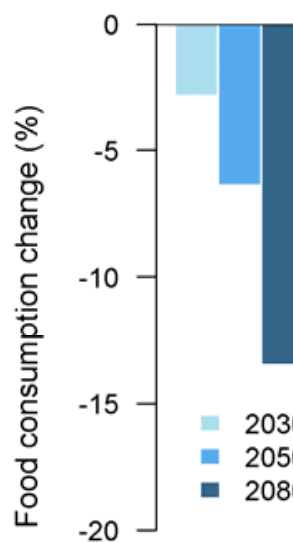

World SSP5

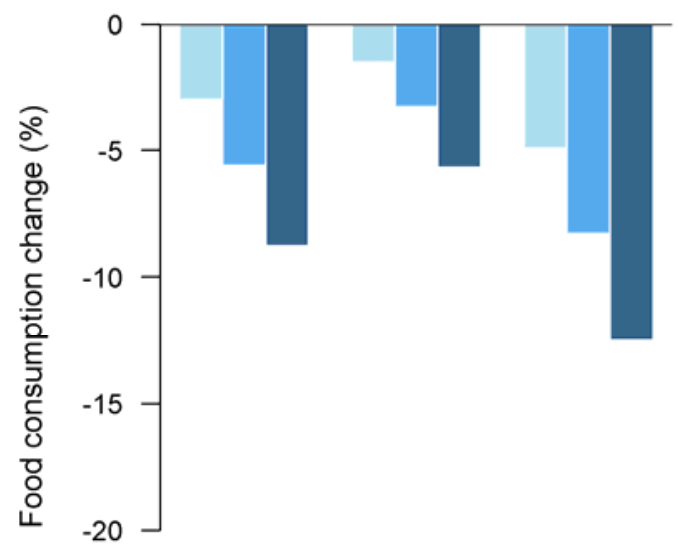

FullTech LowEl LimBio

Figure 20 Relative change in global food consumption level in the alternative stabilization scenarios compared to the reference by 2030 [kcal per capita per day]. Both crop and livestock products are considered.

Regional patterns illustrate the differentiated impacts between regions with high food demand resilience and more vulnerable ones (Figure 21). While North America, Western Europe and Developed Pacific would see food availability reduced by less than $1 \%$ under FullTech compared to the reference, LMI regions would be affected by a reduction between 2 and $3 \%$ already in 2030. The impacts are even higher for the LimBio scenario, with around $5 \%$ of consumption loss for South Asia, Eastern Asia \& Pacific and Sub-Saharan Africa. Overall, the effects of mitigation policies on food availability seem rather small at this time horizon, but they would become more important as carbon price and demand for bioenergy are projected to increase more substantially over time. For instance under SSP4, high income regions would see calorie availability reduced by about $5 \%$ by 2080 , and the LMI regions by $10-$ $15 \%$.

Impacts globally appear much higher under SSP4, due to the limited possible trade adjustments and the more elastic demand due to lower GDP per capita in LMI regions. When examining to regional results however, effects appear more ambivalent depending on the region. Most regions are more severely affected by the mitigation policies under SSP5 in relative terms, to the exception of SubSaharan Africa that experience a greater reduction of food demand under SSP4. However, because food consumption for these regions is higher under SSP5 baseline (by $7 \%$ globally in 2030 , and by $20 \%$ in the case of Sub-Saharan Africa), the same relative impact from mitigation has more adverse implication under SSP4. For instance, in Sub-Saharan Africa, food availability improvement on the 2000-2030 period is reduced by 53\% under FullTech with SSP4 and ends at $2345 \mathrm{kcal} / \mathrm{cap} /$ day in 2030 . Under FullTech with SSP5, the growth is only reduced by 13\%, resulting in food supply of 2830 $\mathrm{kcal} / \mathrm{cap} /$ day in 2030. 

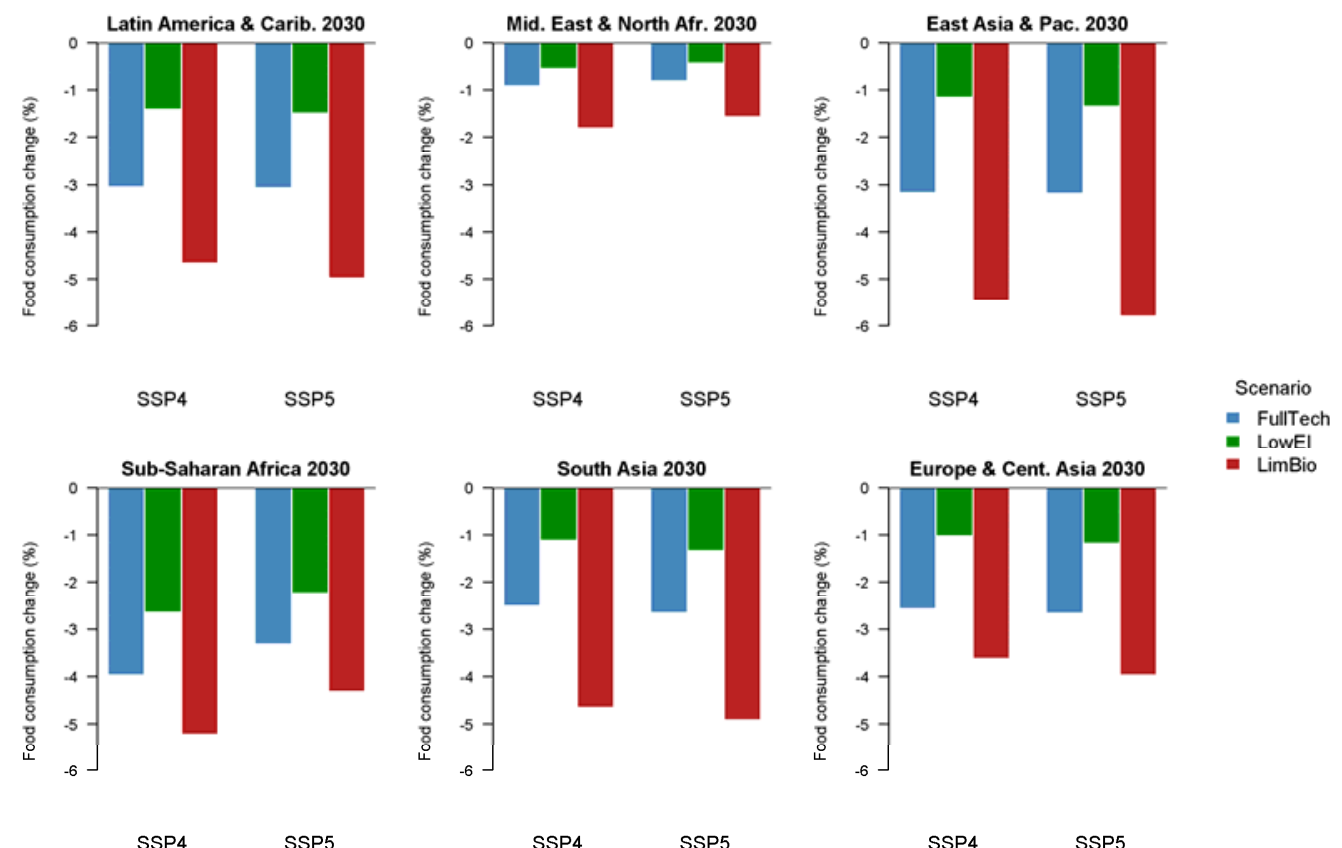

Figure 21 Change in food consumption level in the different mitigation scenarios, compared to the reference SSP4 and SSP5, at regional level

\subsection{Comparison climate impacts vs mitigation}

Both climate change impact and climate change mitigation were shown to affect agricultural prices and food consumption. However, as can be seen in Figure 22, the effects of these scenarios are rather limited in the medium term. In 2030, effects of climate change are significant only when effects of elevated $\mathrm{CO}_{2}$ concentration are not taken into account. For their part, stabilization scenarios lead to food availability losses in the range of 50-100 kcal/cap/day, except for the case of low energy intensity. As observed above, the two RCPs are quite undifferentiated at that time horizon, and the effect of SSPs is also less discriminating.

In the long run, food availability would suffer from the potentially strong effects of an idealized mitigation policy taxing all GHG emissions without differentiating among the sectors or regions. Such a policy, corresponding to a carbon price of $\$ 200$ to $\$ 960$ per ton of $\mathrm{CO}_{2}$ e by 2080 , would lead to food availability reduction in the range $200-400 \mathrm{kcal} / \mathrm{cap} /$ day under SSP5, and up to $500 \mathrm{kcal} / \mathrm{cap} /$ day under the SSP4 scenario. Because of the higher reference level in SSP5, the food availability would with 3166 $\mathrm{kcal} / \mathrm{cap} /$ day remain well above the 2000 level of $2700 \mathrm{kcal} / \mathrm{cap} /$ day even for the LimBio scenario. However, under SSP4, it would go down to $2592 \mathrm{kcal} / \mathrm{cap} /$ day in the FullTech scenario, and even 2440 $\mathrm{kcal} / \mathrm{cap} /$ day in the LimBio scenario, which are levels below the 2000 average value. Climate change impacts also show negative effects, not much differentiated across SSPs. But the food availability losses do not exceed $200 \mathrm{kcal} / \mathrm{cap} / \mathrm{day}$, and thus remain lower than losses due to climate mitigation.

These results should however be interpreted with some prudence, due to the large number of uncertainties in the climate change impacts, and to the "naive" mitigation policy design implemented in the model where a uniform tax is applied to all the emission sectors and its revenue stays outside of 
the sector both on the producer and on the consumer side. We will discuss in the next section the differential effect of including different subsets of the mitigation strategies under the tax scheme. And in the conclusion we will return to the discussion of the use of carbon tax revenues.
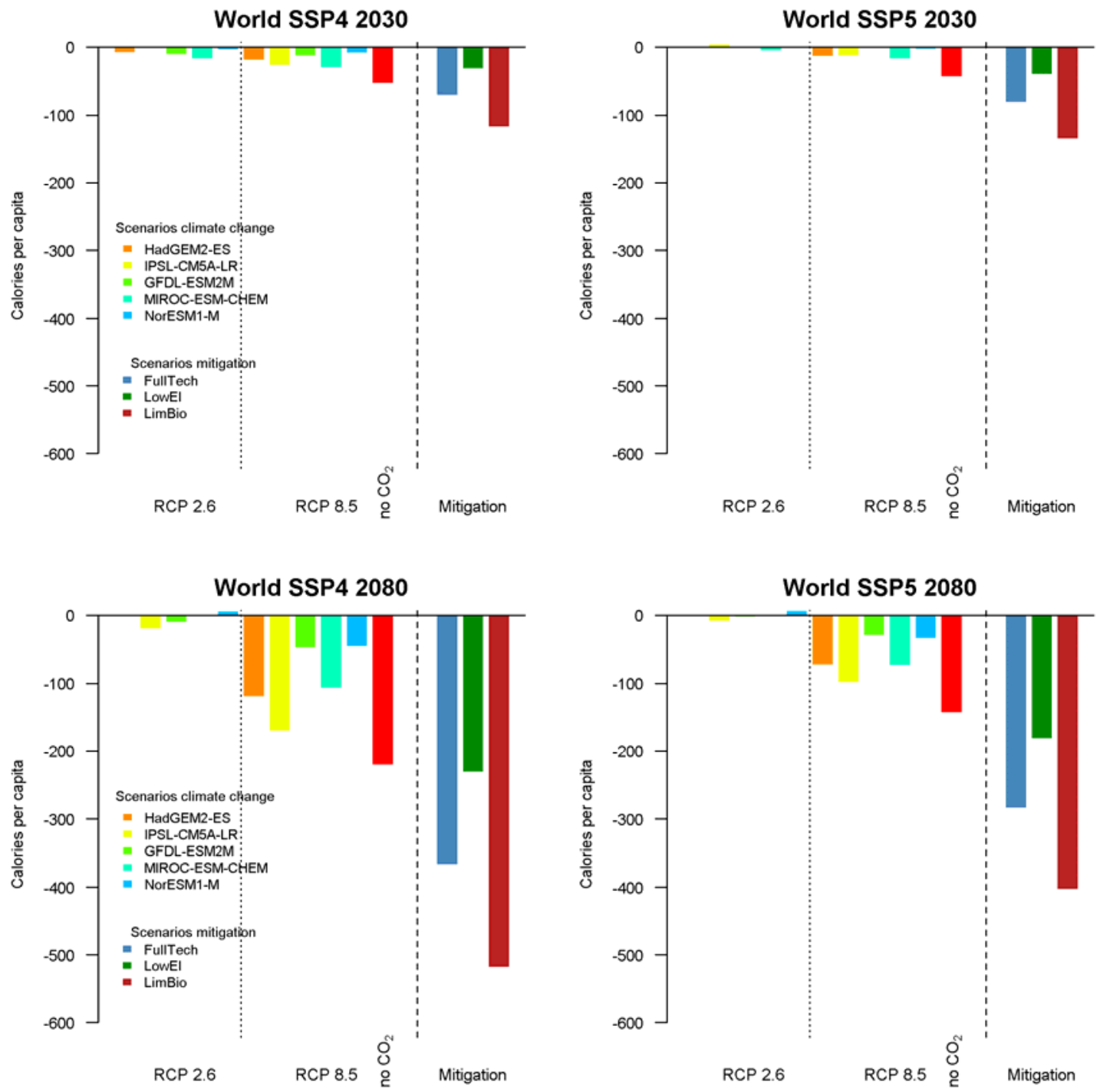

Figure 22 Change in food consumption by 2030 and 2080 for all the climate change impact and stabilization scenarios compared to the reference scenario, at global level, under SSP4 and SSP5 [kcal per capita per day].

\section{Discussion}

\subsection{Climate change impact uncertainty}

The results in this paper provide an overview of how climate change impacts can affect different world regions depending on the level of greenhouse gas emissions in the future and the background socioeconomic context. These results need however to be put in perspective with other findings of the literature, owing to an important number of sources of uncertainties. 
One important source of uncertainty is the response of the climate to change in GHG atmospheric concentration, as well as the resulting patterns of change in terms of precipitation and temperature changes. We used in this paper results from five GCMs but a larger set of results is produced by the CMIP5 community (see full list and results overview in (Collins et al., 2013)). Uncertainties for projections are large in these models, related to various processes difficult to model and whose net effect remain largely uncertain: e.g., the dynamics of cloudiness (in particular in the tropics), the role of surface albedo, or climate induced changes in carbon fluxes (Andrews et al., 2012; Vial et al., 2013; Friedlingstein et al., 2014). As an illustration, although the projected changes in global mean temperature are much less uncertain compared to regional patterns or precipitation changes, CMIP5 models estimate such a global temperature increase to range between 2.1 and $4.7^{\circ} \mathrm{C}$ (Andrews et al., 2012) for a given degree of radiative forcing (quadrupling). As detailed in section 3.2, our climate change scenarios were specifically selected to span a large set of climate responses, and this source of uncertainty should be kept in mind when looking at the average results on a RCP.

The second source of uncertainty stems from the modeling of the crop responses themselves. For this paper, we relied on only one biophysical model, EPIC. However, as illustrated in Rosenzweig et al. (2014), the most commonly used biophysical models predict very different responses to change in temperature and precipitation under high global warming. A pattern commonly observed in crop impact research is a small increase in crop yields in high and middle latitudes under low to moderate global warming and negative impact in tropical areas. When large ensemble of models are compared, impacts by 2050 on major crops remain within the range $-25 \%-+10 \%$ for four fifths of the projections (Porter et al., 2014). However, when looking at details per crop and management type (low or high input, irrigation), results can vary considerably depending on model parameterization (Rosenzweig et al., 2014). One important parameter for instance appears to be the modeling of nitrogen stress and the consideration of historical fertilization patterns. To this extent, our modeling framework explicitly takes into account the diversity of management systems and their specific response to climate change (Leclère et al., 2014).

Another important source of uncertainty at the crop level is the influence of elevated atmospheric $\mathrm{CO}_{2}$ concentration. According to the IPCC, when $\mathrm{CO}_{2}$ effects are taken into account, crop prices are "as likely as not", with range of expected responses from -30\% to + 45\% (Porter et al., 2014). Recent studies illustrate that $\mathrm{CO}_{2}$ effects are not only likely to buffer a part of the impact for crops, but also to boost grassland productivity, with important implications for the livestock sector. Havlík et al. (2015) report a global average effect of climate change of $+12.2 \%$ on grass yield globally using the EPIC model, and $+45 \%$ with the LPJmL model for a RCP8.5 scenario with $\mathrm{CO}_{2}$ effects by 2050 . Without $\mathrm{CO}_{2}$ effects, these impacts would be $+2 \%$ and $+7 \%$, respectively. However, as emphasized by Rosenzweig et al., dispersion across model results are much higher with $\mathrm{CO}_{2}$ effects than without, and substantial additional efforts should be devoted to $\mathrm{CO}_{2}$ effects modeling. Additionally, there is some indication that crop quality, in terms of nutrient content, may decrease under $\mathrm{CO}_{2}$ effects, which would moderate the expected benefits of yield increases (Myers et al., 2014). For these two reasons, the RCP8.5* scenario that does not include the effects of elevated $\mathrm{CO}_{2}$ concentration is an important counterfactual to consider in this paper, based here on the HadGEM2-ES model.

There are however some other sources of yield impacts that are absent or imperfectly represented in our modeling framework and could lead to either higher or lower climate change biophysical impacts. Some management responses are partially reflected in a crop model such as EPIC (adjustment of 
planting dates, inputs of fertilizer for high input systems, periods of harvest), but more detailed studies suggest that this gain could be higher, for example if including switch among existing cultivars (Leclère et al., 2013; Osborne et al., 2013). While this would place our results on the pessimistic range, including the impact of changes in water resource availability and droughts would go in the opposite direction: while we don't capture them, literature based on observation has reported frequent underestimation of gridded simulation methods to predict crop response to extreme events (Lobell et al., 2011; Lobell et al., 2014). Similarly, additional negative impacts not accounted for include: rising tropospheric ozone concentration, and potentially higher occurrence of pests and diseases, or increased competition with weeds (Porter et al., 2014). Furthermore, impacts of climate change on livestock are considered here through the feed availability channel only, whereas many other channels could also influence the future of the sector, in particular the role of heat and water stress on the productivity and mortality rate of animals, and the risk of increased spread of vector-borne diseases (Havlík et al., 2015).

For all the reasons above, the biophysical impacts of climate change are subject to a relatively high uncertainty, although some large patterns remain observed. As an illustration, Leclère et al. (2014) try to disentangle in their modeling analysis the signal-to-noise ratio associated with the biophysical shocks coming from the climate change uncertainty. They find negative impacts on crop yield for North America (excl. Canada), Brazil, Sub-Saharan Africa and most of Eastern and South Asia. However, only for Brazil, the signal appears higher than the noise and the negative impact considered as robust across scenarios. The robustness of economic response in models is for this reason limited, and is additionally affected by their own intrinsic parameterization uncertainty, as evidenced by the diversity of economic model specification and parameterization.

Several comparison exercises looked at how different economic models respond to similar sets of climate scenarios to understand where the largest sources of uncertainty lie in economic impact assessments. In the framework of the ISI-MIP project, Nelson et al. (2014) compared the economic responses of 9 global economic models applied to agricultural issues, including GLOBIOM. They showed that models tend to increase the spread of biophysical input shocks when coming to variables such as final yield, area and production responses, but that consumption responses were much less dispersed than the input. Models attributed differently the adjustments to the shock across the different adaptation channels in the model, management, expansion, trade and demand. Most computable general equilibrium models (CGEs) showed less reaction to the climate shock (average below $+25 \%$ after equilibrium at horizon 2050 for a RCP8.5 without $\mathrm{CO}_{2}$ effects). Partial equilibrium models (with the exception of GCAM) and the CGE MAGNET showed average responsiveness in prices above $+25 \%$ for the same shock, with the strongest price sensitivity for MAGPIE (Nelson et al.), Fig S5). In response to price changes, adjustments differed across models, AIM, FARM, GCAM, and MAGNET adjusting mainly through area change, MAGPIE mainly through endogenous yield change, and ENVISAGE, GLOBIOM, GTEM relying almost equally on the two effects. Contribution from trade to absorption of the shock was also very different across models (Nelson et al.), Fig S13 and S14): five models predicted limited trade adjustments (all CGEs except MAGNET, as well as MAGPIE), two models moderate trade adjustments (MAGNET, IMPACT) and two models large trade adjustments (GLOBIOM, GCAM). In the case of GLOBIOM, it is noteworthy that the trade setting for the comparison exercise is the same as considered for this paper for the integrated trade representation of the SSP5 scenario.

The final impact on food consumption in Nelson et al. (2014) was estimated to be $-3 \%$ for RCP 8.5 by 2050, under SSP2. The climate scenarios used were considered without $\mathrm{CO}_{2}$ effects but included a large 
set of both climate (5) and crop (7) models In the analysis of the present paper, using five climate models and one single crop model, we obtain by 2050 a global impact of $-4.7 \%$ for SSP 4 and $-2.8 \%$ for SSP5 (Figure 10). Our estimates therefore appear consistent with Nelson et al. (2014), although they represent for us the upper bound of our result ranges, due to the absence of $\mathrm{CO}_{2}$ effects. Geographical distribution of effects also show a more contrasted picture in terms of specific impact for each region, with Sub-Saharan Africa and South Asia more severely hit than the world average under RCP8.5 (Figure 23). More insight into differences across food demand responses to climate shocks is provided by Valin et al. (2014), which compares the same models with a deeper view on the modeling specifications of food demand. This paper illustrated that GLOBIOM responses in terms of food demand impact were similar in magnitude to those of the IMPACT model, also used in prior climate change analysis (Nelson, 2009), but they were higher by around one half of the overall model average (Fig 8. in (Valin et al., 2014 ). For climate shock models derived from the LPJmL crop model, IMPACT and GLOBIOM estimated an impact of food demand of $-2 \%$ to $-3 \%$ by 2050 compared to no climate change, whereas for the DSSAT crop models, impacts were at $-5 \%$ for both models (see Müller and Robertson (2014), for the analysis of these crop models results). Only CGE models predicted impacts of magnitude as low as $1 \%$, with the exception of GCAM and MAGPIE which did not model demand adjustments.

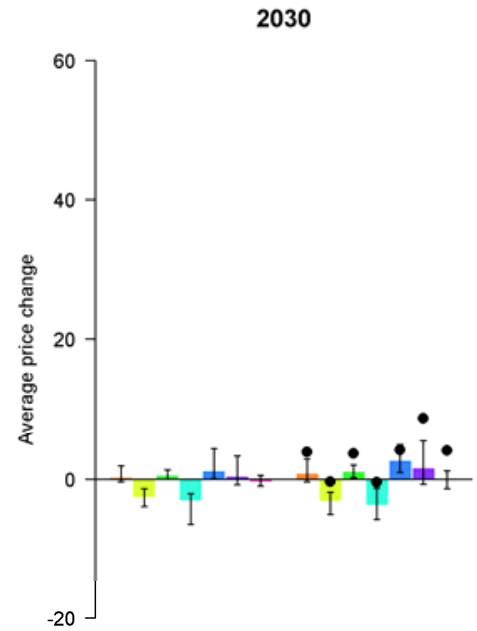

RCP 2.6

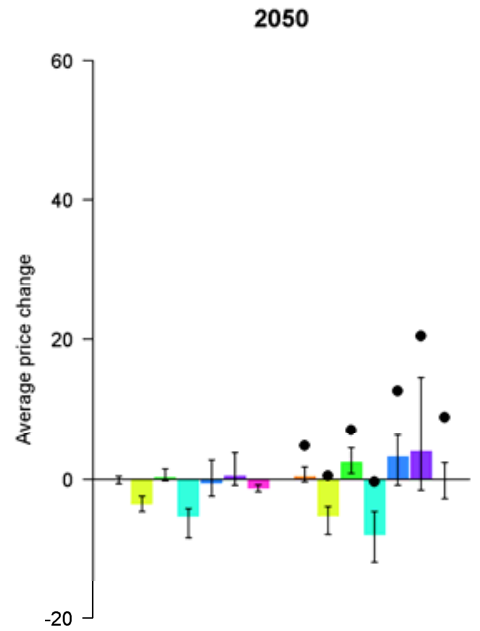

RCP 2.6

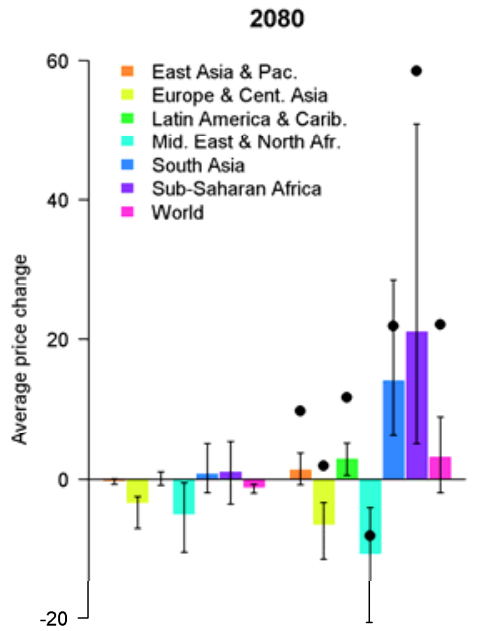

RCP 2.6

RCP 8.5

Figure 23. Impact on food prices of the climate change impact scenarios, at different time horizons. The colored bars indicate the average results for the 5 GCMs. The whiskers represent the range of results across the GCMs. The black dots show the results of the RCP8.5* scenario with the HadGEM2-ES model (no $\mathrm{CO}_{2}$ effects).

\subsection{Trade-offs around sector coverage of mitigation policies}

The stabilization scenarios analyzed above corresponded to an idealized mitigation policy where GHG emissions from all economic sectors and all regions were taxed with a unique, cost-efficient carbon price from 2010 onwards. This is not a realistic, and probably even not a desirable scenario. Implementation of mitigation policies in different regions and different sectors represents various degrees of challenge. Furthermore, ethical considerations risk of negative side effects may lead to a temporary exemption of a region or a sector from a general mitigation policy. The AFOLU sector together with biomass for energy production can be considered as such sensitive sectors. Agriculture 
is included because of its direct link to basic human needs in terms of food but also because of being the main source of livelihood for most of the poor. Land use and land use change are also directly linked with biodiversity and the poor but present considerable challenges in terms of monitoring and implementation in general. Havlík et al. (2014) showed how different the carbon price effects on food availability can be depending on whether a carbon price targets non- $\mathrm{CO}_{2}$ emissions from agriculture or $\mathrm{CO}_{2}$ emissions from land use change. Finally, biomass and its potential competition with food and biodiversity for land and water have been extensively discussed in the literature.

In order to get further insight in this question, we have considered three alternative scenarios to the idealized policy case under FullTech technology assumption: FullTechAgr - a variant of the FullTech scenario with bioenergy demand maintained at the level of the reference scenario without mitigation, and carbon price applied only to non- $\mathrm{CO}_{2}$ emissions from the agricultural sector; FullTechLuc - similar as FullTechAgr but carbon price applied only to $\mathrm{CO}_{2}$ emissions from land use change and forest management; and FullTechBio - bioenergy demand corresponds to the stabilization scenario FullTech, but carbon price is not applied on AFOLU emissions. The effects of these scenarios on food consumption are illustrated in Figure 24.

In terms of AFOLU emissions, implementing the carbon price solely on emissions from agriculture has almost no effect, as only $13 \%$ of the abatement achieved under the idealized FullTech scenario by 2030 is reached. On the other hand, implementing carbon tax on emissions from land use change alone provides more than $90 \%$ of the abatement achieved under FullTech. This comes as no surprise, since a large majority of the emission reductions came under FullTech by 2030 from avoided land use change. Implementing the bioenergy mandate alone would lead to increased emissions from land use change by some $5 \%$ compared to the reference scenario without mitigation policy. This risk is well recognized in the literature on ILUC (Induced Land Use Change), particularly for biofuels, but has been discussed also by Wise et al. (2009) in the Integrated Assessment Modeling context. Since in our framework bioenergy demand is driven by the bioenergy mandates only, the amount of biomass supplied in FullTechAgr and FullTechLuc scenarios is the same as in the reference scenario without climate change, while it corresponds to the FullTech level in the FullTechBio scenario.

Agricultural commodity prices would be affected very differently depending on the targeted sector. If emissions from agriculture only were targeted, the impact on prices would be about half compared to the idealized policy implementation by 2030. Targeting emissions from land use change would have almost no effect on crop prices, and also the effect on livestock prices would be just about a third compared to the full implementation. By 2030, the effect of the bioenergy mandate would stay below $1 \%$ for both crop and livestock prices. We have shown above that the FullTech stabilization scenario under SSP4 would remove almost $70 \%$ of the food availability growth which would otherwise happen between 2000 and 2030. If only agricultural emissions were targeted, FullTechAgr, 37\% of the reference increase would still be lost. From this perspective, the FullTechLuc scenario appears very attractive because $80 \%$ of the reference food availability growth is achieved, while more than $90 \%$ of the AFOLU emissions abatement is also achieved. Hence, the cost of abatement in the land use change sector in terms of lost food availability is relatively low. This result corresponds well to the findings in Havlík et al. (2014) as presented in the Total Abatement Calorie Cost (TACC) framework. Finally, the bioenergy mandate only, FullTechBio scenario, has by 2030 also a limited impact on food availability, less than $15 \%$ loss of the reference scenario growth. This result is in line with Lotze-Campen et al. (2014) who find that even substantial demand for biomass for energy use, has on its own negligible 
effects on agricultural markets when compared with climate change impacts. Hence, climate change mitigation through large scale biomass deployment seems from the perspective of food availability to be the most efficient option among the three possibilities considered above.

There are many other options how to accommodate stabilization goals with overall development objectives. One obvious is delayed participation of some developing regions where the mitigation potential is low but scope for negative effects from mitigation constraints are potentially high. Also the idealized implementation of the mitigation policy in the form of a tax in the AFOLU sector would most likely face some practical difficulties, from an acceptability as well as from an equity standpoint. One of the most advanced initiatives in this sector is REDD+ (Reducing emissions from deforestation and forest degradation, and foster conservation, sustainable management of forests, and enhancement of forest carbon stocks) which intends to rather positively incentivize countries to take actions to slow down or revert forest carbon stock decline. Within this framework, Cohn et al. (2014) analyzed the effect on mitigation of emissions from deforestation through payments for intensification of grassland management in Brazil. They found that despite the theoretically possible rebound effect, this policy would contribute to global emissions reduction. Furthermore, the authors found that such a policy would achieve its objectives even if implemented unilaterally, by Brazil alone, and thus provides arguments for regions to progress with the mitigation agenda even before a global comprehensive policy agreement is reached.
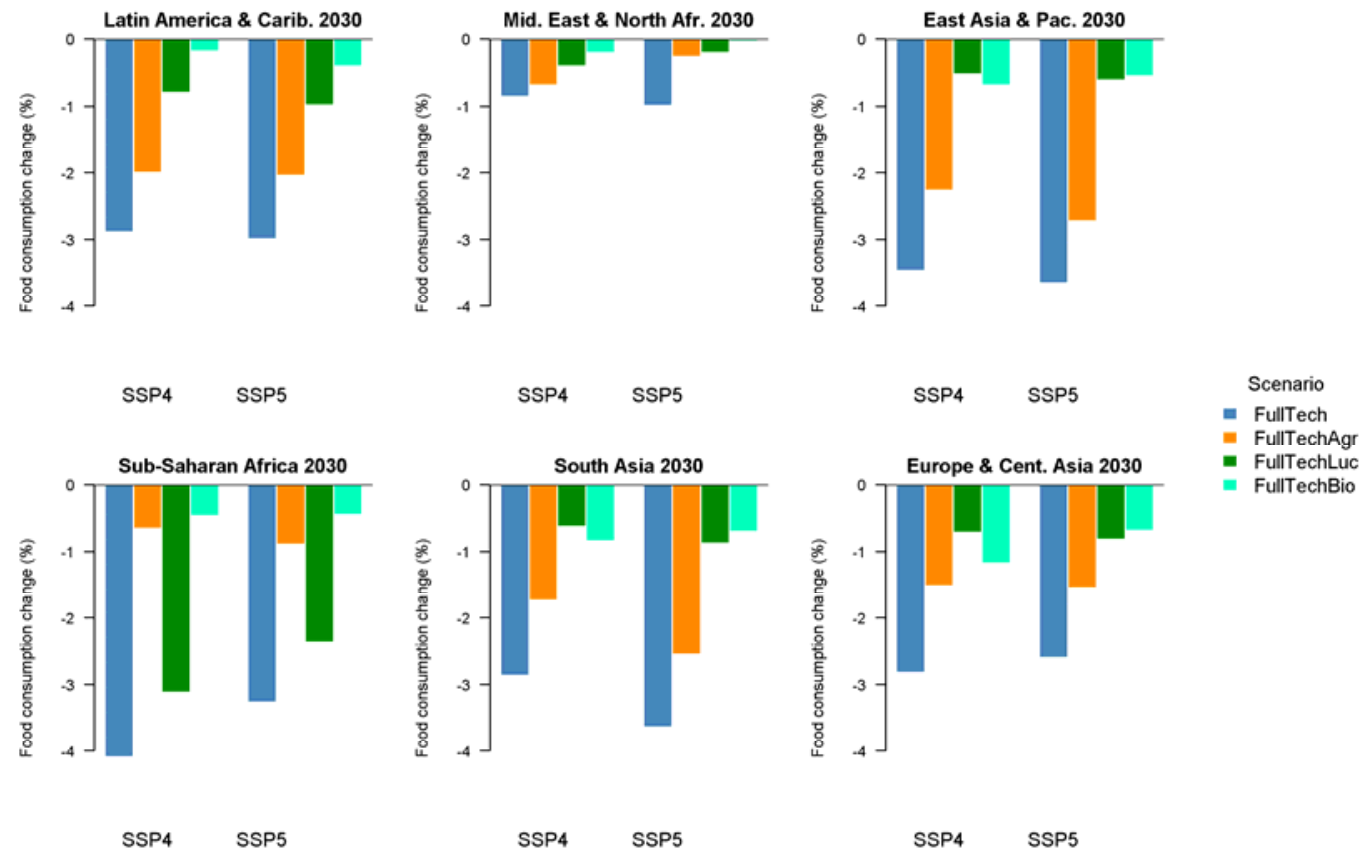

Figure 24. Change in food consumption in the FullTech scenario and its decomposed effects, compared to the reference SSP4 and SSP5, at regional levels.

\section{Conclusion}

Climate change will drive significant changes in the agricultural and food systems over the next century. We show in this paper how impacts can differ depending on the magnitude of GHG emission increase, but also how the choice of climate model and some assumptions on crop sensitivity to environmental conditions such as $\mathrm{CO} 2$ concentration may influence the results. Impacts vary across regions and low 
income countries are relatively more affected than some other regions due to their geographical location, and to the higher vulnerability of their food consumer to change in agricultural prices.

The agriculture and forestry sectors will likely be increasingly asked to contribute to mitigation efforts as well. This participation to achieve GHG reductions could present opportunities for land use sectors, with new demand for biomass, potential payments for carbon sequestration and higher margins for producers. However, mitigation policies could also bring significant challenges, because production costs will also increase with expansion of the production, and the deployment of new technologies will require some significant restructuring of the sectors. More worrying, the consumers will be more directly affected by the increased market prices, with potential challenges for food security.

Comparing the climate change impacts on food availability with the effects of mitigation, if mitigation is not implemented carefully, it could potentially bring worse effects for food availability than climate change itself, at least in the medium term. Hence, a careful design of mitigation policies needs to be adopted by targeting priority sectors and sources where emission abatement can be achieved at lowest costs, without hampering food provision. The contribution of the poorest regions to such scheme should be envisaged prudently, in order to avoid a double burden for people already facing the most severe climate change impact challenges. On the other side, the carbon tax revenue represents a potentially substantial source of new fiscal income, which if managed properly, could be used for funding of direct development programs and hence converted from a thread to an opportunity for the poor.

This study presents a first attempt to provide consistent quantitative assessment of climate change impacts and mitigation in agriculture and forestry on markets and food availability in low and medium income countries. Future improvements could go in several directions. For instance, we have ignored the combined effects of climate change and mitigation. We are convinced that this remains a second order effect of the extreme climate scenarios considered by the present paper, however if intermediate scenarios such as RCP4.5 and RCP6.0 with non-negligible aspects of both climate change impacts and mitigation were to be considered, the two phenomenon might represent important feedbacks; e.g. climate change impacts reducing biomass productivity and hence making the provision of the bioenergy sector more expensive versus afforestation occupying vast areas of land making it not available for crop area expansion to moderate the negative climate impacts.

To conclude, the projected effects of climate change and mitigation on agricultural markets raise important issues for food security in the long run, but remain more limited in the medium term horizon of 2030, providing opportunities for low- and middle-income countries to pursue immediate development needs and thus prepare for later periods when adaptation needs and mitigation efforts will become the greatest.

\section{References}

Alexandratos, N., Bruinsma, J., 2012. World Agriculture Towards 2030/2050: The 2012 Revision. Food and Agriculture Organization of the United Nations, Rome. 
Andrews, T., Gregory, J.M., Webb, M.J., Taylor, K.E., 2012. Forcing, feedbacks and climate sensitivity in CMIP5 coupled atmosphere-ocean climate models. Geophysical Research Letters 39, n/a-n/a.

Beach, R.H., DeAngelo, B.J., Rose, S.K., Li, C., Salas, W., DelGrosso, S.J., 2008. Mitigation potential and costs for global agricultural greenhouse gas emissions. Agricultural Economics 38, 109-115.

Böttcher, H., Frank, S., Havlík, P., Elbersen, B., 2013. Future GHG emissions more efficiently controlled by land-use policies than by bioenergy sustainability criteria. Biofuels, Bioproducts and Biorefining 7, 115-125.

Burney, J.A., Davis, S.J., Lobell, D.B., 2010. Greenhouse gas mitigation by agricultural intensification. Proceedings of the National Academy of Sciences 107, 12052-12057.

Cohn, A.S., Mosnier, A., Havlík, P., Valin, H., Herrero, M., Schmid, E., O’Hare, M., Obersteiner, M., 2014. Cattle ranching intensification in Brazil can reduce global greenhouse gas emissions by sparing land from deforestation. Proceedings of the National Academy of Sciences 111, 7236-7241.

Collins, M., Knutti, R., Arblaster, J., Dufresne, J.-L., Fichefet, T., Friedlingstein, P., Gao, X., Gutowski, W.J., Johns, T., Krinner, G., Shongwe, M., Tebaldi, C., Weaver, A.J., Wehner, M., 2013. Longterm Climate Change: Projections, Commitments and Irreversibility. In: Stocker, T.F., Qin, D., Plattner, G.K., Tignor, M., Allen, S.K., Boschung, J., Nauels, A., Xia, Y., Bex, V., Midgley, P.M. (Eds.), Climate Change 2013: The Physical Science Basis. Contribution of Working Group I to the Fifth Assessment Report of the Intergovernmental Panel on Climate Change. Cambridge University Press, Cambridge, United Kingdom and New York, NY, USA, pp. 1029-1136.

Cramer, W., Kicklighter, D.W., Bondeau, A., lii, B.M., Churkina, G., Nemry, B., Ruimy, A., Schloss, A.L., Intercomparison, T.P.O.T.P.N.M., 1999. Comparing global models of terrestrial net primary productivity (NPP): overview and key results. Global Change Biology 5, 1-15.

de Vries, M., de Boer, I.J.M., 2010. Comparing environmental impacts for livestock products: A review of life cycle assessments. Livestock Science 128, 1 - 11.

Frank, S., Böttcher, H., Havlík, P., Valin, H., Mosnier, A., Obersteiner, M., Schmid, E., Elbersen, B., 2013. How effective are the sustainability criteria accompanying the European Union 2020 biofuel targets? GCB Bioenergy 5, 306-314.

Friedlingstein, P., Meinshausen, M., Arora, V.K., Jones, C.D., Anav, A., Liddicoat, S.K., Knutti, R., 2014. Uncertainties in CMIP5 climate projections due to carbon cycle feedbacks. Journal of Climate 27, 511-526.

Geist, H.J., Lambin, E.F., 2002. Proximate causes and underlying driving forces of tropical deforestation. BioScience 52, 143-150.

Gibbs, H.K., Ruesch, A.S., Achard, F., Clayton, M.K., Holmgren, P., Ramankutty, N., Foley, J.A., 2010. Tropical forests were the primary sources of new agricultural land in the 1980s and 1990s. Proceedings of the National Academy of Sciences 107, 16732-16737.

Havlík, P., Leclère, D., Valin, H., Herrero, M., Schmid, E., Soussana, J.-F., Müller, C., Obersteiner, M., 2015. Global climate change, food supply and livestock production systems: A bioeconomic analysis. In: Elbehri, A. (Ed.), Climate change and food systems: global assessments and implications for food security and trade. Food Agriculture Organization of the United Nations (FAO), Rome. 
Havlík, P., Schneider, U.A., Schmid, E., Böttcher, H., Fritz, S., Skalský, R., Aoki, K., De Cara, S., Kindermann, G., Kraxner, F., Leduc, S., McCallum, I., Mosnier, A., Sauer, T., Obersteiner, M., 2011. Global land-use implications of first and second generation biofuel targets. Energy Policy $39,5690-5702$.

Havlík, P., Valin, H., Herrero, M., Obersteiner, M., Schmid, E., Rufino, M.C., Mosnier, A., Thornton, P.K., Böttcher, H., Conant, R.T., Frank, S., Fritz, S., Fuss, S., Kraxner, F., Notenbaert, A., 2014. Climate change mitigation through livestock system transitions. Proceedings of the National Academy of Sciences 111, 3709-3714.

Havlík, P., Valin, H., Mosnier, A., Obersteiner, M., Baker, J.S., Herrero, M., Rufino, M.C., Schmid, E., 2013. Crop Productivity and the Global Livestock Sector: Implications for Land Use Change and Greenhouse Gas Emissions. American Journal of Agricultural Economics 95, 442-448.

Herrero, M., Havlík, P., McIntire, J., Palazzo, A., Valin, H., 2014. African Livestock Futures: Realizing the potential of livestock for food security, poverty reduction and the environment in Sub-Saharan Africa. Office of the Special Representative of the UN Secretary General for Food Security and Nutrition and the United Nations System Influenza Coordination.

Herrero, M., Havlík, P., Valin, H., Notenbaert, A., Rufino, M.C., Thornton, P.K., Blümmel, M., Weiss, F., Grace, D., Obersteiner, M., 2013. Biomass use, production, feed efficiencies, and greenhouse gas emissions from global livestock systems. Proceedings of the National Academy of Sciences 110, 20888-20893.

Hristov, A.N., Oh, J., Lee, C., Meinen, R., Montes, F., Ott, T., Firkins, J., Rotz, A., Dell, C., Adesogan, A., Yang, W., Tricarico, J., Kebreab, E., Waghorn, G., Dijkstra, J., Oosting, S., 2013. Mitigation of greenhouse gas emissions in livestock production - A review of technical options for non-CO2 emissions. Food and Agriculture Organization of the United Nations, Rome, Italy.

IIASA, 2015. SSP Database v1.

IPCC, 2013. Climate Change 2013: The Physical Science Basis. Contribution of Working Group I to the Fifth Assessment Report of the Intergovernmental Panel on Climate Change. Cambridge University Press, Cambridge, United Kingdom and New York, NY, USA.

IPCC, 2014a. Climate Change 2014: Impacts, Adaptation, and Vulnerability. Part A: Global and Sectoral Aspects. Contribution of Working Group II to the Fifth Assessment Report of the Intergovernmental Panel on Climate Change. Cambridge University Press, Cambridge, United Kingdom and New York, NY, USA.

IPCC, 2014b. Climate Change 2014: Mitigation of Climate Change. Contribution of Working Group III to the Fifth Assessment Report of the Intergovernmental Panel on Climate Change. Cambridge University Press, Cambridge, United Kingdom and New York, NY, USA.

Kindermann, G., Obersteiner, M., Sohngen, B., Sathaye, J., Andrasko, K., Rametsteiner, E., Schlamadinger, B., Wunder, S., Beach, R.H., 2008a. Global cost estimates of reducing carbon emissions through avoided deforestation. Proceedings of the National Academy of Sciences $105,10302$.

Kindermann, G.E., McCallum, I., Fritz, S., Obersteiner, M., 2008b. A global forest growing stock, biomass and carbon map based on FAO statistics. Silva Fennica 42, 387. 
Kriegler, E., Weyant, J., Blanford, G., Krey, V., Clarke, L., Edmonds, J., Fawcett, A., Luderer, G., Riahi, K., Richels, R., Rose, S., Tavoni, M., van Vuuren, D., 2014. The role of technology for achieving climate policy objectives: overview of the EMF 27 study on global technology and climate policy strategies. Climatic Change 123, 353-367.

Lauri, P., Havlík, P., Kindermann, G., Forsell, N., Böttcher, H., Obersteiner, M., 2014. Woody biomass energy potential in 2050. Energy Policy 66, 19 - 31.

Leclère, D., Havlík, P., Fuss, S., Schmid, E., Mosnier, A., Walsh, B., Valin, H., Herrero, M., Khabarov, N., Obersteiner, M., 2014. Climate change induced transformations of agricultural systems: insights from a global model. Environmental Research Letters 9, 1748-9326.

Leclère, D., Jayet, P.-A., De Noblet-Ducoudré, N., 2013. Farm-level Autonomous Adaptation of European Agricultural Supply to Climate Change. Ecological Economics 87, 1-14.

Lobell, D.B., Roberts, M.J., Schlenker, W., Braun, N., Little, B.B., Rejesus, R.M., Hammer, G.L., 2014. Greater Sensitivity to Drought Accompanies Maize Yield Increase in the U.S. Midwest. Science 344, 516-519.

Lobell, D.B., Schlenker, W., Costa-Roberts, J., 2011. Climate Trends and Global Crop Production Since 1980. Science 333, 616-620.

Lotze-Campen, H., von Lampe, M., Kyle, P., Fujimori, S., Havlik, P., van Meijl, H., Hasegawa, T., Popp, A., Schmitz, C., Tabeau, A., Valin, H., Willenbockel, D., Wise, M., 2014. Impacts of increased bioenergy demand on global food markets: an AgMIP economic model intercomparison. Agricultural Economics 45, 103-116.

Lutz, W., Butz, W.P., KC, S., 2014. World Population \& Human Capital in the Twenty-first Century. IIASA, Laxenburg, Austria.

McCarl, B.A., Spreen, T.H., 1980. Price Endogenous Mathematical Programming as a Tool for Sector Analysis. American Journal of Agricultural Economics 62, 87-102.

McCollum, D., Krey, V., Kolp, P., Nagai, Y., Riahi, K., 2014. Transport electrification: A key element for energy system transformation and climate stabilization. Climatic Change 123, 651-664.

Mosnier, A., Havlík, P., Obersteiner, M., Aoki, K., Schmid, E., Fritz, S., McCallum, I., Leduc, S., 2012. Modeling Impact of Development Trajectories and a Global Agreement on Reducing Emissions from Deforestation on Congo Basin Forests by 2030. Environmental and Resource Economics, $1-21$.

Mosnier, A., Obersteiner, M., Havlík, P., Schmid, E., Khabarov, N., Westphal, M., Valin, H., Frank, S., Albrecht, F., 2014. Global food markets, trade and the cost of climate change adaptation. Food Security 6, 29-44.

Müller, C., Robertson, R.D., 2014. Projecting future crop productivity for global economic modeling. Agricultural Economics 45, 37-50.

Myers, S.S., Zanobetti, A., Kloog, I., Huybers, P., Leakey, A.D., Bloom, A.J., Carlisle, E., Dietterich, L.H., Fitzgerald, G., Hasegawa, T., others, 2014. Increasing CO2 threatens human nutrition. Nature 510, 139-142.

Nelson, G.C., 2009. Climate change: Impact on agriculture and costs of adaptation. Intl Food Policy Research Inst. 
Nelson, G.C., Valin, H., Sands, R.D., Havlík, P., Ahammad, H., Deryng, D., Elliott, J., Fujimori, S., Hasegawa, T., Heyhoe, E., Kyle, P., von Lampe, M., Lotze-Campen, H., Mason D'Croz, D., van Meijl, H., van der Mensbrugghe, D., Müller, C., Popp, A., Robertson, R., Robinson, S., Schmid, E., Schmitz, C., Tabeau, A., Willenbockel, D., 2014. Climate change effects on agriculture: Economic responses to biophysical shocks. Proceedings of the National Academy of Sciences $111,3274-3279$.

O'Neill, B., Kriegler, E., Riahi, K., Ebi, K., Hallegatte, S., Carter, T., Mathur, R., Vuuren, D., 2014. A new scenario framework for climate change research: the concept of shared socioeconomic pathways. Climatic Change 122, 387-400.

Obersteiner, M., Azar, C., Kauppi, P., Möllersten, K., Moreira, J., Nilsson, S., Read, P., Riahi, K., Schlamadinger, B., Yamagata, Y., others, 2001. Managing climate risk. Science 294, 786-787.

Osborne, T., Rose, G., Wheeler, T., 2013. Variation in the global-scale impacts of climate change on crop productivity due to climate model uncertainty and adaptation. Agricultural and Forest Meteorology 170, 183-194.

Peters, G.P., Andrew, R.M., Boden, T., Canadell, J.G., Ciais, P., Le Quere, C., Marland, G., Raupach, M.R., Wilson, C., 2013. The challenge to keep global warming below 2 [deg]C. Nature Clim. Change 3, 4-6.

Popp, A., Lotze-Campen, H., Bodirsky, B., 2010. Food consumption, diet shifts and associated non-CO2 greenhouse gases from agricultural production. Global Environmental Change 20, 451-462.

Porter, J.R., Xie, L., Challinor, A.J., Cochrane, K., Howden, S.M., Iqbal, M.M., Lobell, D.B., Travasso, M.I., 2014. Food security and food production systems. In: Field, C.B., Barros, V.R., Dokken, D.J., Mach, K.J., Mastrandrea, M.D., Bilir, T.E., Chatterjee, M., Ebi, K.L., Estrada, Y.O., Genova, R.C., Girma, B., Kissel, E.S., Levy, A.N., MacCracken, S., Mastrandrea, P.R., White, L.L. (Eds.), Climate Change 2014: Impacts, Adaptation, and Vulnerability. Part A: Global and Sectoral Aspects. Contribution of Working Group II to the Fifth Assessment Report of the Intergovernmental Panel of Climate Change. Cambridge University Press, Cambridge, United Kingdom and New York, NY, USA, pp. 485-533-.

Reilly, J., Melillo, J., Cai, Y., Kicklighter, D., Gurgel, A., Paltsev, S., Cronin, T., Sokolov, A., Schlosser, A., 2012. Using land to mitigate climate change: hitting the target, recognizing the trade-offs. Environmental science \& technology 46, 5672-5679.

Reisinger, A., Havlík, P., Riahi, K., Vliet, O., Obersteiner, M., Herrero, M., 2012. Implications of alternative metrics for global mitigation costs and greenhouse gas emissions from agriculture. Climatic Change, 1-14.

Rogelj, J., Meinshausen, M., Knutti, R., 2012. Global warming under old and new scenarios using IPCC climate sensitivity range estimates. Nature Clim. Change 2, 248-253.

Rose, S.K., Ahammad, H., Eickhout, B., Fisher, B., Kurosawa, A., Rao, S., Riahi, K., van Vuuren, D.P., 2012. Land-based mitigation in climate stabilization. Energy Economics, 365--380.

Rosenzweig, C., Elliott, J., Deryng, D., Ruane, A.C., Müller, C., Arneth, A., Boote, K.J., Folberth, C., Glotter, M., Khabarov, N., Neumann, K., Piontek, F., Pugh, T.A.M., Schmid, E., Stehfest, E., Yang, H., Jones, J.W., 2014. Assessing agricultural risks of climate change in the 21st century in a 
global gridded crop model intercomparison. Proceedings of the National Academy of Sciences $111,3268-3273$.

Smith, P., Bustamante, M., Ahammad, H., Clark, H., Don, H., Elsiddig, E.A., Haberl, H., Harper, R., House, J., Jafari, M., Masera, O., Mbow, C., Ravindranath, N.H., Rice, C.W., Aba, C.R., Romanovskaya, A., Sperling, F., Tubiello, F., 2014. Agriculture, Forestry and Other Land Use (AFOLU). Climate Change 2014: Mitigation of Climate Change. Contribution of Working Group III to the Fifth Assessment Report of the Intergovernmental Panel on Climate Change. Edenhofer, O., R. PichsMadruga, Y. Sokona, E. Farahani, S. Kadner, K. Seyboth, A. Adler, I. Baum, S. Brunner, P. Eickemeier, B. Kriemann, J. Savolainen, S. Schlömer, C. von Stechow, T. Zwickel and J.C. Minx, Cambridge, United Kingdom and New York, NY, USA.

Smith, P., Martino, D., Cai, Z., Gwary, D., Janzen, H., Kumar, P., McCarl, B., Ogle, S., O'Mara, F., Rice, C.W., Scholes, B., Sirotenko, O., Howden, M., McAllister, T., Pan, G., Romanenkov, V., Schneider, U., Towprayoon, S., Wattenbach, M., Smith, J., 2008. Greenhouse gas mitigation in agriculture. Philosophical Transactions of the Royal Society B: Biological Sciences 363, 789-813.

Stehfest, E., Bouwman, A.F., van Vuuren, D.P., den Elzen, M., Eickhout, B., Kabat, P., 2009. Climate benefits of changing diet. Climatic Change 95, 83-102.

Takayama, T., Judge, G.G., 1971. Spatial and temporal price and allocation models. North-Holland Amsterdam.

Taylor, K.E., Stouffer, R.J., Meehl, G.A., 2011. An Overview of CMIP5 and the Experiment Design. Bulletin of the American Meteorological Society 93, 485-498.

Thornton, P.K., van de Steeg, J., Notenbaert, A., Herrero, M., 2009. The impacts of climate change on livestock and livestock systems in developing countries: A review of what we know and what we need to know. Agricultural Systems 101, 113-127.

Tubiello, F.N., Amthor, J.S., Boote, K.J., Donatelli, M., Easterling, W., Fischer, G., Gifford, R.M., Howden, M., Reilly, J., Rosenzweig, C., 2007. Crop response to elevated CO2\} and world food supply: A comment on "Food for Thought..." by Long et al., Science 312:1918-1921, 2006. European Journal of Agronomy 26, 215 - 223.

Valin, H., Havlík, P., Mosnier, A., Herrero, M., Schmid, E., Obersteiner, M., 2013. Agricultural productivity and greenhouse gas emissions: trade-offs or synergies between mitigation and food security? Environmental Research Letters 8, 035019.

Valin, H., Sands, R.D., van der Mensbrugghe, D., Nelson, G.C., Ahammad, H., Blanc, E., Bodirsky, B., Fujimori, S., Hasegawa, T., Havlík, P., Heyhoe, E., Kyle, P., Manson-D'Croz, D., Paltsev, S., Rolinski, S., Tabeau, A., van Meijl, H., von Lampe, M., Willenbockel, D., 2014. The Future of Food Demand: Understanding Differences in Global Economic Models. Agricultural Economics 45, 51-67.

van Vuuren, D., Kriegler, E., O’Neill, B., Ebi, K., Riahi, K., Carter, T., Edmonds, J., Hallegatte, S., Kram, T., Mathur, R., Winkler, H., 2014. A new scenario framework for Climate Change Research: scenario matrix architecture. Climatic Change 122, 373-386.

van Vuuren, D.P., Edmonds, J., Kainuma, M., Riahi, K., Thomson, A., Hibbard, K., Hurtt, G.C., Kram, T., Krey, V., Lamarque, J.-F., Masui, T., Meinshausen, M., Nakicenovic, N., Smith, S., Rose, S.K., 2011. The representative concentration pathways: an overview. Climatic Change 109, 5-31. 
Vial, J., Dufresne, J.-L., Bony, S., 2013. On the interpretation of inter-model spread in CMIP5 climate sensitivity estimates. Climate Dynamics 41, 3339-3362.

von Lampe, M., Willenbockel, D., Ahammad, H., Blanc, E., Cai, Y., Calvin, K., Fujimori, S., Hasegawa, T., Havlík, P., Heyhoe, E., Kyle, P., Lotze-Campen, H., Mason D.'Croz, D., Nelson, G.C., Sands, R.D., Schmitz, C., Tabeau, A., Valin, H., van der Mensbrugghe, D., van Meijl, H., 2014. Why do global long-term scenarios for agriculture differ? An overview of the AgMIP Global Economic Model Intercomparison. Agricultural Economics 45, 3-20.

Warszawski, L., Frieler, K., Huber, V., Piontek, F., Serdeczny, O., Schewe, J., 2013. The Inter-Sectoral Impact Model Intercomparison Project (ISI-MIP): Project framework. Proceedings of the National Academy of Sciences.

Williams, J.R., 1995. The EPIC model. In: Singh, V.P. (Ed.). Water Resources Publications, pp. 909-1000.

Wise, M., Calvin, K., Thomson, A., Clarke, L., Bond-Lamberty, B., Sands, R.D., Smith, S.J., Janetos, A., Edmonds, J., 2009. Implications of Limiting CO2 Concentrations for Land Use and Energy. Science 324, 1183-1186.

Zekarias, H., Thomas, H., Alla, G., 2013. Climate change mitigation policies and poverty in developing countries. Environmental Research Letters 8, 035009. 


\section{Appendices}

\section{A. List of crops used in the paper}

Table-A 1. List of crop codes used in GLOBIOM

\begin{tabular}{ll} 
CODE & NAME \\
\hline WHEA & Wheat \\
RICE & Rice \\
CORN & Corn \\
SOYA & Soybean \\
RAPE & Rapeseed \\
BARL & Barley \\
CASS & Cassava \\
SUNF & Sunflower \\
MILL & Millet \\
SRGH & Sorghum \\
SUGC & Sugar cane \\
BEAD & Dry beans \\
COTT & Cottonseed \\
CHKP & Chick peas \\
SWPO & Sweet \\
& potatoes \\
POTA & Potatoes \\
GNUT & Groundnuts \\
OPAL & Oil palm fruit
\end{tabular}




\section{B. Regional grouping}

Table-A 2. List of regions used in the paper, mapping with GLOBIOM regions and corresponding countries

\begin{tabular}{|c|c|c|}
\hline Macro region & $\begin{array}{l}\text { GLOBIOM } \\
\text { regions }\end{array}$ & Countries \\
\hline \multirow[t]{6}{*}{ West Europe } & EU Baltic & Estonia, Latvia, Lithuania \\
\hline & EU Central East & Bulgaria, Czech Republic, Hungary, Poland, Romania, Slovakia, Slovenia \\
\hline & EU Mid West & Austria, Belgium, Germany, France, Luxembourg, Netherlands \\
\hline & EU North & Denmark, Finland, Ireland, Sweden, United Kingdom \\
\hline & EU South & Cyprus, Greece, Italy, Malta, Portugal, Spain \\
\hline & ROWE & Gibraltar, Iceland, Norway, Switzerland \\
\hline \multirow[t]{3}{*}{$\begin{array}{l}\text { Eastern Europe } \\
\text { and Central Asia }\end{array}$} & Former USSR & $\begin{array}{l}\text { Armenia, Azerbaijan, Belarus, Georgia, Kazakhstan, Kyrgyzstan, Moldova, } \\
\text { Russian Federation, Tajikistan, Turkmenistan, Ukraine, Uzbekistan }\end{array}$ \\
\hline & Turkey & Turkey \\
\hline & RCEU & Albania, Bosnia and Herzegovina, Croatia, Macedonia, Serbia-Montenegro \\
\hline \multirow[t]{2}{*}{ North America } & Canada & Canada \\
\hline & United States & United States \\
\hline \multirow{4}{*}{$\begin{array}{l}\text { Latin America } \\
\text { and the } \\
\text { Caribbean }\end{array}$} & Brazil & Brazil \\
\hline & Mexico & Mexico \\
\hline & RCAM & $\begin{array}{l}\text { Bahamas, Barbados, Belize, Bermuda, Costa Rica, Cuba, Dominica, Dominican } \\
\text { Republic, El Salvador, Grenada, Guatemala, Haiti, Honduras, Jamaica, Nicaragua, } \\
\text { Netherland Antilles, Panama, St Lucia, St Vincent, Trinidad and Tobago }\end{array}$ \\
\hline & RSAM & $\begin{array}{l}\text { Argentina, Bolivia, Chile, Colombia, Ecuador, Guyana, Paraguay, Peru, Suriname, } \\
\text { Uruguay, Venezuela, RB }\end{array}$ \\
\hline \multirow{4}{*}{$\begin{array}{l}\text { Eastern Asia and } \\
\text { Pacific }\end{array}$} & China & China \\
\hline & RSEA OPA & $\begin{array}{l}\text { Brunei Daressalaam, Indonesia, Singapore, Malaysia, Myanmar, Philippines, } \\
\text { Thailand }\end{array}$ \\
\hline & RSEA PAC & Cambodia; Korea, Dem. People's Rep.; Lao PDR; Mongolia; Vietnam \\
\hline & Pacific Islands & Fiji Islands, Kiribati, Papua New Guinea, Samoa, Solomon Islands, Tonga, Vanuatu \\
\hline \multirow{3}{*}{$\begin{array}{l}\text { Pacific } \\
\text { Developed }\end{array}$} & ANZ & Australia, New Zealand \\
\hline & Japan & Japan \\
\hline & Korea, Rep. & Korea, Rep. \\
\hline \multirow[t]{2}{*}{ South Asia } & India & India \\
\hline & RSAS & Afghanistan, Bangladesh, Bhutan, Maldives, Nepal, Pakistan, Sri Lanka \\
\hline $\begin{array}{l}\text { Middle-East and } \\
\text { North Africa }\end{array}$ & $\begin{array}{l}\text { Middle East and } \\
\text { North Africa }\end{array}$ & $\begin{array}{l}\text { Algeria, Bahrain, Egypt, Arab Rep., Iran, Islamic Rep., Iraq, Israel, Jordan, Kuwait, } \\
\text { Lebanon, Libya, Morocco, Oman, Qatar, Saudi Arabia, Syrian Arab Republic, } \\
\text { Tunisia, United Arab Emirates, Yemen, Rep. }\end{array}$ \\
\hline \multirow[t]{5}{*}{$\begin{array}{l}\text { Sub-Saharan } \\
\text { Africa }\end{array}$} & Congo Basin & $\begin{array}{l}\text { Cameroon, Central African Republic, Congo, Rep., Congo, Dem. Rep., Equatorial } \\
\text { Guinea, Gabon }\end{array}$ \\
\hline & Eastern Africa & Burundi, Ethiopia, Kenya, Rwanda, Tanzania, Uganda \\
\hline & South Africa & \\
\hline & $\begin{array}{l}\text { Southern Africa } \\
\text { (Rest of) }\end{array}$ & $\begin{array}{l}\text { Angola, Botswana, Comoros, Lesotho, Madagascar, Malawi, Mauritius, } \\
\text { Mozambique, Namibia, Swaziland, Zambia, Zimbabwe }\end{array}$ \\
\hline & $\begin{array}{l}\text { West and } \\
\text { Central Africa }\end{array}$ & $\begin{array}{l}\text { Benin, Burkina Faso, Cape Verde, Chad, Côte d'Ivoire, Djibouti, Eritrea, Gambia, } \\
\text { Ghana, Guinea, Guinea Bissau, Liberia, Mali, Mauritania, Niger, Nigeria, Senegal, } \\
\text { Sierra Leone, Somalia, Sudan, Togo }\end{array}$ \\
\hline
\end{tabular}




\section{List of scenarios}

The list of scenarios below has been used for this paper. These have been run under two macroeconomic context: SSP4 and SSP5. Therefore, 36 scenarios were in total analysed.

Table-A 3. Full list of scenarios used in the paper

\begin{tabular}{|c|c|c|c|c|}
\hline ID & GCM & $\begin{array}{l}\text { CLIMATE } \\
\text { CHANGE }\end{array}$ & $\begin{array}{l}\text { CLIMATE } \\
\text { MITIGATION }\end{array}$ & COMMENT \\
\hline B & None & No CC & None & Baseline \\
\hline C1 & HadGEM2-ES & RCP2.6 & None & Climate scenario RCP2.6 with $\mathrm{CO}_{2}$ effects \\
\hline C2 & IPSL-CM5A-LR & RCP2.6 & None & Climate scenario $\mathrm{RCP} 2.6$ with $\mathrm{CO}_{2}$ effects \\
\hline C3 & GFDL-ESM2M & RCP2.6 & None & Climate scenario $\mathrm{RCP} 2.6$ with $\mathrm{CO}_{2}$ effects \\
\hline C4 & $\begin{array}{l}\text { MIROC-ESM- } \\
\text { CHEM }\end{array}$ & RCP2.6 & None & Climate scenario RCP2.6 with $\mathrm{CO}_{2}$ effects \\
\hline C5 & NorESM1-M & $\mathrm{RCP} 2.6$ & None & Climate scenario $\mathrm{RCP} 2.6$ with $\mathrm{CO}_{2}$ effects \\
\hline C6 & HadGEM2-ES & RCP8.5 & None & Climate scenario $\mathrm{RCP} 8.5$ with $\mathrm{CO}_{2}$ effects \\
\hline C7 & IPSL-CM5A-LR & RCP8.5 & None & Climate scenario RCP8.5 with $\mathrm{CO}_{2}$ effects \\
\hline C8 & GFDL-ESM2M & RCP8.5 & None & Climate scenario $\mathrm{RCP} 8.5$ with $\mathrm{CO}_{2}$ effects \\
\hline C9 & $\begin{array}{l}\text { MIROC-ESM- } \\
\text { CHEM }\end{array}$ & RCP8.5 & None & Climate scenario $\mathrm{RCP} 8.5$ with $\mathrm{CO}_{2}$ effects \\
\hline C10 & NorESM1-M & RCP8.5 & None & Climate scenario RCP8.5 with $\mathrm{CO}_{2}$ effects \\
\hline C11 & HadGEM2-ES & RCP8.5* & None & Climate scenario RCP8.5 without $\mathrm{CO}_{2}$ effects \\
\hline CX1 & Avg & RCP2.6 & None & Average over $\mathrm{GCMs} \mathrm{RCP} 2.6$ with $\mathrm{CO}_{2}$ effects \\
\hline $\mathrm{CX} 2$ & Avg & RCP8.5 & None & Average over $\mathrm{GCMs}$ RCP8.5 with $\mathrm{CO}_{2}$ effects \\
\hline CX3 & Avg & RCP8.5* & None & $\begin{array}{l}\text { Average over GCMs RCP8.5 without } \mathrm{CO}_{2} \text { effects } \\
\text { (equal to } \mathrm{C} 11 \text { ) }\end{array}$ \\
\hline M1 & None & No CC & FullTech & $\begin{array}{l}\text { Mitigation policy } 2 \text { degrees - high energy intensity } \\
\text { world - high biomass use }\end{array}$ \\
\hline M2 & None & No CC & LowEI & $\begin{array}{l}\text { Mitigation policy } 2 \text { degrees - low energy intensity } \\
\text { world - high biomass use }\end{array}$ \\
\hline M3 & None & No CC & LimBio & Mitigation policy 2 degrees - limited biomass use \\
\hline M1A & None & No CC & FullTechAgr & $\begin{array}{l}\text { Mitigation policy } 2 \text { degrees - M1 - carbon tax on } \\
\text { agriculture only }\end{array}$ \\
\hline M1B & None & No CC & FullTechLUC & $\begin{array}{l}\text { Mitigation policy } 2 \text { degrees - M1 - carbon tax on } \\
\text { land use emissions only }\end{array}$ \\
\hline M1C & None & No CC & FullTechBio & $\begin{array}{l}\text { Mitigation policy } 2 \text { degrees - M1 - bioenergy } \\
\text { expansion only }\end{array}$ \\
\hline
\end{tabular}




\section{Complementary figures}
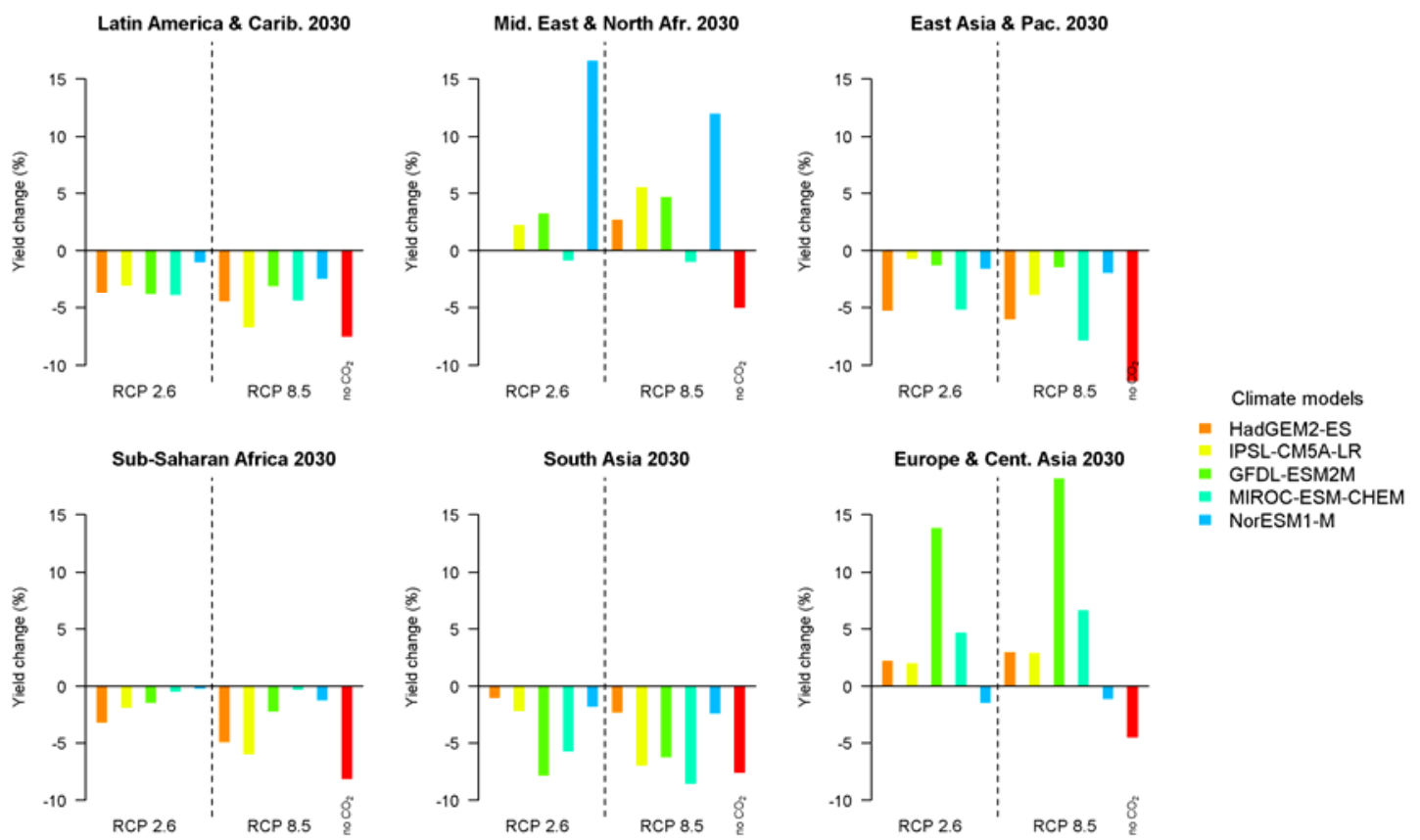

Figure D-1. Climate change impact on average crop yield for six regions in 2030 for different climate scenarios and climate models. Crops correspond to the 18 species represented in GLOBIOM and are aggregated on a dry matter yield basis.

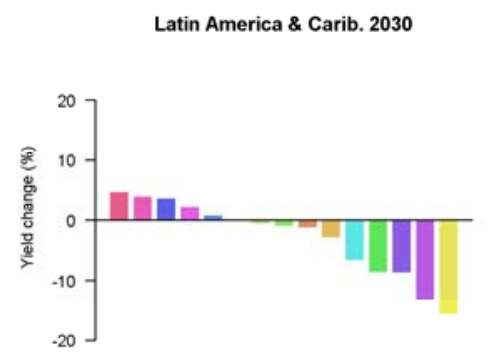

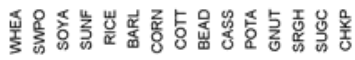

Sub-Saharan Africa 2030

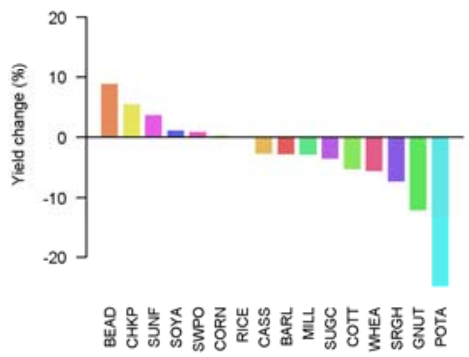

Mid. East \& North Afr. 2030

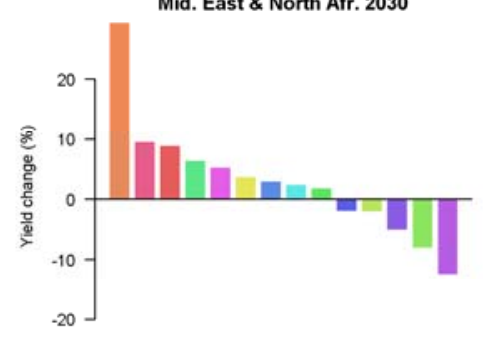

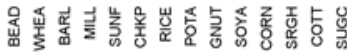

South Asia 2030

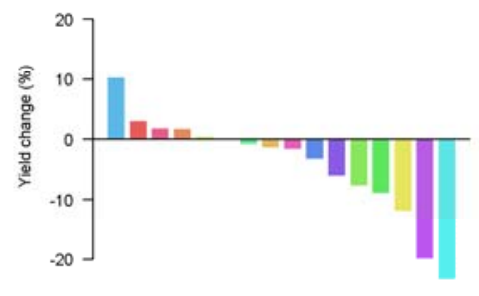

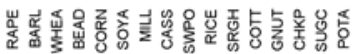

East Asia \& Pac. 2030

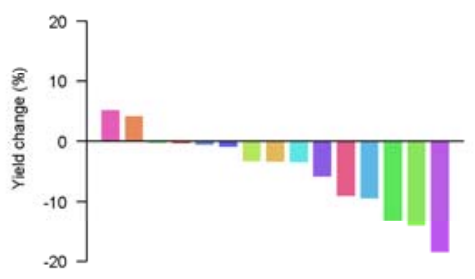

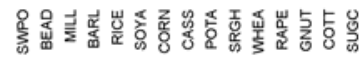

Europe \& Cent. Asia 2030

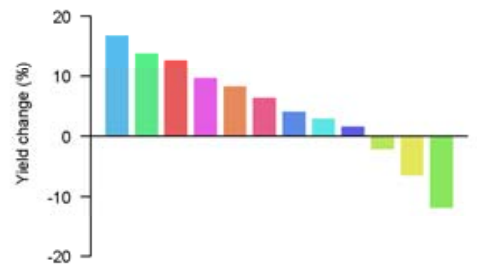

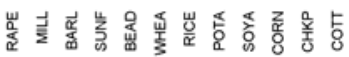

Figure D-2. Climate change impact on by crop for six regions in 2030 for the RCP 8.5 scenario with $\mathrm{CO}_{2}$ effects. Impacts are averaged across the five GCMs in the analysis. Only crops with cultivated areas greater than 100,000 ha in 2000 are represented. Crop acronyms: $W H E A=$ wheat, $R I C E=$ rice, $C O R N=$ corn, SOYA = soybean, RAPE = rapeseed, $B A R L=$ barley, CASS = cassava, SUNF = sunflower, MILL = millet, SRGH = sorghum, SUGC = sugar cane, BEAD = dry beans, COTT = cottonseed, $C H K P=$ chick peas, $S W P O=$ sweet potatoes, $P O T A=$ potatoes, GNUT $=$ groundnuts . 

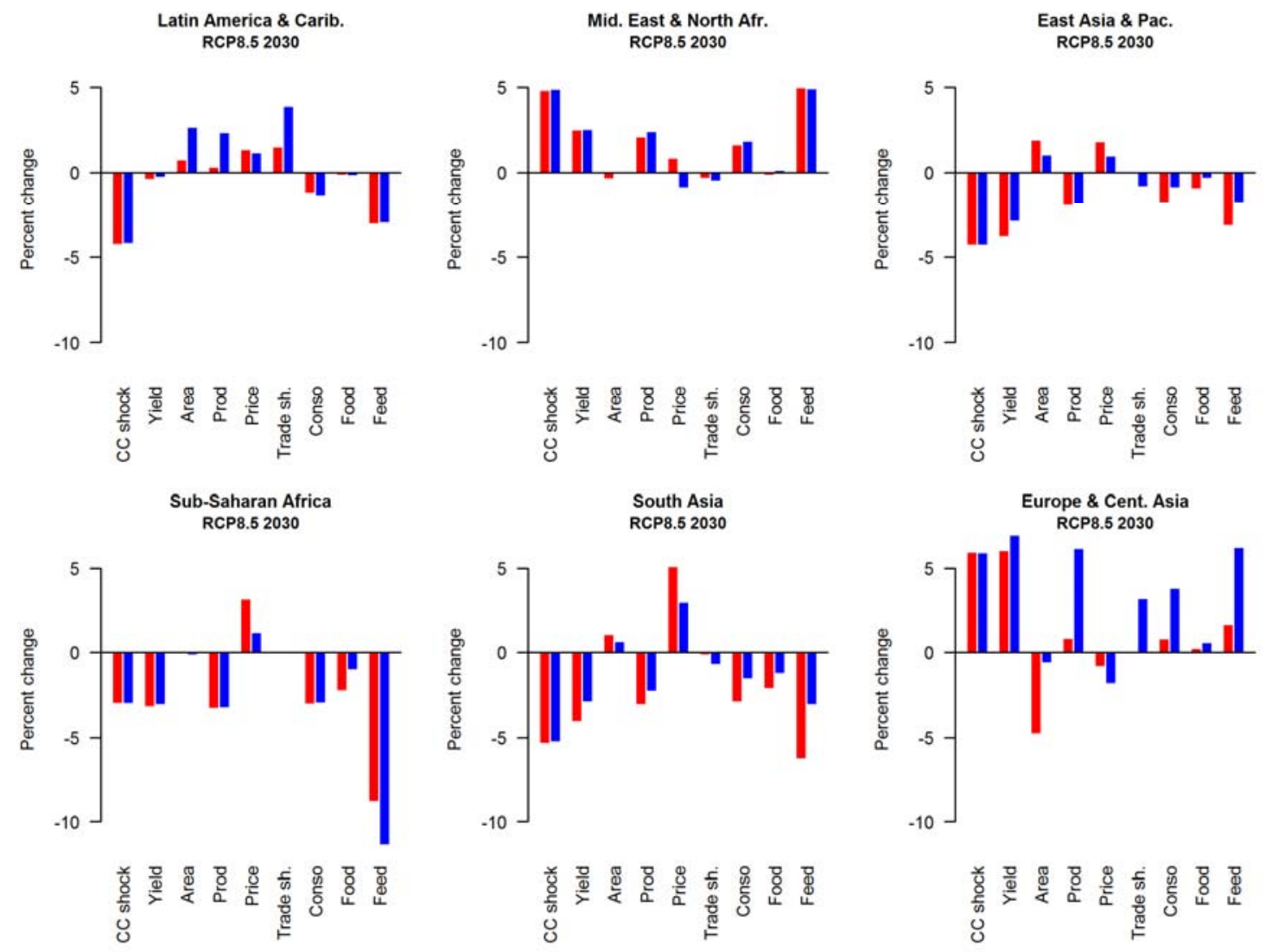

Figure D-3. Propagation of climate change impact along the chain of economic indicators for SSP4 and SSP5 in 2030 for RCP 8.5 with $\mathrm{CO}_{2}$ effects. CC shock corresponds to the average biophysical impact of climate change on dry matter yield; Yield corresponds to final resulting dry matter yield, including adaptation response; Area is the total change in harvested area; Prod is the change in total crop production in dry matter basis; Price is the average crop price index; Trade sh. corresponds to difference in the share of interregional trade (export-import) in total crop production; conso is the change in total crop consumption, and food and feed the relative change in the consumption of food and feed. Units are relative change to the baseline. 